\title{
Analysis of Production Decline in Geothermal Reservoirs
}

Elliot J. Zais

Elliot Zais \& Associates, Inc.

OEIVED

LAWRENEE

Gunnar Bodvarsson BKELEY LABORATORY

Oregon State University

DEC 111980

September 1980

LIEFARY AND

DCUMENTS SEC

\section{Genthermal}

Reservair

臣gineering

\Uปanagement

program
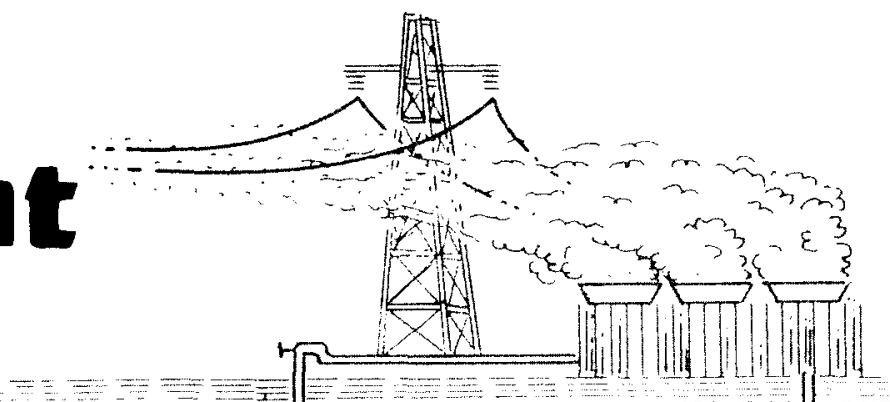

TWO-WEEK LOAN COPY

This is a Library Circulating Copy which may be borrowed for two weeks. For a personal retention copy, call Tech. Info. Division, Ext. 6782.

turin sciences Division Lawrence Berkeley Laboratory II 


\title{
ANALYSIS OF PRODUCTIOT
}

DECLINE IN GEOTHERMAI RESERVOIRS

Prepared by

E11iot J. Zais

Elliot Zais \& Associates, Inc.

7915 NW Siskin Drive

Corvallis, Oregon 97330

Gunnar Bodvarsson

School of Oceanography

Oregon State University

Corval1is, Oregon 97331

\author{
Submitted to \\ LAWRENCE BERKELEY LABORATORY
}

as an

ACCOUNTING OF RESEARCH

under the

GEOTHERMAL RESERVOIR ENGINEERING MANAGEMENT

Order 非 4503010

This work was supported by the U.S. Department of Energy. Division of Geothermal Fnergy

Under Contract $W-7405-E N G-48$ 
CONTENTS

ACKNOWLEDGMENTS . . . . . . . . . . . . . . . . . . . . . iv

I. INTRODUCTION AND CONCLUSIONS . . . . . . . . . . . . . . 1 Objectives and Rationale . . . . . . . . . . . . . . 1 Data and Analysis Methods . . . . . . . . . . . . . 1 Conclusions . . . . . . . . . . . . . . . . . . . 1

II. THEORY OF RESERVOIR DECLINE MODELS . . . . . . . . . . . . 2

Decline Mechanism .................... . 2 Pressure-Flow Fields in Slightly Compressible Formations

with Darcy Type Flow . . . . . . . . . . . . . 3

Nonstationary Boundaries: Effects of a Free Liquid

Surface . . . . . . . . . . . . . . . 4 4

Reservoir Simulation by Lumping . . . . . . . . . 7

III. REVIEW OF METHODS. . . . . . . . . . . . . . . . . 9

Petroleum Reservoirs.................. 9

Geothermal Reservoirs . . . . . . . . . . . . 9

IV. DATA PROCESSING. . . . . . . . . . . . . . . . 21

Data Sets........................ 21

Graphical Treatment of Data . . . . . . . . . . . 21

Statistical Treatment of Data . . . . . . . . . 23

Discussion of Data Scatter. . . . . . . . . . . 26

V. RESUlTS. . . . . . . . . . . . . . . . . . . . 27

Arp's Equations..................... . 27

Type-curve Methods. . . . . . . . . . . . . . . 27

Coats' Influence Function Method. . . . . . . . . . . 27

Bodvarsson's Linearized Free Surface Method . . . . . . . 29

VI. STANDARD OPERATING PROCEDURE FOR DATA GATHERING AND ANALYSIS . • . 31

Data Gathering. . . . . . . . . . . . . . . . . . . . . 31

Data Analysis... . . . . . . . . . . . . 31

REFERENCES. . . . . . . . . . . . . . . . . . . . 32

APPENDIX. . . . . . . . . . . . . . . ...... 34

Computer Listings and Examples... . . . . . . . . . 36

SPSS Programs. . . . . . . . . . . . . . . . . . . 36

Example Calculations Using SPSS . . . . . . . . . . . . . . 39

Estimating Field Influence Functions - Program Usage . . . . . . 47

Influence Function Programs. . . . . . . . . . . . . . . 49

Example Calculations Using INFUNC . . . . . . . . . . 57

Linearized Free Surface Programs . . . . . . . . . . . . 61

Example Calculations Using LFS . . . . . . . . . . . . 69 


\section{ACKNOWLEDGMENTS}

Support for these studies comes from the Department of Energy, Division of Geothermal Energy, through Lawrence Berkeley Laboratory under the Geothermal Reservoir Engineering Management Program, order \#4503010. The authors wish to express their gratitude to the program's technical monitors, Sally
Benson, Alex Graf, Jack Howard, Marcelo Lippmann, Werner Schwarz, and the contract administrator, Paul Marshall of the Lawrence Berkeley Laboratory (LBL) for their advice, consideration and review of this study. The support and encouragement of William Avera, Richard Couch, Nancy Kneisel, Tom Lindstrom, Suzi Maresh, Bill Millison and Jeff Stander of Oregon State University (OSU) are gratefully acknowledged. 


\section{INTRODUCTION AND CONCLUSIONS}

\section{Objectives and Rationale}

The najor objectives of the Decline Curve project were to

1. Test the decline analysis methods used in the petroleum industry on geothermal production data,

2. Examine and/or develop new analysis methods,

3. Develop a standard operating procedure for analyzing geothermal production data.

Various analysis methods have long been available but they have not been tested on geothermal data because of the lack of publicly available data. The recent release to publication of substantial data sets from Wairakei, New Zealand, Cerro Prieto, Mexico and The Geysers, U.S.A. has made this study possible. Geothermal reservoirs are quite different from petroleum reservoirs in many ways so the analysis methods must be tested using geothermal data.

\section{Data and Analysis Methods}

Data and analysis methods were gathered from the petroleum, geothermal, and hydrological literature. The data sets examined include

1. Wairakei, New Zealand - 141 wells

2. Cerro Prieto, Mexico - 18 wells
3. The Geysers, U.S.A. - 27 wells

4. Larderello, Italy - 9 wells and groups

5. Matsukawa and Otake, Japan -8 wells

6. Olkaria, Kenya - 1 we11

The analysis methods tested were

1. Arps's equations

2. Fetkovich type curves

3. Slider's method for Arps

4. Gentry's method for Arps

5. Gentry's \& McCray's method

6. Other type curves

7. P/z vs. Q method

8. Coats' influence function method

9. Bodvarsson's Linearized Free Surface Green's Function method

Conclusions

The conclusions are

1. The exponential equation fit is satisfactory for geothermal data.

2. The hyperbolic equation should be used only if the data fit well on a hyperbolic type curve.

3. The type curve netlods are useful if the data are not too scattered. They work well for vapor dominated systems and poorly for liquid dominated systems.

4. Coats' influence function method can be used even with very scattered data.

5. Bodvarsson's method is still experimental but it shows much promise as a useful tool. 


\section{THEORY OF RESERVOIR DECLINE MODELS*}

\section{(1) Decline mechanism}

A geothermal reservoir has essentially three capacitances, (1) fluid/rock compressibility, (2) free liquid surface mobility and (3) reservoir liquid vaporization. In essence, item (3) is also a compressibility effect similar to (1). In this section, we will very briefly review in a semi-quantitative manner, the relative magnitudes of the effects listed above.

Consider a reservoir consisting of a slab of thickness $\mathrm{H}$ and of a large horizontal extent. The porosity/permeability can be of the fracture or intergranular type but is assumed to be sufficiently homogeneous that an average porosity $\phi$ and capacitivity $s$ (storage coefficient) can be defined.

On these premises, we find that lowering the pressure by $\Delta p$ in a vertical column of unit area, releases because of compressibility a total liquid mass of

$$
\Delta q_{c}=\rho s H \Delta p
$$

where $\rho$ is the density of the liquid. We can then define a specific release per unit area of

$$
\mathrm{dq}_{\mathrm{e}} / \mathrm{dp}=\rho \mathrm{sH}
$$

Let $g$ be the acceleration of gravity. Lowering the pressure by $\Delta p$ corresponds to a lowering of the free liquid surface by $\Delta p / \rho g$. Hence, for the same $\Delta p$, the free surface releases a total of

$$
\Delta \mathrm{q}_{\mathrm{f}}=\rho \phi \Delta \mathrm{p} / \rho \mathrm{g}=\phi \Delta \mathrm{p} / \mathrm{g},
$$

and then the specific release

$$
\mathrm{dq}_{\mathrm{f}} / \mathrm{dp}=\phi / \mathrm{g} \text {. }
$$

Finally, we consider the effect of intergranular vaporization. Let $\rho_{S}$ be the density of the vapor, L the latent heat of vaporization of the liquid and $T$ the temperature in kelvins. The Clausius-Clapeyron equation for the liquid is then approximately

$$
\left(\mathrm{dp}_{\mathrm{S}} / \mathrm{dT}\right)_{\mathrm{v}}=\rho_{\mathrm{S}}^{\mathrm{L} / \mathrm{T}}
$$

where $p_{S}$ is the vapor pressure along the saturation line that is denoted by the subscript v. Hence, assuming saturation conditions, the lowering of the pressure by $\Delta p$ lowers $T$ by

$$
\Delta \mathrm{T}=\mathrm{T} \Delta \mathrm{p} / \rho_{\mathrm{s}} \mathrm{L}
$$

and the release of heat per unit volume of the wet formation is

$$
\Delta h=\rho_{r} C T \Delta p / \rho_{s}{ }^{L}
$$

*Chapter II was written by Gunnar Bodvarsson, Geophysics Group, School of Oceanography, Oregon State University, Corvallis, Oregon. where $\rho_{r}$ is the density and $C$ is the heat capacitivity of the wet formation. The release of vapor is then

$$
\Delta \mathrm{q}_{\mathrm{v}}=\Delta \mathrm{h} / \mathrm{L}=\rho_{\mathrm{r}} \mathrm{CT} \Delta \mathrm{p} / \rho_{\mathrm{s}} \mathrm{L}^{2},
$$

and we can thus define a specific rate per unit area of a slab of thickness $H$

$$
\mathrm{dq}_{\mathrm{f}} / \mathrm{d}_{\mathrm{p}}=\rho_{\mathrm{r}} \mathrm{CTH} / \rho_{\mathrm{s}} \mathrm{L}^{2} \text {. }
$$

The ratio of free surface to compressibility effect follows from (2) and (4)

$$
\left(\mathrm{dq}_{\mathbf{r}} / \mathrm{dp}\right) /\left(\mathrm{dq}_{\mathrm{c}} / \mathrm{dp}\right)=\phi / \mathrm{g} \rho \mathrm{sH}
$$

Considering porosities in the range $\phi=0.01$ to 0.2 , a thickness of $\mathrm{H}=10^{3} \mathrm{~m}$ and taking that $s=2 \times 10^{-11} \mathrm{~Pa}^{-1}$, we find that the ratio given in (10) varies from 50 to $10^{3}$. Thus, at normal reservoir conditions the free surface lowering releases a much larger amount of reservoir liquid mass per unit pressure decline than the compressibility.

Along similar lines we obtain the ratio of the vaporization to the compressibility effect on the basis of (2) and (9)

$$
\left(\mathrm{dq}_{\mathrm{v}} / \mathrm{dp}\right) /\left(\mathrm{dq}_{\mathrm{c}} / \mathrm{dp}\right)=\rho_{\mathrm{r}} \mathrm{CT} / \rho_{\mathrm{s} \rho} \mathrm{L}^{2} .
$$

Considering the case of $\mathrm{T}=200^{\circ} \mathrm{C}=473 \mathrm{~K}$ and using standard values $\rho_{\mathrm{r}}=2500 \mathrm{~kg} / \mathrm{m}^{3}, \mathrm{C}=10^{3}$ $\mathrm{J} / \mathrm{kg} \cdot \mathrm{K}, \mathrm{s}=2 \times 10^{-11}, \rho_{\mathrm{S}}=7 \mathrm{~kg} / \mathrm{m}^{3}$ and $\mathrm{L}=2 \times 10^{6}$ $\mathrm{J} / \mathrm{kg}$, we find a ratio of about $2 \times 10^{3}$. Since $\rho_{\mathrm{S}}$ is the main variable in (11) this ratio will decrease with increasing temperature.

Summing up the results of the present section, we conclude that in the case of liquid dominated reservoirs with common porosities and where no vaporization takes place, the free surface effect is larger than the compressibility effect by a factor of $10^{2}-10^{3}$. In such cases, the reservoir response to long-term production will be dominated by the free surface effect.

The situation is more complex when vaporization takes place. Theoretically, this effect can rzlease approximately as much fluid mass as the free surface effect. However, in most practical cases where production is initiated at liquid dominated conditions, the vaporization is more or less confined to the local volumes around the boreholes and the ratio in (11) has then to be reduced br a volume factor that may very roughly be of the order of 0.1 or less. The free surface effect would also then dominate the global reservoir response to long term production.

Vapor dominated reservoirs have, as a matier of course, different characteristics. There i; no near-surface free liquid surface and $p s$ in equition (2) has then to be replaced by the product $\phi \gamma$ there $\gamma$ is the steam compressibility. Usually, there is a vaporization at a deep liquid surface and this effect dominates the long term reservoir behavior. 
(2) Pressure-flow fields in slightly compressible formations with Darcy type flow

(2.i) Diffusion equation. Let $p(t, P)$ be the pressure field at time $t$ and at the point $P$ in a Darcy type domain $B$ with the stationary boundary surface $\Sigma$. Consider a general setting where the permeability $k$ is a linear matrix operator and the kinematic viscosity of the fluid $v$ is also taken to be variable. It is convenient to introduce the fluid conductivity operator $c=k / v$ and express Darcy's law

$$
\overrightarrow{\mathrm{q}}=-\mathrm{cvp}
$$

where $\vec{q}$ is the mass flow density. Moreover, let $\rho$ be the fluid density, $s$ the capacitivity or storage coefficient of the formation and $f$ be a source density. Combining (12) with the equation for the conservation of mass,

$$
\nabla \cdot \vec{q}=-\rho \partial_{t} p+f
$$

we obtain the diffusion equation for the pressure field

$$
\rho \mathrm{s}^{\prime}{ }_{\mathrm{t}} \mathrm{p}+\Pi(\mathrm{c}) \mathrm{p}=\mathrm{f}
$$

where $\Pi(c)=-\nabla(c \nabla)$ is the generalized Laplacian operator. Appropriate boundary conditions that may be of the Dirichlet, Neumann, mixed or more complex convolution type, have to be ajoined to equation (14). The case of a homogeneous/isotropic/isothermal formation results in the simplication $\Pi(c)=c \Pi=-c \nabla^{2}$ where $c$ is a constant. Moreover, stationary pressure fields satisfy the potential equation

$$
\pi(c) p=f .
$$

(2.ii) Eigenfunctions of the Laplacian. The eigenfunctions $u_{n}(P)$ of $\Pi(c)$ in $B$ associated with (14) satisfy the equations

$$
\pi(c) u_{n}=\lambda_{n} u_{n}, n=1,2, \ldots .
$$

where the constants $\lambda$ are the eigenvalues and the bouindary conditions on $\Sigma$ are homogeneous of the same type as those satisfied by $p(t, P)$ in (14) and $(15$.

\section{(2.iii) Types of solutions. The key to} solving equation (14) is the causal impulse response or Green's function $G(P, Q, t)$ which represents the pressure response of the causal system to an instantaneous injection of an unit mass of fluid at $t=0+$ at the source point $Q$. This function satisfies the same boundary conditions as the eigenfunctions $u_{n}(P)$. Solutions to (14) in the case of a general source density $f(t, p)$, non-causal initial values and general boundary conditions can then be expressed in terns of integrals over the Green's function (Du:f and Naylor, 1966).

Two Eundamental types of expressions for the Gren's function are available. First, in the cası of simple layered domains $B$ with a boundary $\Sigma$ cmposed of a few plane faces, $G(P, Q, t)$ can be expressed as a sum (or integral) over the fundamental whole space source function

$$
\begin{aligned}
G_{0}(P, Q, t)=(8 \rho s)^{-1} & (\pi a t)^{-3 / 2} \\
& \exp \left(-r^{2}{ }_{P Q} / 4 a t\right) U_{+}(t)
\end{aligned}
$$

and its images. The symbol $U_{+}(t)$ is the causal unit step function, $a=c / p s$ the diffusivity, and $r_{p O}$ is the distance from $Q$ to $P$. Whenever applicable, sums of this type represent the most elementary local and/or global expressions for $G(P, Q, t)$.

Second, the Green's function can be expanded in a series or integral over the eigenfunctions of $\pi(c)$. If $\rho$ and $s$ are constants, then

$$
G(P, Q, t)=(1 / \rho s) \sum_{n} u_{n}(P) u_{n}(Q) \exp \left(-\lambda_{n} t / \rho s\right)
$$

The series expansion (18) is of a more general applicability than solutions of the type based on the fundamental source function (17).

The formal link between the two types (17) and (18) is provided by the Poisson sunmation formula (Stakgold, 1967). It is important to underline that all solutions of the type (17) can be expressed in the form (18).

From the numerical point of view, the form given by (17) is more convenient for the computation of relatively short term field responses, in particular, in the case of layered half-spaces. However, long-term responses in bounded domains are more effectively computed on the basis of (18). This expression is a sum over exponentials where the convergence improves with time.

A different type of solution of (14) that is of interest in the present context can be obtained by operational methods. Limiting ourselves to the pure initial value problem with $p(0, P)=p_{0}(P)$ in the case of an infinite domain, we can, since $\rho, s$ and $\Pi(c)$ are independent of $t$, formally express the solution of the homogeneous form of (14) as

$$
\mathrm{p}=\exp [-t \Pi(\mathrm{c}) / \rho \mathrm{s}] \mathrm{p}_{\mathrm{o}}
$$

where the exponential operator is to be interpreted as a Taylor series in the operator II (c)

$\exp [-t \Pi(c) / \rho s]=1-[t \pi(c) / \rho s]+\left(\frac{1}{2}\right)[t][(c) / \rho s]^{2} \ldots(20)$

The series represents an iteration process where the convergence is limited to (properly defined) small values of $t$. The practical applicability is therefore fundamentally different from (18). Moreover, it is of considerable interest that rather general situations with regard to II (c) can be admitted in (19) and (20).

A number of other analytical and/or numerical techniques are available for solving (14). These include the path-integral technique of the Feynman-Kac type (Simon, 1979), compartmentalization or lumping and, as a matter of course, a series of numerical techniques. 
(3) Nonstationary boundaries: effects of a free liquid surface

The presence of a free liquid surface in a reservoir requires the introduction of a rather complex non-stationary surface boundary condition. Let $\Sigma$ now represent the free liquid surface at equilibrium and $\Omega$ be the free surface in a perturbed state. The boundary $\Omega$ is a surface of constant pressure which without loss of generality can be taken to vanish. The free surface condition (Lamb, 1932) is then expressed

$$
\mathrm{Dp} /\left.\mathrm{Dt}\right|_{\mathrm{p}=0}=0
$$

where $D / D t$ is the material derivative. This is an essentially non-linear condition which leads to a much more complex problem setting. Losing the principle of superposition the construction of solutions to the forward problem becomes a difficult task.

Bodvarsson (1977) has shown that when $\Omega$ deviates only little from $\Sigma_{1}(21)$ can be simplified and linearized. For this purpose, we place a rectangular coordinate system with the $z$-axis vertically down such that the $(x, y)$ plane coincides with $\Sigma$. Moreover, let the amplitude of $\Omega$ relative to $\Sigma$ be $u$ and the scale of the undulation of $\Omega$ be L. Then provided $|u / L|<<1$, the condition (21) can be replaced by the approximation

$$
(1 / w) \partial_{t} p-\partial_{z} p=0
$$

where $\mathrm{w}=\mathrm{cg} / \mathrm{s}^{\prime}$ is a new parameter, namely, the free sinking velocity of the pore liquid under gravity ( $\mathrm{g}=$ acceleration of gravity). Under these circumstances, the solution of the forward problem is obtained by constructing a solution to (14) which satisfies (22) at the free surface and appropriate conditions at other sections of the reservoir boundary.

The presence of a first order derivative with respect to time in the free-surface condition (21) obviously leads to an additional relaxation process analog to the purely diffusive phenomena associated with the first order time derivative in the basic equation (14). As we shall conclude below, the individual time scales of the two phenomena are, however, different.

For the sake of brevity, we shall limit the present discussion to the simplest but practically quite relevant case of the semi-infinite liquid saturated homogeneous, isotropic and isothermal half-space. To consider the pure free-surface related phenomena, we eliminate pressure field diffusion by neglecting the compressibility of the liquid/rock system. As shown in section (I) above, the long term dynamics of liquid reservoirs is dominated by the free surface phenomena. In this setting we can combine the potential equation (15) and the surface condition (22) in one single equation confined to the $\Sigma$ plane (Bodvarsson, 1978a), which expressed in terms of the fluid surface amplitude $u(t, x, y)=p / \rho g$ takes the form

$$
(1 / \mathrm{w}) \partial_{t} u+J_{2}^{\frac{1}{2}} u=f / \rho g c
$$

where $\Pi_{2}^{\frac{1}{2}}=\left(-\partial x x^{-}-\partial y\right)^{\frac{1}{2}}$ is th square root of the two-dimensional Laplacian and $f$ is an appropriately defined surface source density. To obtain the pressure field in the space $z>0$, the boundary values derived from (23) have to be continued into the lower half-space on the basis of standard potential theoretical methods. The fractional order of the Laplacian in (23) is quite unusual, but the operator is well defined and poses no mathematical problems.

Some solutions of equations (23) of practical interest have been obtained by Bodvarsson (1977). Confining ourselves first to the simple semiinfinite half-space, some important results are given below.

(3.i) The source-free case. In a sourcefree case where $f=0$, the homogeneous equation (23) is most easily solved by solving

$$
-\nabla^{2} p=0, \quad z \geq 0
$$

with the boundary condition (22) combined with a given initial condition which takes the form

$$
\mathrm{p}=\rho \mathrm{gh}_{\mathrm{o}}, \quad \mathrm{t}=0, \quad \mathrm{z}=0
$$

where $h_{0}(S)$ is a given initial free-surface amplitude.

This solution is obtained immediately by observing that a pressure function of the form

$$
\mathrm{p}=\mathrm{p}(\mathrm{x}, \mathrm{y}, \mathrm{z}+\mathrm{wt})
$$

satisfies the boundary condition (22) at all times. Consequently, introducing the Dirichlet type Green's function for the half-space $z>0$ (Duff and Naylor, 1966, page 276) which gives the pressure $p(P)$ in $z>0$ for a pressure $p_{0}(S)$ on $\Sigma$

$$
p(P)=(z / 2 \pi) \int_{\Sigma}\left(1 / r_{P U}^{3}\right) P_{O}(U) d a_{U}, \quad z \geq 0
$$

where $U=\left(x^{\prime}, y^{\prime}\right), d a U=d x^{\prime} d y^{\prime}$ and

$$
r_{P U}=\left[\left(x-x^{\prime}\right)^{2}+\left(y-y^{\prime}\right)^{2}+z^{2}\right]^{\frac{1}{2}}
$$

the solution to the present problem is

$$
\begin{gathered}
p(P, t)=[\rho g(z+w t) / 2 \pi] \int_{\Sigma}\left(1 / r_{P U t}^{3}\right) h_{0}(U) d a_{U}, \\
t \geq 0, \quad z \geq 0,
\end{gathered}
$$

where

$$
r_{\text {PUt }}=\left[\left(x-x^{\prime}\right)^{2}+\left(y-y^{\prime}\right)^{2}+(z+w t)^{2}\right]^{\frac{1}{2}}
$$

The motion of the fluid surface is obtained by letting $z=0$ in (13) and hence,

$$
\begin{gathered}
h(S, t)=(w t / 2 \pi) \int_{\Sigma}\left(1 / r_{S U t}^{3}\right) h_{o}(U) d a_{U}, \\
t>0
\end{gathered}
$$

where now

$$
r_{\text {Sut }}=\left[\left(x-x^{\prime}\right)^{2}+\left(y-y^{\prime}\right)^{2}+(w t)^{2}\right]^{\frac{1}{2}} .
$$

(3.ii) Flow fields with sources. To select a relevant and important case of flow fields with 
sources, we will consider the following situation. Let the fluid at $t=0$ be in static equilibrium and the fluid surface at $t=0$ therefore coincide witl $\Sigma$. Consider a concentrated sink of strength uniiy at the point $Q=(0,0, d)$ which at $t=0+$ stats withdrawing fluid mass at a constant rate equil to unity. In this case we have to solve

$$
\Pi_{\mathrm{p}}=-\nabla^{2} \mathrm{p}=(-1 / \mathrm{c}) \delta(\mathrm{P}-\mathrm{Q}) \mathrm{U}_{+}(\mathrm{t})
$$

whese $U_{+}(t)$ is the causal unit step function for which $U_{+}(0)=0$. The boundary condition on $\Sigma$ is aga:n given by (22) and the initial condition is $\mathrm{p}=0$ at $\mathrm{t}=0$.

A simple method of solving this problem has beet given by Bodvarsson (1977). In the present context, it is of some interest to present a different approach via the combined Laplace-Hankel transform method.

Let $\hat{p}(P, s)$ be the Laplace-transform of $p(P, t)$. The transform of (33) and (22) are then

$$
\Pi \hat{\mathrm{p}}=(-1 /(\mathrm{cs})) \delta(\mathrm{P}-\mathrm{Q})
$$

and

$$
s \hat{p}-w \partial z \hat{p}=0, \quad z=0
$$

Moreover, let $\tilde{\mathrm{p}}(\mathrm{k}, \mathrm{z}, \mathrm{s})$ be the (two-dimensional) Hankel-transform of $\hat{p}(P, s)$ and $D=d / d z$. The transform of (34) is then

$$
k^{2} \tilde{p}-D^{2} \tilde{p}=(-1 / 2 \pi c s) \delta(z-d)
$$

and (35) takes the form

$$
s \tilde{p}-w D \tilde{p}=0, \quad z=0
$$

The solutions of (36) for $z \geqslant z^{\prime}$ are of the form $\exp \left({ }^{ \pm} \mathrm{kz}\right)$ and we thus obtain

$$
\tilde{\mathrm{p}}=\operatorname{Aexp}(\mathrm{kz})+\operatorname{Bexp}(-k z), 0<z<z^{\prime},
$$

and

$$
\tilde{\mathrm{p}}=\operatorname{Cexp}(-k z), \quad z>z^{\prime},
$$

where $\mathrm{A}, \mathrm{B}$ and $\mathrm{C}$ are integration constants (with respect to $z$ ). From (37) we obtain the relation

$$
A(s-w k)+B(s+w k)=0,
$$

and our solution has to be continuous at $z=d$ such that

$$
A \exp (k d)+B \exp (-k d)=C \exp (-k d),
$$

Finally, integrating (36) with respect to $z$ from $\mathrm{d}-$ to $\mathrm{d}+$, we obtain the necessary third condition

$$
\left.D \tilde{p}\right|_{d-} ^{d+}=-(1 / 2 \pi c s)
$$

which yields the relation

$$
-k \operatorname{eexp}(-k d)-k[A \exp (k d)-B \exp (-k d)]=-(1 / 2 \pi c s)
$$

Solving (40), (41) and (43) for A, B and C and inserting in (38) leads to

$$
\begin{gathered}
p=(-1 / 4 \pi c k s) \exp [-k(d-z)]-[(s-w k) /(s+w k)] \\
\exp [-k(z+d)]
\end{gathered}
$$

which holds for $z>0$. Using the identity

$$
(s-w k) / s(s+w k)=[2 /(s+w k)]-(1 / s),
$$

(44) is easily Hankel-Laplace inverted into $(P, t)$ space (tables in Duff and Naylor, 1966) and the result is

$$
\begin{gathered}
\mathrm{p}(\mathrm{P}, \mathrm{t})= \\
(-1 / 4 \pi \mathrm{c})\left[1 / \mathrm{r}_{\mathrm{PQ}}+\left(1 / \mathrm{r}_{\mathrm{PQ}}{ }^{\prime}\right)-\left(2 / \mathrm{r}_{\mathrm{PQ}^{\prime} \mathrm{t}}\right)\right]
\end{gathered}
$$

where

$$
\begin{aligned}
r_{P Q} & =\left[\left(x-x^{\prime}\right)^{2}+\left(y-y^{\prime}\right)^{2}+(z-d)^{2}\right]^{\frac{1}{2}}, \\
r_{P Q^{\prime}} & =\left[\left(x-x^{\prime}\right)^{2}+\left(y-y^{\prime}\right)^{2}+(z+d)^{2}\right]^{\frac{2}{2}} \\
r_{P Q^{\prime} t} & -\left[\left(x-x^{\prime}\right)^{2}+\left(y-y^{\prime}\right)^{2}+(z+w t+d)^{2}\right]^{\frac{1}{2}}
\end{aligned}
$$

The surface elevation $\mathrm{h}=\mathrm{p} / \mathrm{fg}$ is

$$
h(S, t)=(-1 / 2 \pi \rho g c)\left[\left(1 / r_{S Q}\right)-\left(1 / r_{S Q^{\prime} t}\right)\right]
$$

where $S=(x, y)$ and

$$
\begin{aligned}
r_{S Q} & =\left[\left(x-x^{\prime}\right)^{2}+\left(y-y^{\prime}\right)^{2}+d^{2}\right]^{\frac{1}{2}} \\
r_{S Q^{\prime} t} & =\left[\left(x-x^{\prime}\right)^{2}+\left(y-y^{\prime}\right)^{2}+(w t+d)^{2}\right]^{\frac{1}{2}}
\end{aligned}
$$

It is of a particular interest to note that the Hankel-inversion leading to the last term in (46) follows upon a Laplace-inversion on the basis of the Sommerfeld integral

$$
\int_{0}^{\infty} \exp [-(z+w t+d) k] J_{0}(r k) d k=1 / r Q^{\prime} t^{\prime}
$$

which we rewrite

$$
\int_{0}^{\infty} \exp (-w k t) E(r, z, k) d k=1 / x_{P Q^{\prime} t},
$$

where

$$
E(r, z, k)=\exp [-(z+d) k] J_{0}(r, k),
$$

Equation (46) reveals that the effect of the free fluid surface on the pressure drawdown due to the concentrated sink of strength unity starting at time $t=0$ can be represented by the pressure field due to a stationary image sink of strength unity located at $Q^{\prime}=\left(x^{\prime}, y^{\prime},-d\right)$ and a moving image source of strength 2 located at $Q^{\prime} t=\left[x^{\prime}, y^{\prime},-\right.$ $(w t+d)]$. At time $t=0+$ the image sink and $1 / 2$ of the image source cancel resulting in an initial pressure field of

$$
\left.\mathrm{P}(\mathrm{P}, \mathrm{O}+)=-[1 /(4 \pi \mathrm{c})]\left[1 / \mathrm{r}_{\mathrm{PQ}}\right]-\left(1 / \mathrm{r}_{\mathrm{PQ}}\right)\right] .
$$

At very large times, that is at $t \gg d / w$, when the image source has retreated far into the negative half space, the third term in (46) becomes negligible and the pressure field reaches its stationary value $\mathrm{p}_{\mathrm{S}}$ given by

$$
\left.\left.\mathrm{p}(\mathrm{P})\right|_{t \rightarrow \infty}=-[1 /(4 \pi \mathrm{C})]\left[1 / \mathrm{r}_{\mathrm{PQ}}\right)+\left(1 / \mathrm{r}_{\mathrm{PQ}}\right)\right],
$$


The source-sink situation is illustrated in Figure 1.

It is appropriate to reiterate that the above free surface results have been obtained by neglecting the rock/liquid compressibility.

(3.iii) Flow in slab with a free surface. The results for the half-space set forth in the previous section are easily generalized to the model of a slab of thickness $H$ and of infinite horizontal extent. As given in equation (46) and shown in Figure 1, the free surface dynamics reduces at any fixed time to a source-sink situation. Applying well known results of elementary potential theory, we can extend equation (46) to the case of the slab by adding an infinite sequence of source-sink images that is obtained by reflecting the source and the two sinks in Fig. 1 at the bottom and the equilibrium surface boundaries. Appropriate reflection coefficients have to be applied in this process. We will refraim from entering into details of the procedure. The practically most important case is obtained when the basement is impermeable and the reflection coefficient at the boundary is equal to unity. As shown above, the equilibrium surface has also a reflection coefficient of unity but on any reflection, we have to observe the splitting of an image source into a stationary image and a double moving image with an opposite sign. The picture is therefore a little more complex than in the usual cases involving single images.

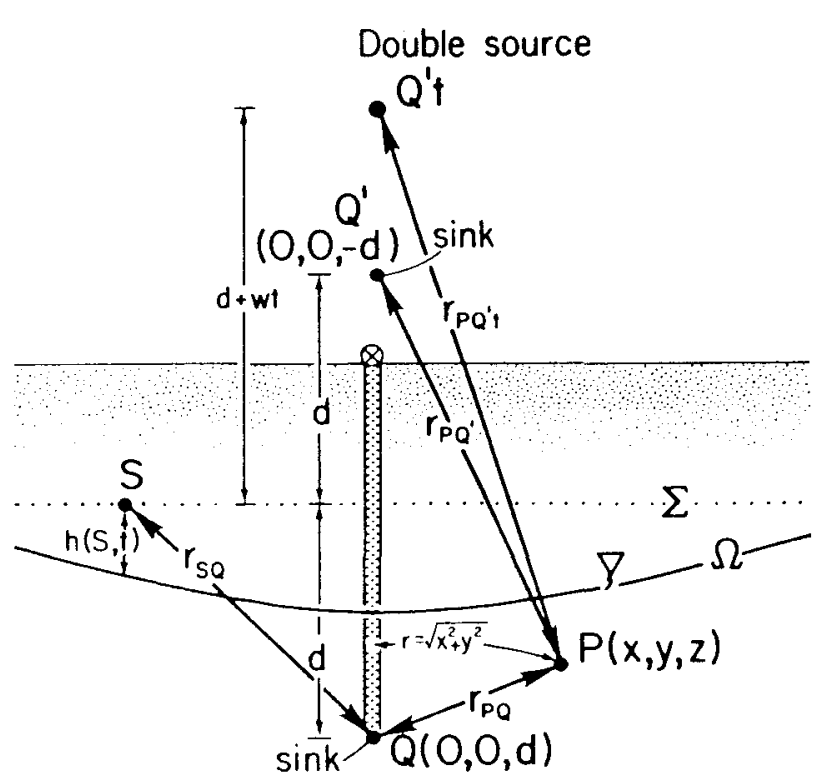

fic $i$. 1a. Intinite half space of linearized free surface method (3.iv) Discussion. Equations (18) and (53) above show that both compressibility and free surface effects lead to decline functions that ire sums or integrals over exponentials of negative time. In essence, therefore, the decline proce;ses are governed by very simple functional rela:ionships. Moreover, the analysis in section (I) ixdicates that from the quantitative point of view, the free surface effect dominates in all liquid reservoirs.

The decline or relaxation time is another parameter of major interest. By definition thi; is the time $t_{r}$ during which the amplitude of a stationary wave of wavelength $L$ decreases to (1/e) of its initial value. Inserting a waveform $\exp \left[-\left(t / t_{r}\right)+i k x\right]$ where $k=(2 \pi / L)$ is the wavenumber, into equation (14) gives for compressibility the time $t_{r}=\left(1 / a k^{2}\right)$. Similarly, we find on tiae basis of (23) for the free surface a value $t_{r}=(1 / w k)$. At the same $L$, the ratio of the free surface to compressibility time is $(\mathrm{ak} / \mathrm{w})=\left(\phi \mathrm{k} / \rho_{\mathrm{sg}}\right)$. Inserting values of interest for long-term reservoir behavior such as, for example, $\phi=0.1, L=$ $6 \mathrm{~km}, \mathrm{~s}=3 \times 10^{-11} \mathrm{~Pa}^{-1}$ we find values of this ratio of about 300. This indicates quite clearly that the compressibility phenomena are on a much shorter time scale and smaller magnitude than the free surface phenomena. Our approach of neglecting compressibility in the above analysis is, therefore, well justified.

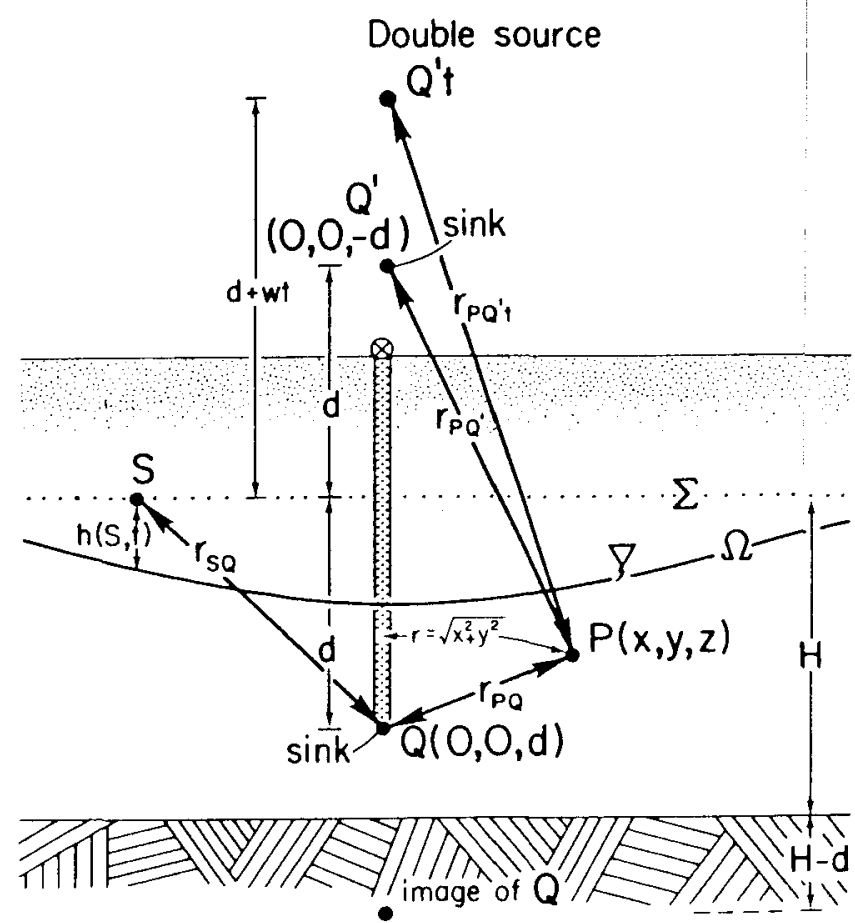

FIC. 1b. Reservoir halt space for linearized free surface nethod with bottom laver. 


\section{Reservoir simulation by lumping}

The fact that the principal decline functions for liquid reservoirs are of the negative time expo nential type suggests the use of lumping as a me thod of reservoir simulation. Below, we will brie fly look onto this possibility.

Consider a liquid geothermal reservoir that is $p$ roducing a constant mass flow q from a number of wells. We assume that the reservoir pressure is $b$ eing monitored at a fixed point where a decrea sing reference pressure function $p(t)$ is being obse rved. Moreover, it is being assumed that product ion, started at time $t=0$ from equilibrium cond itions where we can take that the reference pres sure $p(0)=0$. The producing holes have a bott om-hole pressure of $\mathrm{P}_{\mathrm{w}}(t)$ that is also taken from: an appropriate reference point as $p(t)$ and ther efore $p_{W}(0)=0$.

The simplest lumped model to simulate this syst em is shown in Fig. 2 below.

The model consists of a liquid capacitor or cont ainer (I) with vertical walls having an area A. The production $q$ is being extracted from this capicitor over a conductor that has a conductance $c_{1}$. This element represents the contact resistance of the producing holes. Recharge to the container is s stained from a capacitor (II) of an infinite arei $\mathfrak{l}$ over another conductor that has a conductance $c_{2}$. Reference pressure in the large capacitor is 1 aken to constant and equal to zero. The liquid levt $\geq I$ in $(I)$ is measured by the pressure $p_{1}(t)$. In i 1ccordance with Darcy type flow conditions we asst me that both conductors are linear and hence that: the following system equations hold

$$
\begin{gathered}
q=c_{1}\left(p_{1}-p_{w}\right) \\
(A / g) D p_{1}=c_{2}\left(0-p_{1}\right)-q
\end{gathered}
$$

wher :e $g$ is the acceleration of gravity and $D=d / d t$. Sinc:e we don't observe $p_{w}$, equation (58) is irrelevant: and does not enter into the discussion below. The principal parameters of the simulation system are thus the capacitor area $A$ and the conductance $c_{2}$. Given $q(t)$ and $p_{1}(t)$ for some fixed time int $\epsilon$ rval starting at $t=0$, we are now interested in cleriving values of $A$ and $c_{2}$ such that the model sim llates the given reservoir in the optimal way duri.ng at least a part of the production time. A

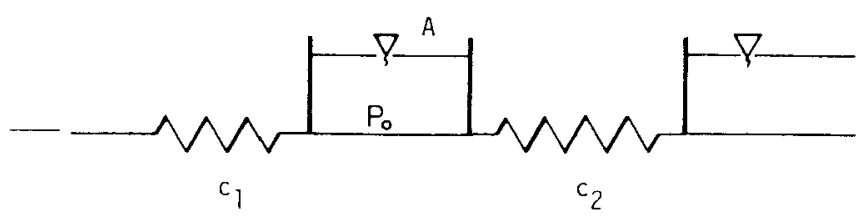

FIGi. 2. Lumped parameter model of simulated rescrvoir convenient way of obtaining these values in the following.

Since we have assumed that $q$ is constant, the present decline function $p_{1}(t)$ is characterized by a smooth negative time exponential behavior. We can then expand the known $p_{1}(t)$ into a Taylor series in $t$ starting at $t=0$ and that is truncated at the second order term,

$$
\mathrm{p}_{1}(\mathrm{t})=\mathrm{p}_{1}(0)+t \mathrm{p}_{1}(0)+\left(\mathrm{t}^{2} / 2\right) \mathrm{D}^{2} \mathrm{p}_{1}(0),
$$

where we have abbreviated $\left.D_{p_{1}}\right|_{t=0}=D p_{1}(0)$ and $\left.\mathrm{D}^{2} \mathrm{p}_{1}\right|_{\mathrm{t}=0}=\mathrm{D}^{2} \mathrm{p}_{1}(0)$.

Since $p_{1}(0)=0$ this series reduces to

$$
p_{1}(t)=t D p_{1}(0)+\left(t^{2} / 2\right) D^{2} p_{1}(0),
$$

Inserting this expression in equation (59) results in

$$
\begin{aligned}
&(A / g)\left[D_{P_{1}}(0)+t D^{2} p_{1}(0)\right]=c_{2}\left[-t D_{P_{1}}(0)-\right. \\
&\left.\left(t^{2} / 2\right) D^{2} p_{1}(0)\right]-q,
\end{aligned}
$$

On a second order appproximation, we obtain from the terms in $t^{\circ}$ and $t$ the parameter relations

$$
A=-g\left[q / D p_{1}(0)\right]
$$

and

$$
\begin{aligned}
c_{2}=-(A / g) D^{2} p_{1}(0) / D p_{1}(0) & = \\
& \left(A^{2} / \mathrm{qg}^{2}\right) D^{2} p_{1}(0) .
\end{aligned}
$$

Since $\mathrm{p}_{1}(t)$ is a known function, the derivatives at $t=0$ are also known and we can thus derive $A$ and $c_{2}$ from (63) and (64) above.

On the basis of the known parameters, we can then solve equation (59) for a given variable input $q(t)$ and obtain

$$
p_{1}(t)=(g / A) \int_{0}^{t} \exp \left[-g c_{2}(t-\tau) / A\right] q(\tau) d t
$$

as a procedure to predict or extend $\mathrm{P}_{1}(\mathrm{t})$ in time.

An analysis of the above type can be carried out on any field decline functions that have been obtained with sufficient accuracy to derive the derivatives. In most practical cases the mass production function will be a variable $q(t)$ and the input function $p_{1}(t)$ for the above analysis will then have to be obtained by a deconvolution, that is by solving an equation

$$
p_{f}(t)=\int_{0}^{t} p_{1}(t-\tau) D q(\tau) d \tau,
$$

where $p_{f}(t)$ is the reference pressure that is the output to $q(t)$. There are no problems in solving (66).

To illustrate the above procedure we will carry out the lumping of the free surface dynanics model leading to equation (46). We obtain then the time derivatives $\mathrm{Dp}_{1}(0)$ and $\mathrm{D}^{2} \mathrm{p}_{1}(0)$ from equation (46) and use (63) and (64) to derive the lumped system parameters. To simplfy the procedure, 
we consider only the case $q=$ constant = unity .

Omitting elementary details and irrelevant factors, the method, in essence, consists in approximating the function

$$
E_{1}(t)=-\left[1-\left(R_{0} / R_{1}\right)\right]
$$

by the function

$$
f_{2}(t)=-\left[(z+d)^{2} / R_{2}^{2}\right]\left[1-\exp \left[-w t R_{2}^{2} / R_{o}^{2}(z+d)\right)\right],(68)
$$

where

$$
R_{0}=\left[r^{2}+(z+d)^{2}\right]^{\frac{1}{2}}
$$
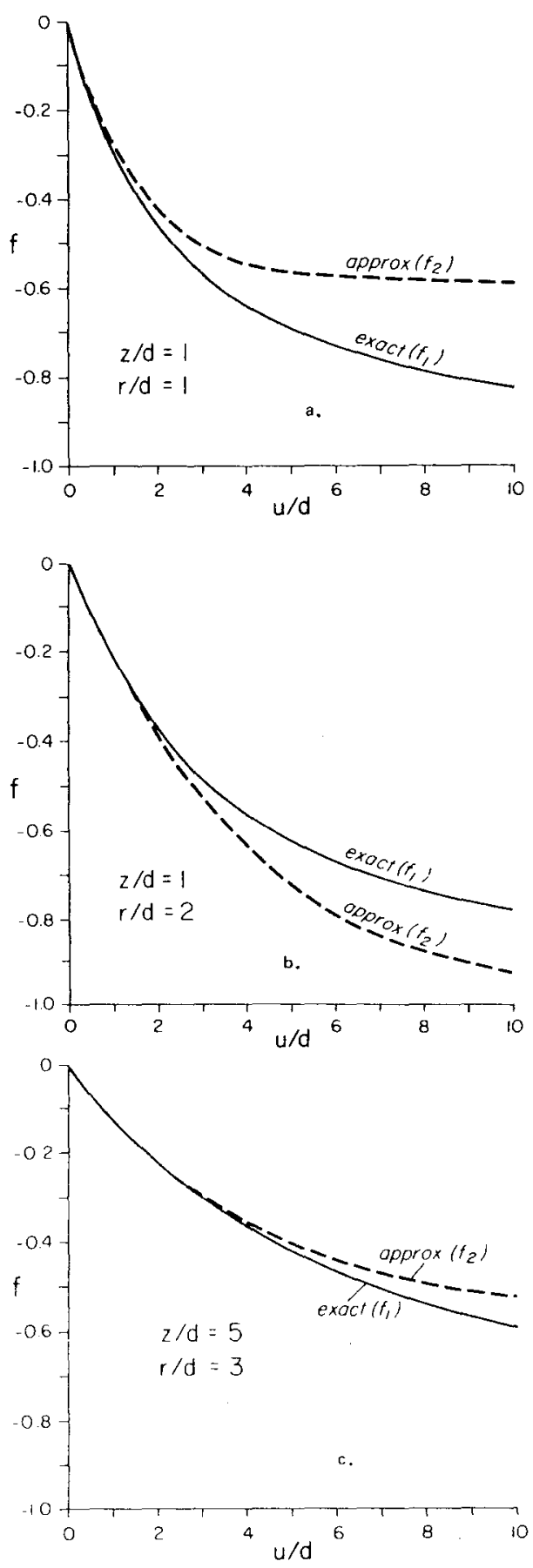

$$
\begin{aligned}
R_{1} & =\left[r^{2}+(z+w t+d)^{2}\right]^{\frac{1}{2}} \\
R_{2} & =\left[2(z+d)^{2}-r^{2}\right]^{\frac{1}{2}} \\
& \text { with } r^{2}<2(z+d)^{2}
\end{aligned}
$$

The results of a numerical evaluation are illustrated in Fig. 3. It is evident that the lumped approximation holds quite well until the factor wt is of the order of a few depths d. Quite often $w$ is of the order of $10^{-5} \mathrm{~m} / \mathrm{s}$ and $\mathrm{d}$ about $10^{3} \mathrm{~m}$. In this case the lumped approximation will give good results for a period of a $\mathrm{f} \in \mathrm{w}$ years.
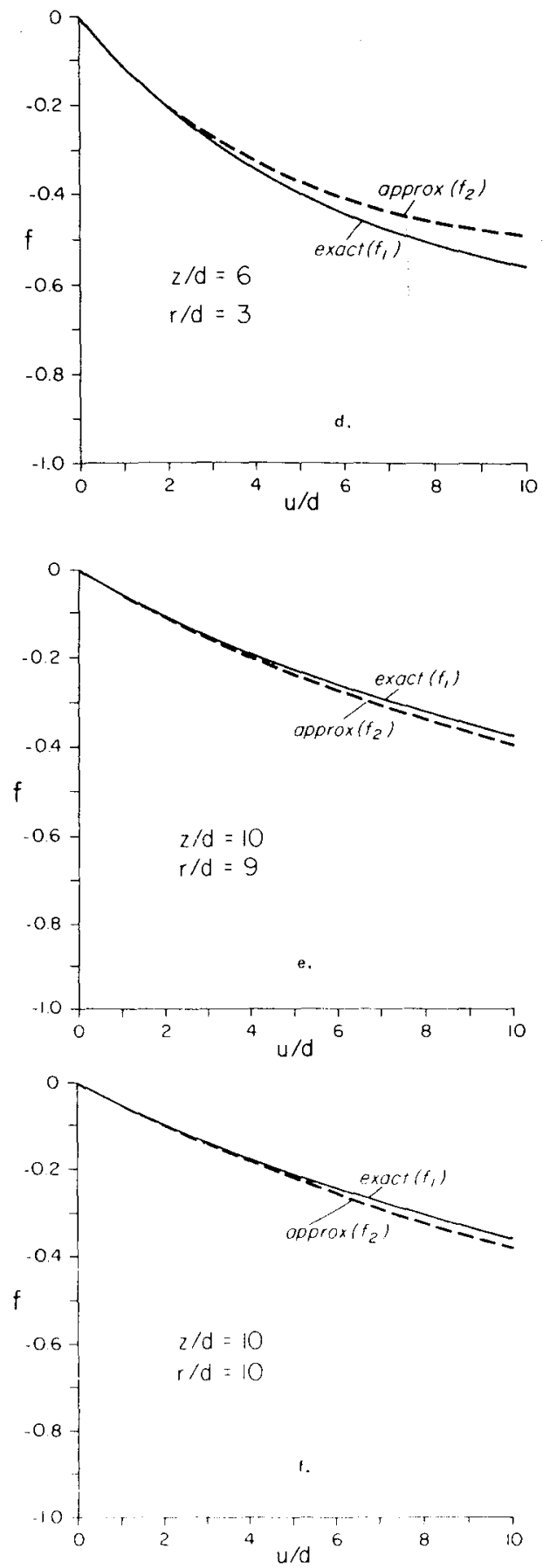

FICS. 3a-3f. Comparisons between lumped parameter approximation and exact solution. 


\section{REVIEW OF METHODS}

\section{Petroleum Reservoirs}

Production decline methods are probably the most commonly used tool of the reservoir engineer because production data are always recorded and filed whereas temperature and pressure records are far less common. The uses of these methods are at least two fold. First, they are used to predict future production and second, they can provide insight into reservoir mechanisms and geology.

Production data for fields and individual wells are usually plotted on a monthly basis so a year's worth of data might be enough to use with the standard methods. When fields have been produced for a number of years, e.g., 10, production data are plotted on an annual basis and fitted. In the petroleum industry great care must be taken in trying to extrapolate past trends because conditions can change. For example, the reservoir pressure might pass through a bubble point causing dissolved gas to outgas thereby drastically changing flow conditions. The best discussion of and warning about decline methods is in Brons (1963).

Reserve estimates are calculated from predicted future production. It the predictions are bad, the estimates are bad. Brons shows an example using production from two wells, each with constant but different percentage decline rates. When their productions are added together and fitted with a hyperbolic eqn (the best fit) we get a very different reserve estimate from the one obtained by looking at each well separately. As always, the reservoir analyst must supply a great deal of insight.

Decline methods are not directly applicable to new fields except that if the new field appears to be similar to a previously studied field we might make some intelligent guesses about its production characteristics.

Decline methods are used to determine when additional wells should be drilled and when wells should be worked over. Production in individual wells can decrease in a steady regular manner from sand plugging the formation. This can be seen on a production vs. time graph.

\section{Geothermal Reservoir}

The decline methods developed for analyzing oil and gas wells can be used for geothermal wells but we must recognize that petroleum and geothermal reservoirs are very different from each other. These differences can cause production mechanisms to be drastically different in the two cases. Some of the more important differences and their consequences are as follows:

a. Petroleum reservoirs are usually sedimentary formations. Geothermal reservoirs are usually fractured igneous or metamorphic formations. Darcy flow holds in the first case and fracture flow in the second. b. Temperature is relatively unimportant in petroleum production. It is critical in geothermal production. High temperatures stress tubing and cement in the wellbore.

c. Geothermal well flow volumes are often 1 to 2 orders of magnitude greater then petroleum volumes.

d. Precipitation is much more serious in geothermal wells than in petroleum wells.

e. Petroleum is a complex mixture with volatile components. Geothermal water is essentially one species.

Fracture size, quantity and distribution are drastically affected by precipitation, changes in temperature and seismic activity. Geothermal reservoirs seen to be much more complex than petroleum reservoirs so methods taken into geothermal work must be examined carefully. We have done this with the data and methods available but more work must be done as we produce more geothermal fields over time.

\section{1. $\underline{\text { Arps }}$}

Arps's (1945, 1956) work forms the basis for all the decline curve methods currently in use. He brought together and codified work on oil reserve estimation that had been done as early as 1908. The commonest methods were graphical in which production $\mathrm{q}$ or cumulative production $Q$ was plotted vs. time t. See Fig. 4 from Arps (1956). Examinations of production data showed that data with constant first differences fit an exponential equation while data with constant second differences fit a hyperbolic or harmonic equation. All three equations can be expressed as

$$
\mathrm{a}=\mathrm{Kq}^{\mathrm{b}}=\frac{-\mathrm{dq} / \mathrm{dt}}{\mathrm{q}}
$$

where

$a=$ fractional decline

some authors use $D=$ fractional decline $q=$ production rate of time $t$

$\mathrm{K}=$ constant

$b=$ constant

The solutions to equation (72) are shown in Table 1.

Guerrero (1961) gives a good "cookbook" approach to analyzing data using these methods. See Table 2 for problems worked out by Guerrero. Arps's equations were considered to be strictly empirical until 1973 when Fetkovich proposed some theoretical basis for the exponential equation (see below). The hyperbolic equation is still considered to be empirical.

\section{Fetkovich}

Fetkovich (1973) showed that log-log type curves can be used to analyze production data in an analogous manner to analyzing pressure data. He presented $\log -\log$ plots of dimensionless flow rate, $q_{D d}=q(t) / q_{i}$, vs. dimensionless time, $t_{D d}=D_{i} t$, for $0 \leq b<1$ and $D_{i}=1$ (see Fig. 5). $b=0$ is the exponential solution while $b=1$ is the harmonic solution. 
RATE-TIME CURVES
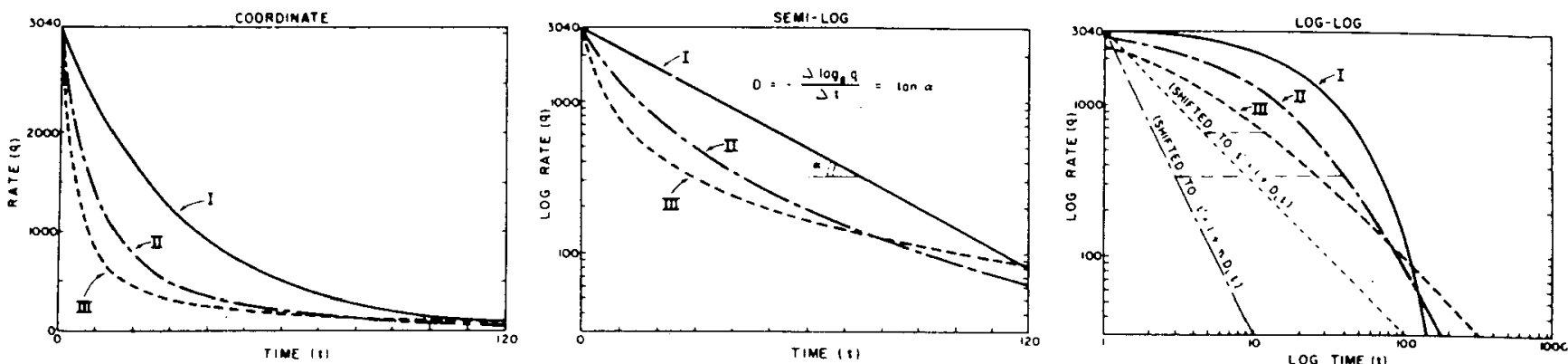

RATE - CUMULATIVE CURVES
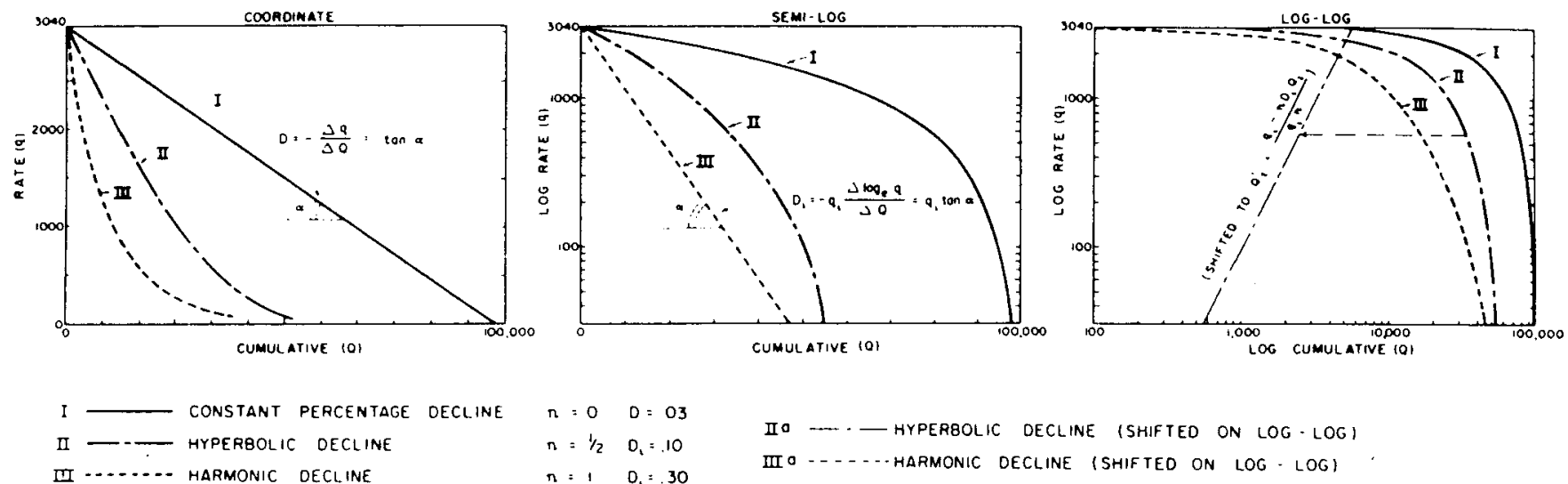

$\begin{array}{ll}n=0 & 0=03 \\ n=1 / 2 & 0_{1}=10 \\ n=1 & D_{4}=30\end{array}$

II - - HYPER8OLIC DECLINE (SHIFTED ON LOG - LOG)

IIIO--..-HARMONIC OECLINE (SHIFTED ON LOG - LOG)

FIG. 4. Three types of production decline curves on coordinate, semi-log, and log-log graph paper (from Arps, 1956).

The exponential curve is given by

$$
\mathrm{q}_{\mathrm{Dd}}=\exp \left(-\mathrm{D}_{\mathrm{i}} \mathrm{t}\right), \quad \mathrm{D}_{\mathrm{i}}=1
$$

while the hyperbolic curves are given by

$$
\mathrm{q}_{\mathrm{Dd}}=\left(I+\mathrm{bD}_{i} \mathrm{t}\right)^{-1 / \mathrm{b}} \text { for } 0<\mathrm{b} \leq 1 \text {. }
$$

Using an overlay technique as shown very clearly in Earlougher (1977), (see Fig. 6), production data can be plotted over the curves and a decline exponent can be picked. For $\mathrm{t}_{\mathrm{Dd}}<0.3$ all the curves are coincident.

Fetkovich showed that the exponential decline has a fundamental base by deriving it as a solution to the constant well pressure case. The equation for dimensionless flow rate is

$$
\mathrm{q}_{\mathrm{Dd}}=\mathrm{q}(\mathrm{t}) / \mathrm{q}_{\mathrm{i}}=\exp \left[-\left(\mathrm{q}_{\mathrm{i}}\right)_{\max } \mathrm{t} / \mathrm{N}_{\mathrm{pi}}\right]
$$

This equation can be related to (73) by setting

$$
\mathrm{D}_{i}=\left(\mathrm{q}_{\mathbf{i}}\right)_{\max } / \mathrm{N}_{\mathrm{p} i}
$$

then

$$
\mathrm{t}_{\mathrm{Dd}}=\frac{\left(\mathrm{q}_{\mathrm{i}}\right)_{\max }{ }^{\mathrm{t}}}{\mathrm{N}_{\mathrm{p} i}}
$$

We define

$$
\begin{aligned}
& \mathrm{N}_{p i}=\frac{\pi\left(\mathrm{r}_{\mathrm{e}}^{2}-\mathrm{r}_{\mathrm{w}}^{2}\right) \phi \mathrm{c}_{t} \mathrm{hp}_{\mathrm{i}}}{5.615 \mathrm{~B}} \\
& \left(\mathrm{q}_{\mathrm{i}}\right)_{\max }=\frac{\mathrm{khp_{i }}}{141.3 \mu \mathrm{B}\left[\ln \left(\mathrm{r}_{\mathrm{e}} / \mathrm{r}_{\mathrm{w}}\right)-1_{2}\right]}
\end{aligned}
$$

Fina11y we get

$$
\mathrm{q}_{D d}=\frac{\mathrm{q}(\mathrm{t})}{\frac{\mathrm{kh}\left(\mathrm{p}_{\mathbf{i}}-\mathrm{p}_{\mathrm{wf}}\right)}{141.3 \mu \mathrm{B}\left[\ln \left(\mathrm{r}_{\mathrm{e}}-\frac{2}{2}\right)\right]}}
$$

Fetkovich showed that production decline curve data could be used to derive values for permeability thickness kh which is usually obtained from pressure data. (see Fig. $7 \mathrm{a}$ and $7 \mathrm{~b}$ ). Compare kh calculations from rate-time data and pressure time data.

\section{S1ider's Method}

Slider (1968) proposed a simple method of curve matching to obtain the hyperbolic exponent 
TABLE 1. CLASSIFICATION OF PRODUCTION DECLINE CURVES

\begin{tabular}{|c|c|c|c|}
\hline DECLINE TYPE & $\begin{array}{l}\text { 1. CONSTANT-PERCENTAGE } \\
\text { DECLINE }\end{array}$ & $\begin{array}{l}\text { II. HYPERBOLIC } \\
\text { DECLINE }\end{array}$ & $\begin{array}{l}\text { III. HARMONIC } \\
\text { DECLINE }\end{array}$ \\
\hline \multirow[t]{2}{*}{$\begin{array}{c}\text { BASIC } \\
\text { CHARACTERISTIC }\end{array}$} & $\begin{array}{c}\text { DECLINE IS CONSTANT } \\
n=0\end{array}$ & $\begin{array}{c}\text { OECLINE IS PROPORTIONAL } \\
\text { TO A FRACTIONAL POWER (n) } \\
\text { OF THE PRODUCTION RATE } \\
0<n<1\end{array}$ & $\begin{array}{c}\text { DECLINE IS PROPORTIONAL } \\
\text { TO PROOUCTION RATE } \\
n=1\end{array}$ \\
\hline & $\begin{array}{l}D=K \cdot q^{0}=-\frac{d q d t}{q} \\
\int_{0}^{t} D d t=-\int_{q_{i}}^{q_{t}} \frac{d q}{q} \\
-D t=\log _{e} \frac{q_{t}}{q_{t}}\end{array}$ & $\begin{array}{l}D=K \cdot q^{n}=-\frac{d q / d t}{q} \\
\text { FOR INITIAL CONDITIONS: } \\
K=\frac{D_{i}}{q_{i}^{n}} \\
\int_{0}^{l} \frac{D_{i}}{q_{i}^{n}} \cdot d t=-\int_{q_{i}}^{q_{t}} \frac{d_{q}}{q^{n+1}} \\
\frac{n D_{i} i}{q_{i}^{n}}=q_{i}^{-n}-q_{i}^{-n}\end{array}$ & $\begin{array}{l}D=K \cdot q^{\prime}=-\frac{d q / d t}{q} \\
\text { FOR INITIAL CONOITIONS: } \\
k=\frac{D_{i}}{q_{i}} \\
\int_{0}^{t} \frac{D_{i}}{q_{i}} \cdot d t=-\int_{q_{i}}^{q_{t}} \frac{d_{q}}{q^{2}} \\
\frac{D_{L} t}{q_{i}}=\frac{1}{q_{L}}-\frac{1}{q_{t}}\end{array}$ \\
\hline \multirow[t]{2}{*}{$\begin{array}{l}\text { RATE - TIME } \\
\text { RELATIONSHIP }\end{array}$} & $q_{t}=q_{i} \cdot e^{-D t}$ & $q_{t}=q_{i}\left(1+n D_{l} t\right)^{-\frac{1}{n}}$ & $q_{i}=q_{i}\left(1+D_{i} t\right)^{-1}$ \\
\hline & $\begin{array}{l}Q_{t}=\int_{0} q_{t} \cdot d t=\int_{0} q_{t} \cdot e^{-D t} \cdot d t \\
Q_{t}=\frac{q_{3}-q_{i} \cdot e^{-D t}}{D} \\
\text { Substitute From Rote-time Equotion: } \\
q_{i} \cdot e^{-D t}=q_{t} \\
\text { To Find: }\end{array}$ & $\begin{array}{l}Q_{t}=\int_{0} Q_{t} \cdot d t=\int_{0}\left(1+n D_{i} t\right)^{-\frac{1}{n}} \cdot d t \\
Q_{t}=\frac{Q_{i}}{(n-1) D_{i}}\left[\left(1+\pi D_{t} t\right)^{\frac{n-1}{n}}-1\right] \\
\text { Substitute From Rate-time Equation: } \\
\left(1+n D_{i} t\right)=\left(\frac{q_{i}}{q_{t}}\right)^{n} \\
\text { To Find: }\end{array}$ & $\begin{array}{l}a_{t}=\int_{0} Q_{t} \cdot d t=\int_{0} Q_{i}\left(1+D_{i} t\right)^{-1} \cdot d t \\
a_{t}=\frac{a_{i}}{D_{i}}\left[\log _{e}\left(1+D_{i} t\right)\right] \\
\text { Substitute From Rote - time Equotion: } \\
\left(1+D_{i} t\right)=\frac{q_{i}}{a_{t}} \\
\text { To Find: }\end{array}$ \\
\hline $\begin{array}{c}\text { RATE - CUMULATIVE } \\
\text { RELATIONSHIP }\end{array}$ & $Q_{t}=\frac{Q_{t}-q_{t}}{D}$ & $Q_{t}=\frac{q_{i}^{n}}{(1-n) D_{i}}\left(q_{i}^{1-n}-q_{i}^{1-n}\right)$ & $Q_{t}=\frac{q_{i}}{D_{i}} \log _{0} \frac{q_{i}}{q_{t}}$ \\
\hline $\begin{array}{l}D=\text { Decline do o froct } \\
D_{1}=\text { initiol decline } \\
q_{1}=\text { Initial production } \\
1=\text { Time }\end{array}$ & $\begin{array}{l}\text { ion of production rote } \\
\text { rote }\end{array}$ & $\begin{array}{l}Q_{t}=\text { Production rate at time } t \\
Q_{t}=\text { Cumulative oil production ot time } \\
k=\text { Constant } \\
n=\text { Exponent }\end{array}$ & \\
\hline
\end{tabular}

TABLE 2. EXAMPLE OF USE OF EXPONENTTAL EQUATION

(1)

(2)

(3)

(4)

(5)

(8)

\begin{tabular}{|c|c|c|c|}
\hline Year & $\begin{array}{l}\text { Time, } \\
\text { Total }\end{array}$ & $\begin{array}{l}\text { years } \\
\text { Ave. }\end{array}$ & $\begin{array}{c}\mathrm{q}_{0}= \\
0 i 1 \text { prod. rate } \\
\text { bbl./yr. }\end{array}$ \\
\hline $\begin{array}{l}1947 \\
1948 \\
1949 \\
1950 \\
1951 \\
1952 \\
1953\end{array}$ & $\begin{array}{l}1 \\
2 \\
3 \\
4 \\
5 \\
6 \\
7\end{array}$ & $\begin{array}{l}0.5 \\
1.5 \\
2.5 \\
3.5 \\
4.5 \\
5.5 \\
6.5\end{array}$ & $\begin{array}{l}99,200 \\
88,210 \\
73,240 \\
63,990 \\
54,910 \\
47,400 \\
41,580\end{array}$ \\
\hline
\end{tabular}

Future Performance

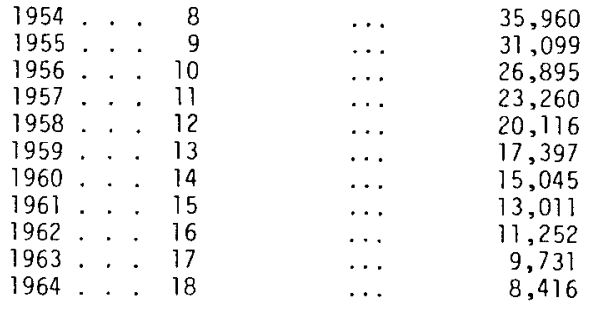

$(4)_{n-7}^{\Delta q_{0}}-(4)_{n}$
$i 0,990$
14,970
9,250
9,080
7,510
5,820

(6) (7)

$\Delta=$

7)

qoav. $^{(4)_{n-1}+(4)_{n}}$
$\frac{2}{93,705}$
80,725
68,615
59,450
51,155
44,490

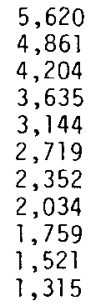
Cav. oil ${ }^{\mathrm{N}}=$ Cum. (5): (6) 0 il recover

$$
\begin{array}{lr}
0.117 & 99,200 \\
0.187,410 \\
0.185 & 260,650 \\
0.135 & 324,640 \\
0.153 & 379,550 \\
0.147 & 426,950 \\
0.131 & 468,530 \\
\cline { 1 - 1 } 0.868 &
\end{array}
$$

$D_{a v,}=0.868: 6=0.145$

38,170

33,530

33,530
28,997

25,078

21,688

18,757

16,221

14,028

12,132

10,492

10,492
9,074
504,490

535,589

562,484

585,744

605,860

623,257

638,302

651,313

662,565

672,296

680,712
0.145

0.145
0.145
0.145

0.145
0.145

0.145

0.145

0.145

0.145

0.145

0.145
0.145
(9) $N_{p} \frac{\Delta N_{p}}{2}$

(8)

49,600

143,305

224,030

292,645

352,095

403,250

447,740

....

$\ldots .$.

....

....

.....

....

....

....

$\cdots$ 


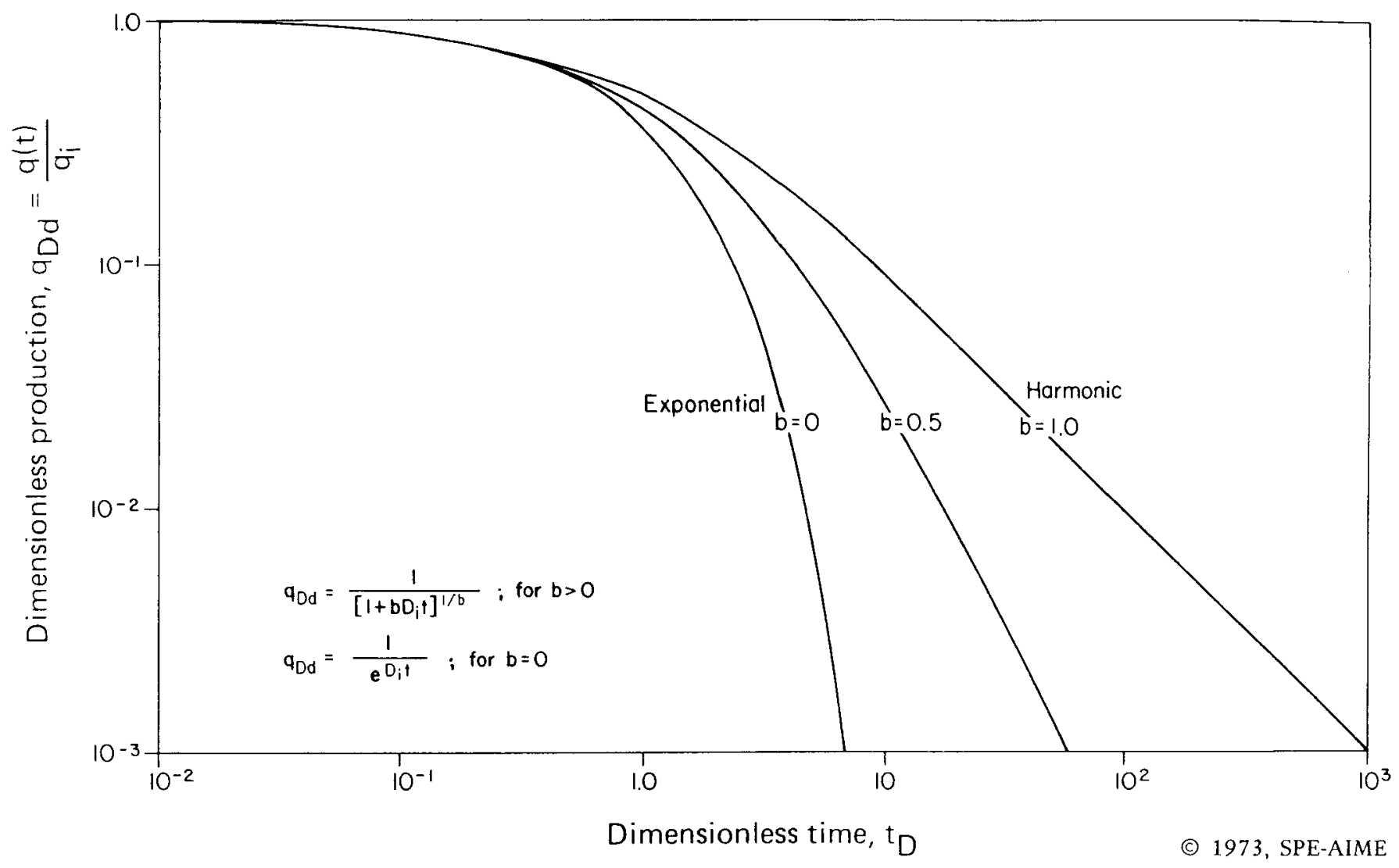

FIG. 5. Log-log type-curve of dimensionless flow rate vs dimensionless time (after Fetkovich, 1973).

$b$ and the initial decline rate $q_{i}$. To use the method one needs to construct a set of curves of $\mathrm{q}_{\mathrm{q}} \mathrm{q}_{i}$ vs. $\log$ time for various values of $\mathrm{a}_{i}$ and b using Arps's hyperbolic equation. Production data can then be plotted on the curves by using a transparent overlay. The overlay can be moved around until the best fit is found thus giving $b$ and $a_{i}$. From equations or from a second set of curves, future production rates $\mathrm{q}$ and future cumulative production $Q$ can easily be estimated. This method is easy to apply but it requires a separate set of curves for each possible value of $b$. Later methods eliminate this shortcoming.

\section{Gentry's Method}

Gentry (1972) developed curves which are much easier to use then Slider's because only one set is needed for all values of $\mathrm{b}$ between 0 and 1 . (see Figs. 8a and 8b) We can find b from a plot of $Q / \mathrm{tq}_{i}$ vs. $\log \mathrm{q}_{i} / \mathrm{q}$. With this $\mathrm{b}$ we go to a plot of $q_{i}$ vs. $\log q_{i} / q$ and find $a_{i}$. This gives us all the factors we need for a reserve analysis.

\section{Gentry and McCray}

Reservoir analysts have usually assumed that $0<b<1$ in the solution of Arps's equations. See
Higgins and Lechtenberg (1970) for exceptions. There is no mathematical basis for this restriction. $\mathrm{b}=0$ and $\mathrm{b}=1$ are special cases, the exponential and harmonic, respectively, but this does not restrict $b$ from being larger than 1 . Gentry and McCray (1978) investigated decline curve methods using semi-log plots of $q_{i} / q$ vs. Q/qit, cartesian plots of $\mathrm{q} / \mathrm{q}_{i}$ vs. $Q$, and semi-log plots of $\mathrm{q} i / \mathrm{q}$ vs. $a_{i} t$. See Figures $9 a, 9 b$, and $9 c$. Some of their conclusions are $\left(\mathrm{N}_{\mathrm{p}}=\mathrm{Q}\right)$

1. The dimensionless curves $N_{p} / q_{i} t$ vs. $q_{i} / q$ $a_{i t}$ vs. $q_{i} / q$ for a particular fluidpermeability system are not affected by the absolute permeability or size of the reservoir. The behavior of these plots is determined by (1) the characteristics of the contained fluid, (2) the relative permeability characteristics of the reservoir rock, (3) the reservoir drive mechanism, (4) reservoir heterogeneity, and (5) manual manipulation of production.

2. Reservoir heterogeneity tends to increase the magnitude of $b$ as the degree of heterogeneity is increased. It is also apparent that b for a heterogeneous system 


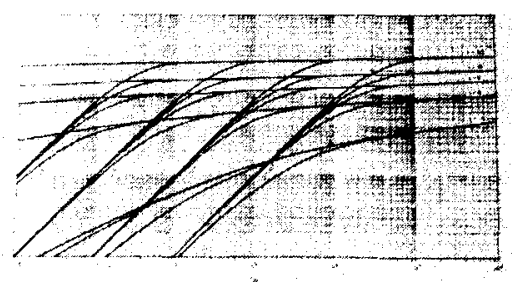

(a) Choose a type curve.

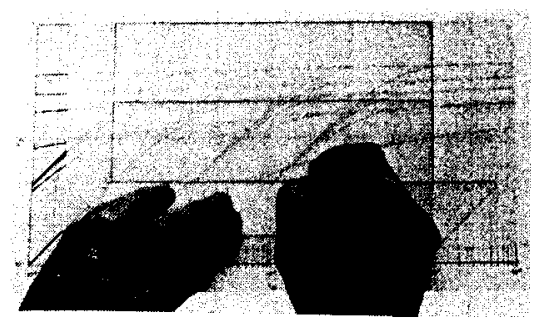

(c) Trace major grid lines.

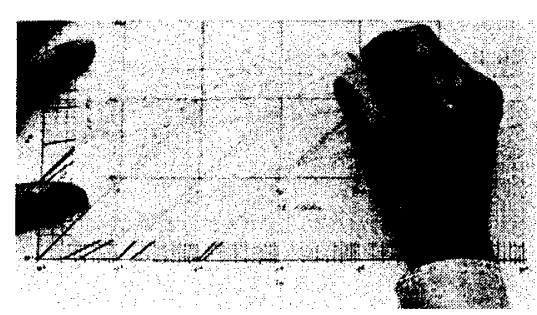

(e) Plot observed data using type-curve grid.

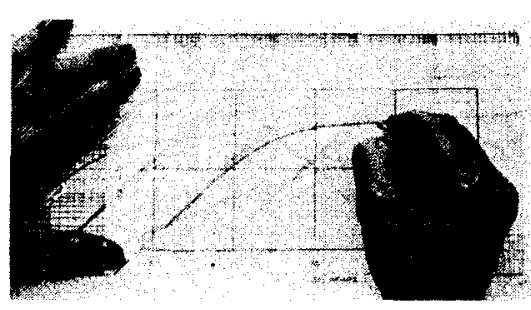

(g) Trace the matched curve.

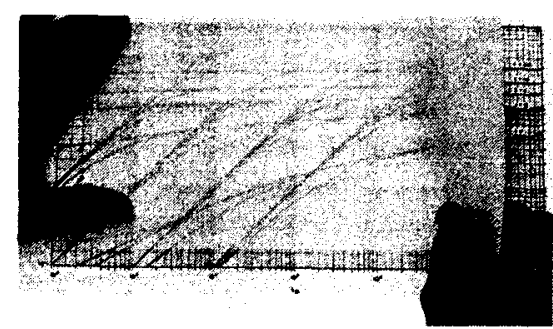

(b) Overlay with tracing paper.

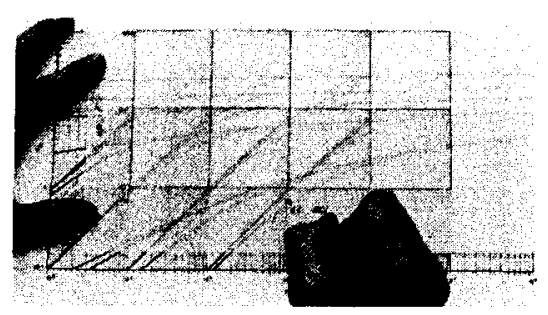

(d) Label axes.

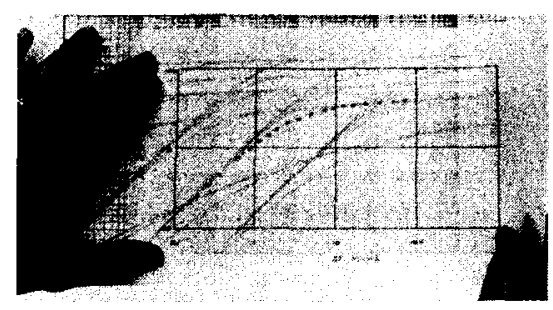

(f) Slide tracing paper to match a type curve.

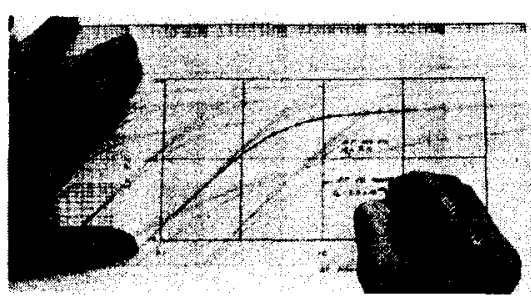

(h) Pick a match point

(C) 1977, SPE-AIME

FIG. 6. Steps in type-curve matching (from Earlougher, 1977). 


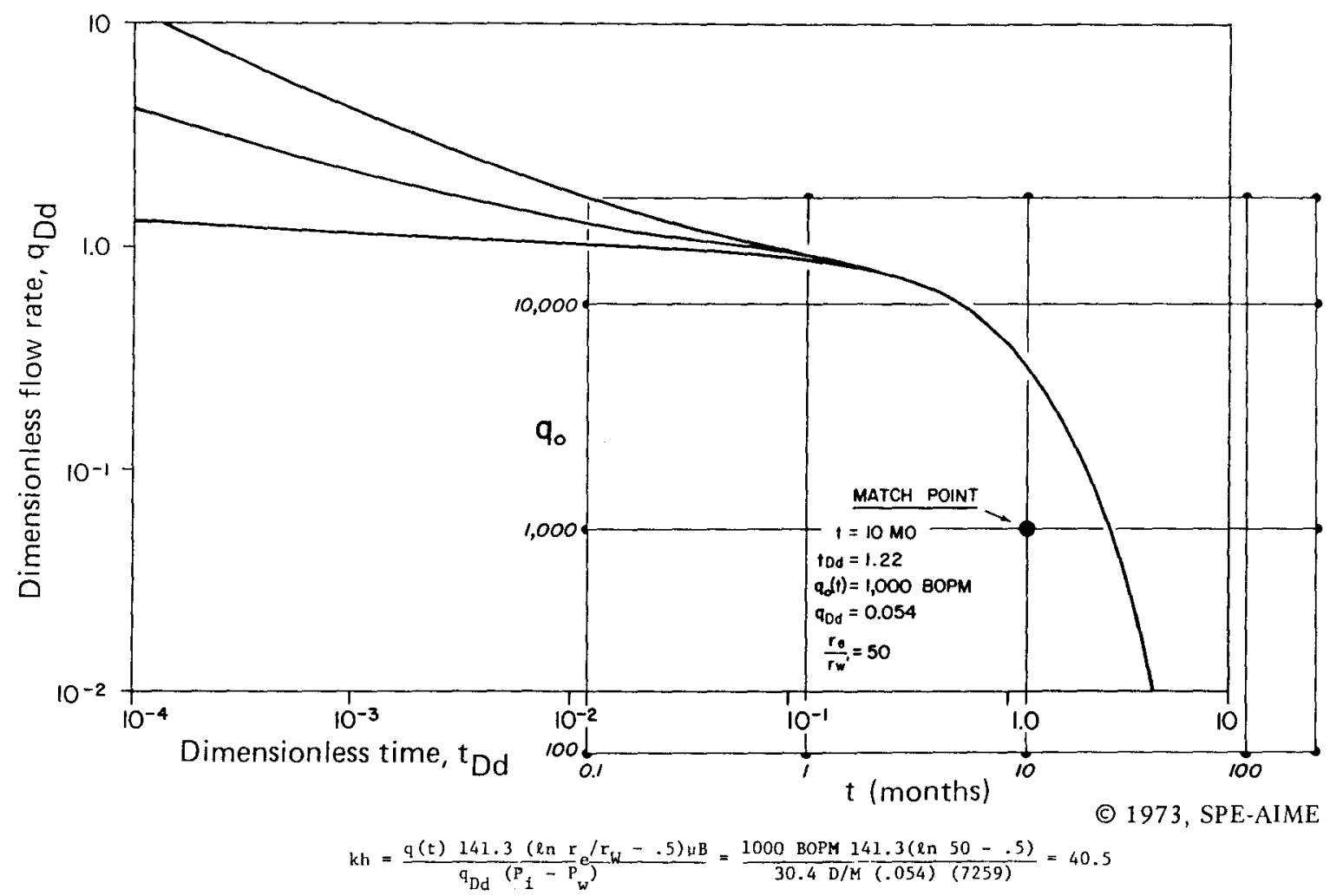

FIG. 7a. Type-curve matching example for calculating Kh using decline curve data (after Fetkovich, 1973).

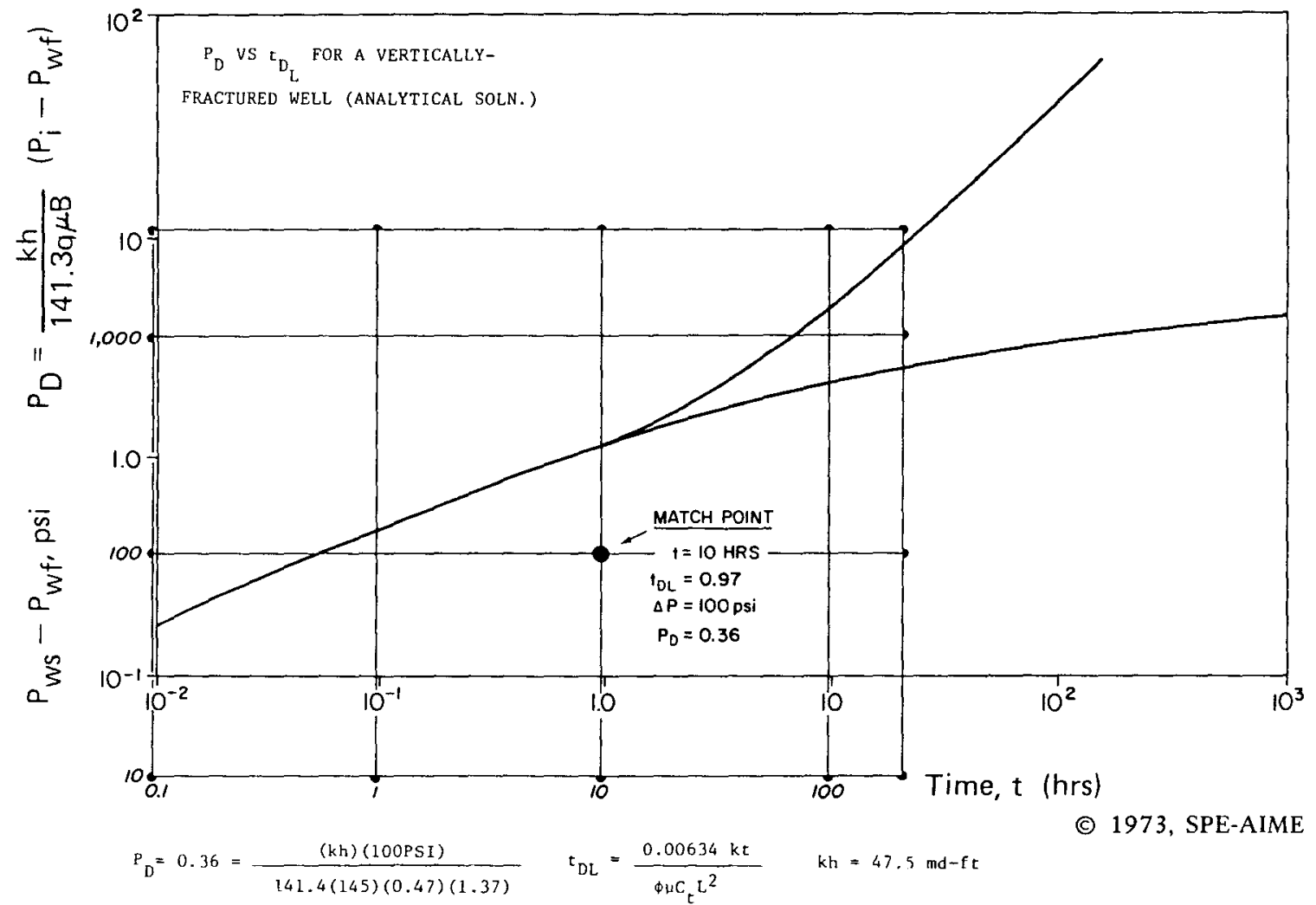

FIG. 7b. Type-curve matching example for calculating Kh from pressure buildup (after Fetkovich, 1973). 


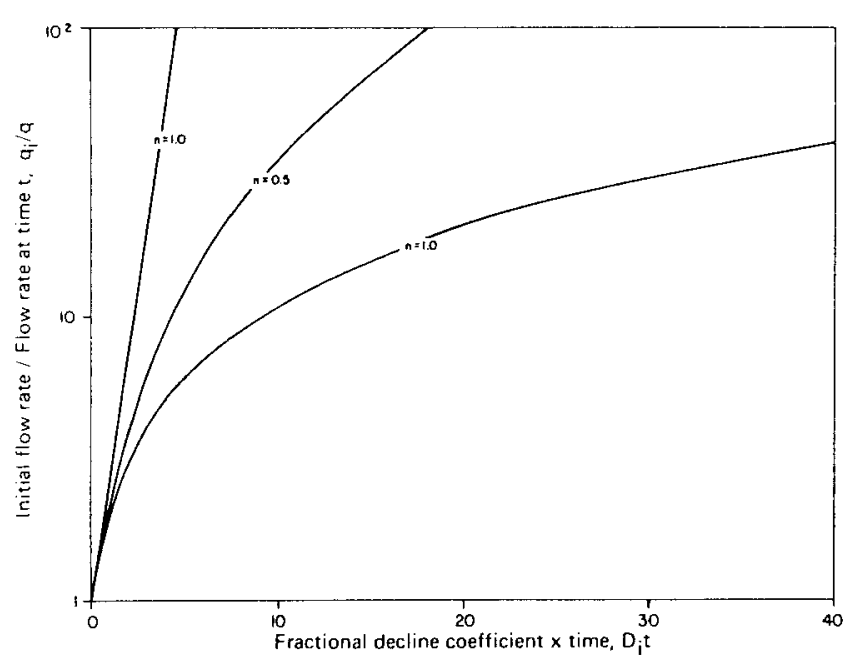

(C) 1972, SPE-AIME

FIG. 8a. Decline curve analysis chart relating production rate to time (after Gentry, 1972).

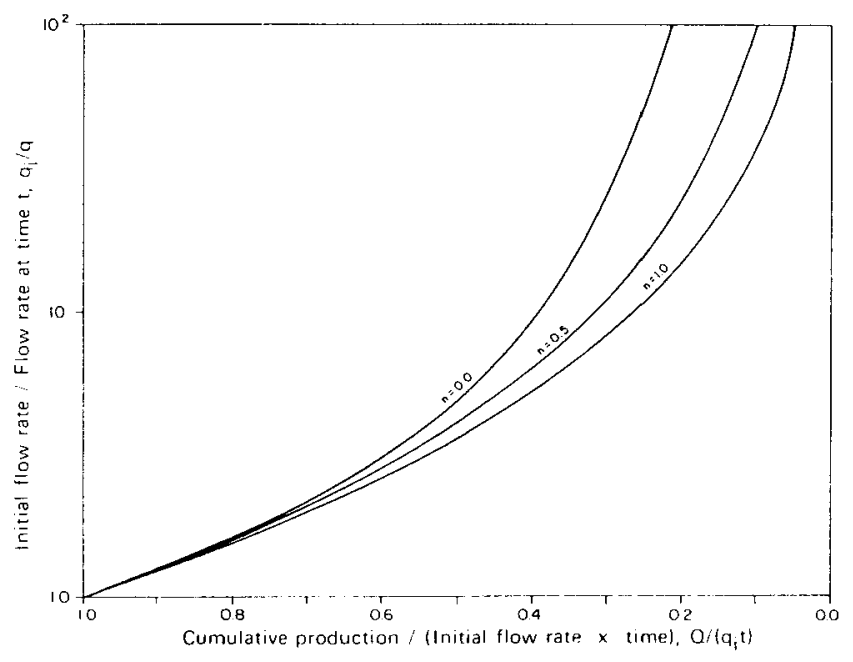

(C) $1972, \mathrm{SPE}-\mathrm{AIME}$

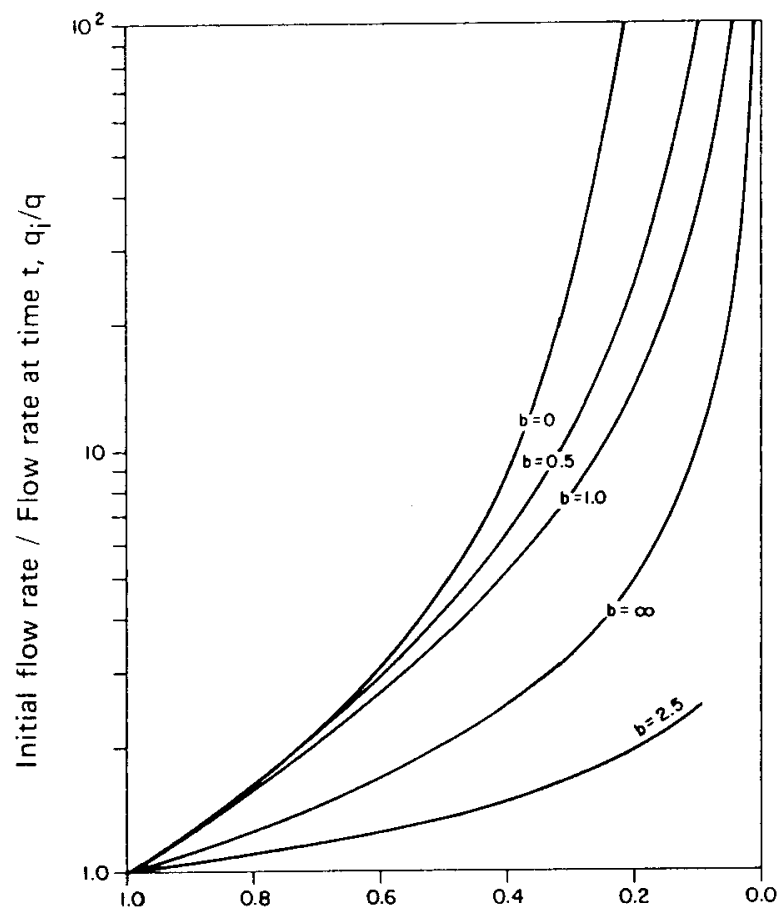

Cumulative production / (Initial flow rate $\times$ time), $Q /\left(q_{i} t\right)$

(C) 1978 APE-AIME

FIG. 9 a. $Q /\left(\mathrm{q}_{\mathrm{i}} \mathrm{t}\right)$ vs $\mathrm{q}_{\mathrm{i}} / \mathrm{q}$ (after Gentry \& McCray, 1978).

FIG. 8 b. Decline curve analysis chart relating production rate to cumulative production (after Gentry, 1972). 


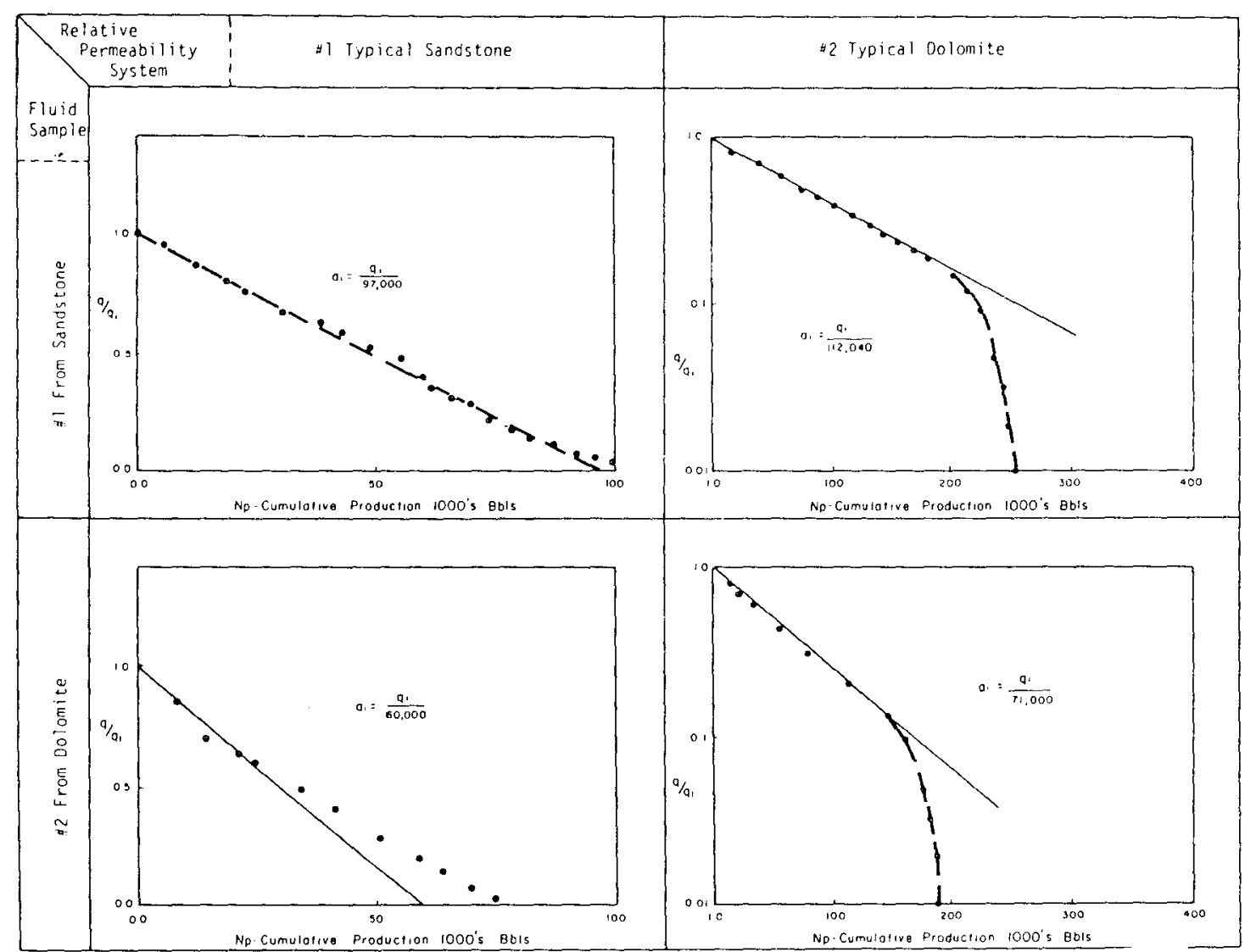

FIG. 9b. Plots of cumulative production vs $\mathrm{q} / \mathrm{q}_{1}$ for four fluid-permeability systems (after Gentry \& McCray, 1978). (C 1978, SPE-AIME

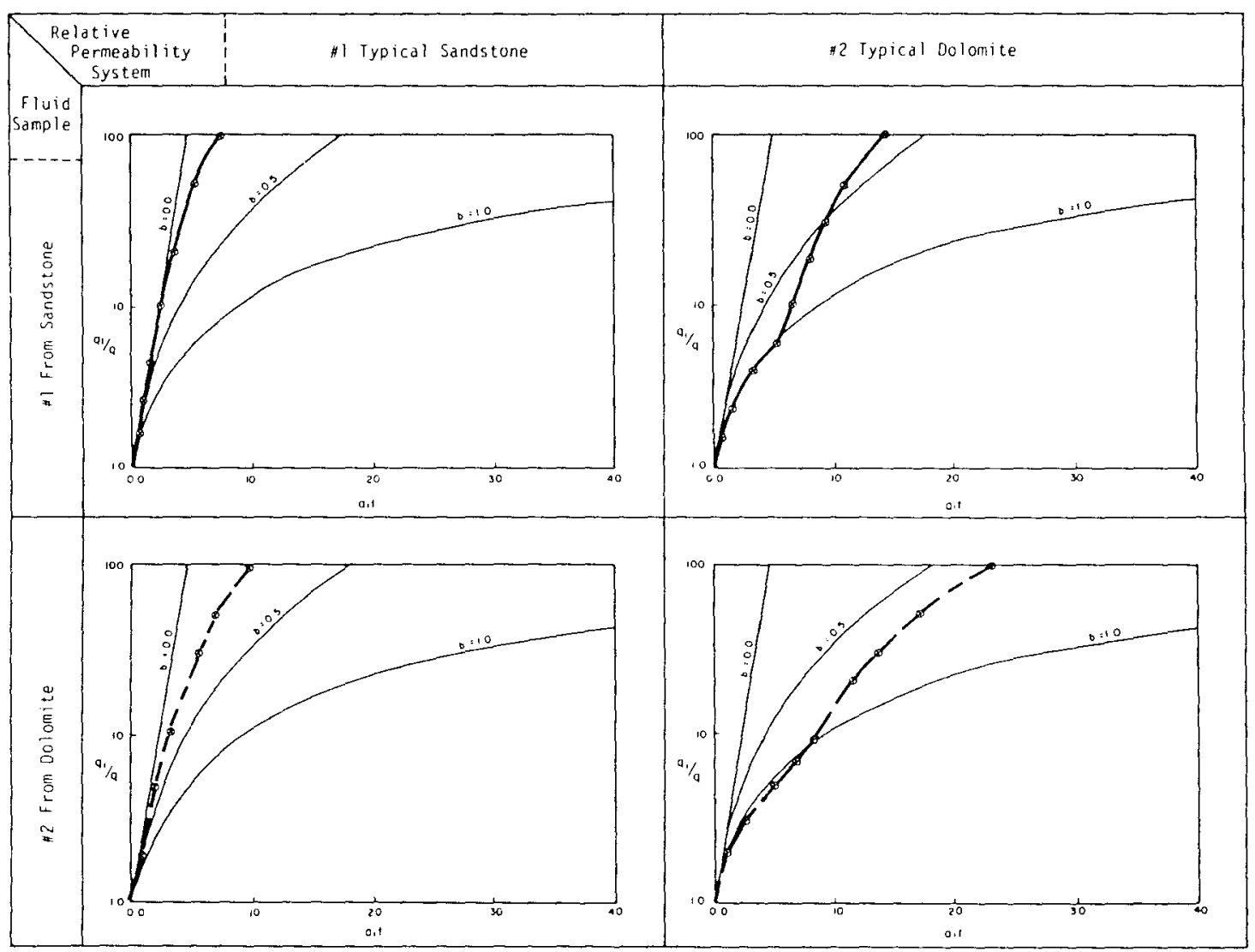

FIG. 9C. Dimensionless $a_{i} t$ curve histories for four fluid-permeability systems (after Gentry \& McCray, 1978). (C) 1978, SPE-AIME 
will increase to a maximum value and then as the ratio $q_{i} / q$ becomes large, $b$ will decrease and approach its homogeneous value.

3. Reservoir heterogeneity can and does cause $b$ values to be greater than 1.0 .

4. Manual manipulation of production can and does cause $b$ values to be greater than 1.0 .

5. The dimensionless plots for heterogeneous systems of 1 and $3 \mathrm{md}, 3$ and $9 \mathrm{md}$, and 5 and 15 md all plotted the same curve. This indicates that heterogeneous systems in the ratio of $1: 3$ will plot congruous dimensionless curves.

6. It appears that the relative-permeability characteristics of the reservoir have the greater effect on the decline exponent $b$, while the fluid characteristics have a greater influence on the constants $a_{i}$ and $q_{i}$.

7. The equation

$$
\mathrm{N}_{\mathrm{p}} /\left(\mathrm{q}_{i} \mathrm{t}\right)=\left(\mathrm{q}_{\mathrm{q}} \mathrm{q}_{i}\right)^{\alpha}
$$

may better define certain decline curves than do the Arps equations.

8. The plotting of production data on the $\mathrm{N}_{\mathrm{p}} /\left(\mathrm{q}_{\mathrm{i}} \mathrm{t}\right)$ vs. $\mathrm{q}_{i} / \mathrm{q}$ curve can be a helpful diagnostic tool for evaluating the production history of a well or lease."

\section{Other Type Curves}

Fetkovich developed log-log type curves using dimensionless production vs. dimensionless time, $Q_{D}$ vs. $t_{D}$, but other variables can be used. We tried plots of dimensionless cumulative production vs. dimensionless time and dimensionless production vs. dimensionless cumulative production, $q_{D} v s$. $Q_{D}$. The plots were made by using the exponential equation and the hyperbolic equation for several values of b. See Figs. $10 a$ and $10 b$. We had the same data scatter problem with these type curves as we did with Fetkovich's. A few data sets plotted very nicely on a particular curve, but most sets plotted very ambiguously.

\section{7. $P / z$ vs. $Q$}

The natural gas industry has long used decline curves in which pressure divided by gas deviation factor, $\mathrm{p} / \mathrm{z}$, is plotted against cumulative production, Q (Katz, 1959). The straight line can be extrapolated to the economic limit of producing pressure quite easily. Brigham and Morrow (1974) have proposed adapting this method to steam fields. In plotting computer generated data they found that curve shape was strongly influence by porosity. Also, the presence of a boiling interface is critical. "If the wells are completed in the vapor zone it would be natural to graph p/z vs. production, as though this were a gas reservoir, and use an extrapolation of the best straight line as a predictive method to calculate
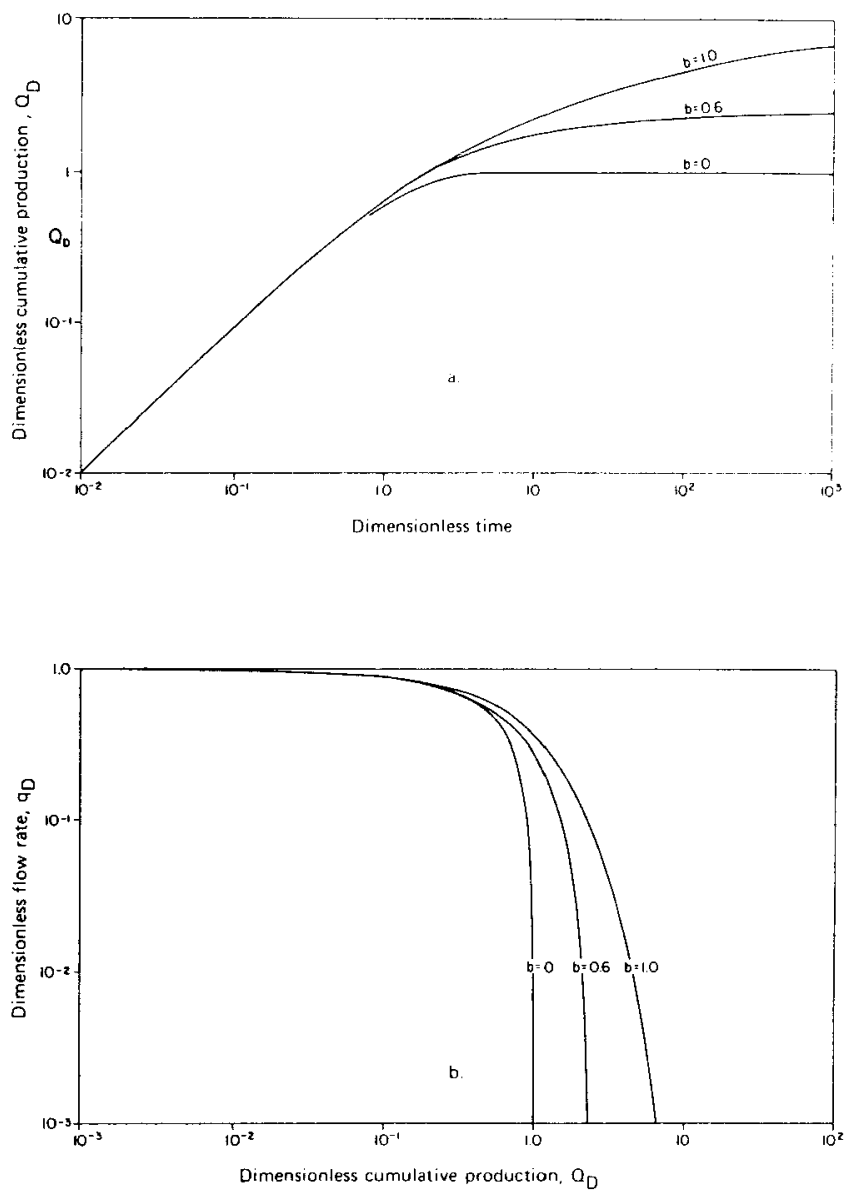

FIGS. 10a-b. Log-log type-curve.

reserves. The efficiency of this technique will be strongly dependent on the porosity if the actual reservoir contains boiling liquid." (see Fig. 11.)

Pruess et al. (1979a, 1979b) have used the simulator SHAFT78 to test the use of $\mathrm{p} / \mathrm{z}$ vs. Q plots for geothermal reservoirs. They conclude that ". . the standard technique of estimating reserves by extrapolating a plot of $\mathrm{p} / \mathrm{z}$ vs. cumulative production is not applicable to two-phase geothermal reservoirs." and ". . . in many cases pressure will be a linear function of cumulative production, with the slope allowing an estimate of reservoir volume. Reserve assessment requires knowledge of average porosity and vapor saturation, which cannot be obtained from pressure decline curves."

Brigham (1979) applied $\mathrm{p} / \mathrm{z}$ techniques to a study of depletion in the Cabbro zone at LarderelIn, but he stated that the linearity of $\mathrm{p} / \mathrm{z}$ with cumulative production doesn't hold for the entire life of a reservoir with a boiling interface. He claims that linearity is a good approximation for the first one-third to one-half of the reservoir's life. 


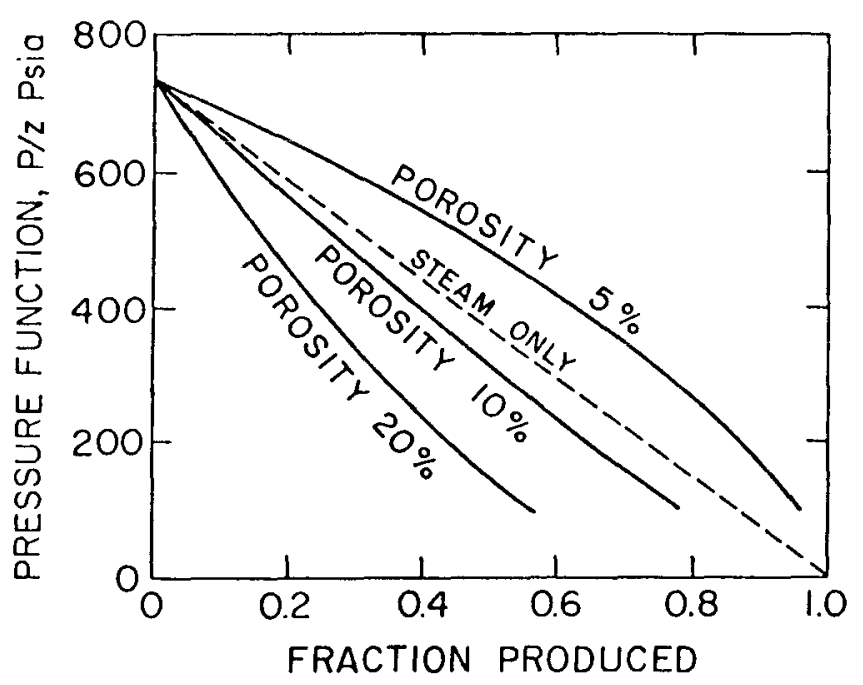

(C) 1974, SPE-AIME

FIG. 11. Pressure depletion vs recovery, falling liquid level (from Brigham \& Morrow, 1974).

\section{Influence Functions}

Unsteady state isothermal flow of slightly compressible liquid through a porous medium can be described using the diffusivity equation

$$
\begin{aligned}
& \nabla\left(\frac{k \nabla p}{\mu}\right)=\phi c \frac{\partial p}{\partial t} \\
& \frac{1 \partial}{r \partial r}\left(\frac{r k \partial p}{\mu \partial r}\right)=\phi c \frac{\partial p}{\partial t}
\end{aligned}
$$

The equation can be solved using a Green's function approach to derive a "response", "resistance", "memory", or "influence" function. Katz and Coats (1969) in describing water movement in aquifers defined two influence functions: 1$) P(t)=$ the "rate case" influence function which is defined as the pressure drop at the reservoir boundary (a function of time) corresponding to a unit rate (e.g. 1 cu. ft./day) of water influx." For a constant flow rate $q$ we get $p_{0}-p(t)=q P(t)$, the constant terminal rate case equation. 2) $Q(t)$ $=$ the "pressure case" influence functions since a constant pressure $\mathrm{p}_{\mathrm{b}}$ is specified at the outer boundary. The constant terminal pressure equation is $q(t)=\left(p_{o}-p_{b}\right) Q(t)$.

$P(t)$ and $Q(t)$ can be calculated either for idealized models or from field data. Let $F(t)=$ $Q(t)$ or $P(t)$. For an idealized $F(t)$ we must specify "1) model geometry, 2) exterior boundary conditions (e.g. infinite, closed or constant pressure), and 3) model parameters." The specification of reservoir parameters and geometry is particularly difficult in geothermal reservoirs so the calculation of $F(t)$ from field data is more attractive and easier than trying to devise a thoroughly specified model. The advantages of the field method are "1) none of the above choices are required, and 2) an influence function which reflects unknown (and practically speaking, indeterminate) aquifer properties, as reflected by actual field performance, is determined. Disadvantages are $I$ ) the resemblance of the backed out $F(t)$ to the true function is proportional to the accuracy of field data, and 2) the influence function is obtained only up to the time of last available field data; extrapolation is required for purposes of predicting future water movement."

Coats et al. (1964) recommended the use of field influence functions for oil fields with adjacent aquifers. The method is directly applicable to geothermal fields. The influence function $F$ can easily be generated as a function of pressure $p$ and flowrate $q$ using the following equations:

Integral form

$$
\Delta p=\int_{0}^{t} \frac{d q(t-\tau)}{d t} F(\tau) d \tau=\int_{0}^{t} q(t) \frac{d F(t-\tau)}{d \tau} d \tau
$$

Discrete form

$$
\Delta \mathrm{p}_{i}=\mathrm{p}_{0}-\mathrm{p}_{i}=\sum_{j=1}^{i}\left(\mathrm{q}_{i}-\mathrm{q}_{i-1}\right) \mathrm{F}_{i-j+1}
$$

Bodvarsson (1980, personal communication) has shown how the influence function problem can be formulated in a slightly different manner. The function $F$ defined by coats is a unit step response function. Instead of the unit step response, we can use the impulse response $h$, where $h=d F / d t$. The equation to be solved is then

$$
\begin{gathered}
\Delta p=\int_{0}^{t} \frac{d q(\tau)}{d \tau} F(t-\tau) d \tau=\int_{0}^{t} q(\tau) \frac{d F(t-\tau) d \tau}{d t} d \tau \\
\text { Integral form } \Delta p=\int_{q}(\tau) h(t-\tau) d \tau \\
\text { Discrete form } p_{0}-p_{i}=\sum_{j=1}^{i} q_{j} h_{i-j+1}
\end{gathered}
$$

The first derivative of the curve from the $F$ formulation should be identical to the curve derived from the $h$ formulation. $F$ can be calculated by hand (Jargon and van Poolen, 1965) and Hutchinson and Sikora, 1959) but we recommend against it. An $F$ can be calculated which fits the data well, but which has no physical meaning.

Katz and Coats cite an example in Katz et al. (1963) in which an influence function is calculated by direct methods which exactly reproduces past performance but which cannot be extrapolated. The smoothness constraints below assure a physically meaningful solution and they can be arrived at both intuitively and analytically. From Katz and coats "if water is injected into an aquifer at a constant rate through some fixed inner aquifer boundary (surface), then intuitively the pressure change at that boundary must always be positive. In addition, the pressure should always increase and the rate of increase should continually decrease with time." The analytical proof for the constraints is given in Coats et al. 
Linear programming methods such as the package MPOS should be used with the smoothness constraints on $\mathrm{F}$ or $\mathrm{h}$ :

$$
\begin{array}{ll}
\mathrm{F}>0, \mathrm{t}>0 & \mathrm{~h}>0, \mathrm{t}>0 \\
\frac{\mathrm{dF}}{\mathrm{dt}} \geq 0 & \frac{\mathrm{dh}}{\mathrm{dt}} \leq 0 \\
\frac{\mathrm{d}^{2} F}{\mathrm{dt}} \leq 0 & \frac{\mathrm{d}^{2} \mathrm{~h}}{\mathrm{dt^{2 }}} \geq 0
\end{array}
$$

If the data are not "smooth and regular enough" the use of simple hand calculations can lead to the results shown in Fig. 12. The F function will reproduce the pressure very well, but the function cannot be extrapolated and is physically meaningless. The F calculated by the linear program is shown on the same figure for comparison.

Hutchinson and Sikora and Coats et al. discuss the effects of field geometry on the behavior of the pressure drop and the influence function. As production time increases, the rate of pressure change decreases. If the reservoir outcrops, both the pressure drop and the influence function become constant. This is an effect we will look for in geothermal areas which we know have fluid recharge. If the reservoir is infinite-acting or bounded the influence function and the pressure drop will increase monotonically for all time greater than 0 .

Hutchinson and Sikora show how to extrapolate calculated influence functions. If a definite straight line has developed from the field data

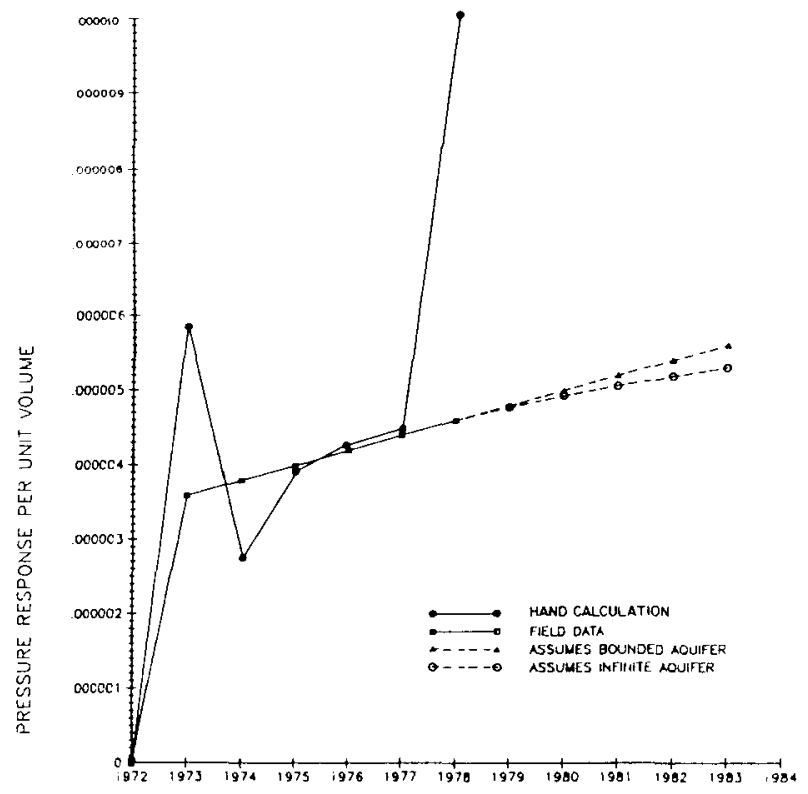

LIOUID INFLUENCE FUMCTION - - CERRO PRIETO TOTAL FIEI.D - $1972-1978$ (Fitness meosure $\rho=i 00058$ )

FIG. 12. Liquid influence function - Cerro Prieto total field. it may be extrapolated and the field assumed to be bounded. If no definite straight line has developed, the last 3 or 4 values of $F$ should be examined. If the average $\Delta F$ for these times gives a good match to past performance the curve may be extrapolated using the slope of the average $F$. The extreme extrapolation assumes an infinite aquifer. In this case

$$
\Delta F_{n+1}=\Delta F_{n} \frac{\log [(n+1) / n]}{\log [n /(n-1)]} .
$$

All these extrapolations are included in our MPOS program.

\section{Linearized Free Surface-Green's Function}

One of the main vitures of the influence function method is described above is that it can be used to predict reservoir behavior without specifying a physical model for the reservoir. Long-time behavior of the influence function can tell something about the boundaries. If the reservoir has a free liquid surface and is assumed to be a porous half-space, Fig. la, a simple, distributed parameter model can be posited. Bodvarsson (1977) 1inearized the free surface condition and derived the following equations for pressure

$$
\begin{aligned}
& \mathrm{p}(P, t)=\frac{-q}{4 \mathrm{c}}\left(\frac{1}{r_{P Q}}+\frac{1}{r_{P Q^{\prime}}}-\frac{2}{r_{P Q^{\prime} t}}\right) \\
& p=\text { pressure, meters of head } \\
& q=\text { flow rate, kg/s (constant) } \\
& r_{P Q}=\left(\left(x-x^{\prime}\right)^{2}+\left(y-y^{\prime}\right)^{2}+(z-d)^{2}\right)^{\frac{1}{2}} \\
& r_{P Q^{\prime}}=\left(\left(x-x^{\prime}\right)^{2}+\left(y-y^{\prime}\right)^{2}+(z+d)^{2}\right)^{\frac{1}{2}} \\
& r_{P Q^{\prime} t}=\left(\left(x-x^{\prime}\right)^{2}+\left(y-y^{\prime}\right)^{2}+(z+w t+d)^{2}\right)^{\frac{1}{2}}
\end{aligned}
$$

Bodvarsson (1978) also showed that the impulse response of a linearized free surface can be expressed as

$$
\begin{aligned}
G(t, S, Q)=\frac{-1}{2 \pi \phi \rho}(w t+d)\left(x^{2}+y^{2}+\right. \\
\left.(w t+d)^{2}\right)^{-3 / 2} U_{+}(t)
\end{aligned}
$$

where

$$
\begin{aligned}
& \mathrm{d}=\text { depth from free surface to sink } \\
& \mathrm{G}=\text { Green's function } \\
& \mathrm{S}=(\mathrm{x}, \mathrm{y}) \text { a point on the free surface } \\
& \phi=\text { porosity, fraction } \\
& \rho=\text { density, } \mathrm{kg} / \mathrm{m}^{3} \\
& \mathrm{w}=\mathrm{kg} /(\mathrm{v} \phi)=\text { sinking velocity, } \mathrm{m} / \mathrm{s} \\
& v=\mathrm{kinematic} \text { viscosity, } \mathrm{m}^{2} / \mathrm{s} \\
& g=y .8 \mathrm{~m} / \mathrm{s}^{2} \\
& \mathrm{k}=\text { permeability, } \mathrm{m}^{2}
\end{aligned}
$$




$$
\begin{aligned}
\mathrm{U}_{+}(\mathrm{t}) & =\text { unit impulse function } \\
\mathrm{r} & =\left(\mathrm{x}^{2}+\mathrm{y}^{2}\right)^{\frac{1}{2}}, \text { radial distance from sink. }
\end{aligned}
$$

He obtained the following expression for drawdown in meters for $\mathrm{P}$ at a distance $\mathrm{r}$ from the sink (we11bore)

$$
\begin{aligned}
h(t) & =\int_{0}^{t} G(t-\tau) q(\tau) d \tau \\
& \approx \sum_{\tau=0.5}^{t-0.5} G(t-\tau) q(\tau) \Delta \tau
\end{aligned}
$$

See Chpt. II for the derivation of these equations. The impulse response, $h$, is the drawdown in meters at the point, $P$, caused by the instantaneous withdrawal of one unit fluid mass at point Q. At a continuous withdrawal the total drawdown at $P$ would be a summation over all fluid sinks. The equation is

$$
h_{\operatorname{total}}(P)=\sum_{n=1}^{N} G_{n}(t-\tau) q_{n}(\tau) d \tau
$$

This equation for drawdown can be compared directly with the $h$ function formulation of the influence function as described above.

If the reservoir has a relatively impermeable zone below the producing zone the half space assumption can be modified. An image source term or terms as necessary can be added to the equation for $G$. See Fig. Ib. With one image term the expression is

$$
\begin{array}{r}
G=\frac{-1}{2 \pi \phi \rho}\left[\frac{w t+d}{\left[\frac{x^{2}+y^{2}+(w t+d)^{2}}{3 / 2}\right.}+\right. \\
\left.\left[\frac{2 H-d+w t}{x^{2}+y^{2}+(2 H-d+w t)^{2}}\right]^{3 / 2}\right]
\end{array}
$$

More terms can be added as necessary.

The distributed model described above can be approximated by a lumped parameter model as described more fully in Chpt. II. 
IV. DATA PROCESSING

\section{Data Sets}

The most complete data set is from Wairakei, New Zealand by Pritchett et al. (1978) published by Systems, Science and Software for Lawrence Berkeley Laboratory. Individual well monthly heat and mass flow rates are given from 1953 through 1976 for 141 wells. Furthermore, a fair amount of pressure and temperature data are presented.

The authors presented a substantial amount of data on the geology and subsidence problems at Wairakei. In addition to this report we received from Malcolm Grant, DSIR, a set of annotated individual well production graphs which indicated when wells were shut in and which steam lines the wells were connected to. See Fig. 13a for map.

The data set for Cerro Prieto by Bermejo et al. (1979) published by Lawrence Berkeley Laboratory included graphical production histories of most of the wells from 1973 to 1978. These graphs were digitized for analysis. The production was broken down into liquid and vapor production. In addition, we received data from Marcelo Lippman, LBL, which showed individual well total mass

flow rates. The two data sets were treated separately and then compared. A theoretical pressure drawdown curve was taken from Sanchez and de 1 a Palma (1979). See Fig. I3b for map.
The last large data set is from The Geysers, California, courtesy of the California Dept. of Conservation, Div. of Oil and Gas. The data include production injection and pressure data from 27 wells from March 1971 through December 1979. Additional pressure data are from Lipman, Strobel, and Gulati (1977). See Fig. 13c for map.

The Larderello data were taken from Sestini (1970). The sparse data for other fields were from various sources. See Fig. 13d for map.

\section{Graphical Treatment of Data}

The first step in the analysis was graphing all the available production data on cartesian paper using SPSS. These graphs allowed us to eliminate from further consideration wells with severely irregular production such as Bore 11 .

Arps (1945, 1956) pointed out that the exponential equation would graph as a straight line on semilog paper. We tried plotting the data for several wells at Wairakei but found that production decline was insufficient to make the semilog plots look very different from the cartesian plots. The log-log plots, however, were significantly different from the cartesian plots so most of the data were plotted on log-log plots. We tried matching the $\log -\log$ plots against Fetkovich's type curves. For the most part the data scatter rendered the method useless. We were also hindered by the fact that dimensionless time for almost all our wells was fairly short,

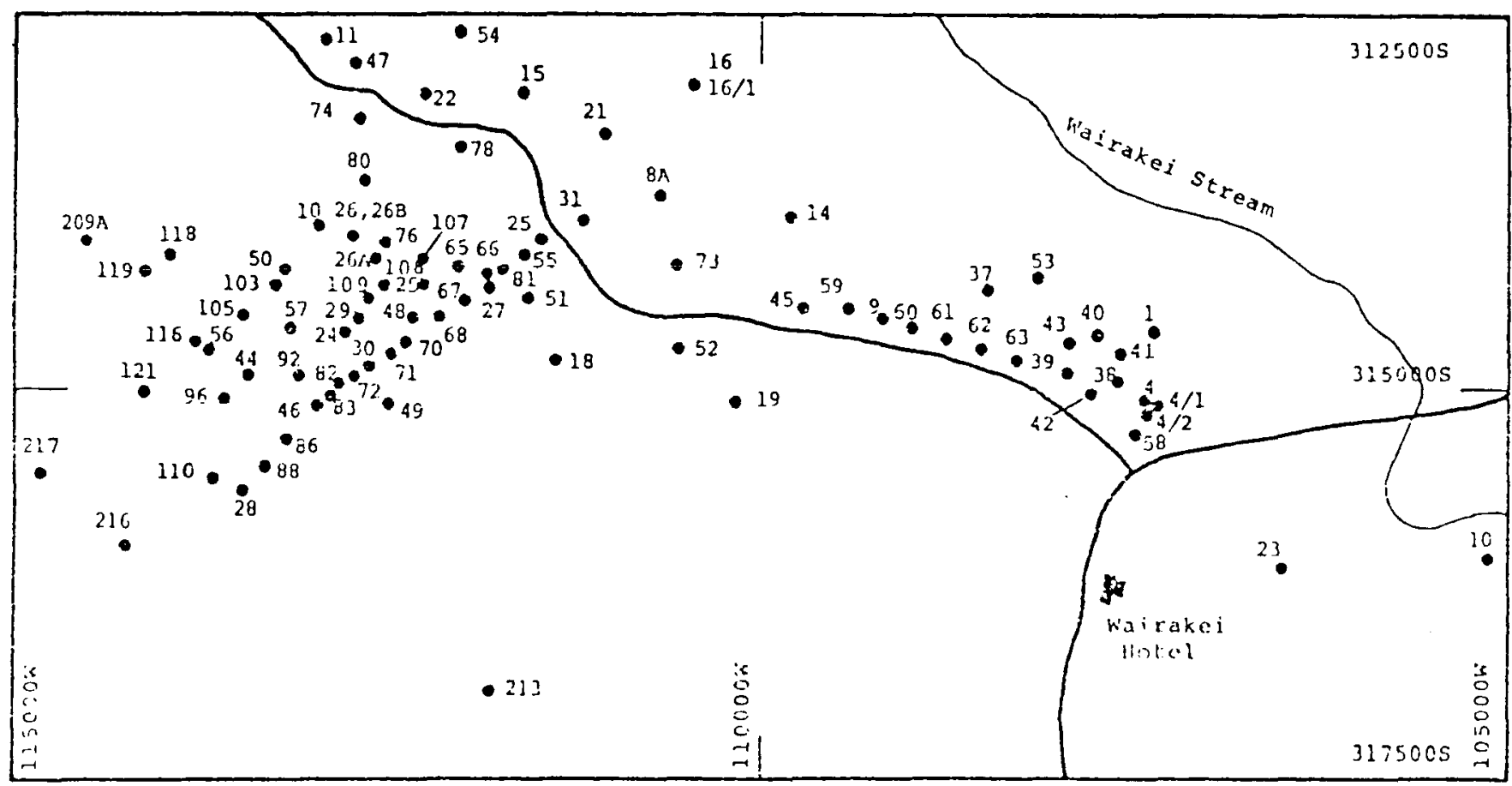

FIG. 13a. Bore locations in main bore field (from Pritchett et al., 1978). 


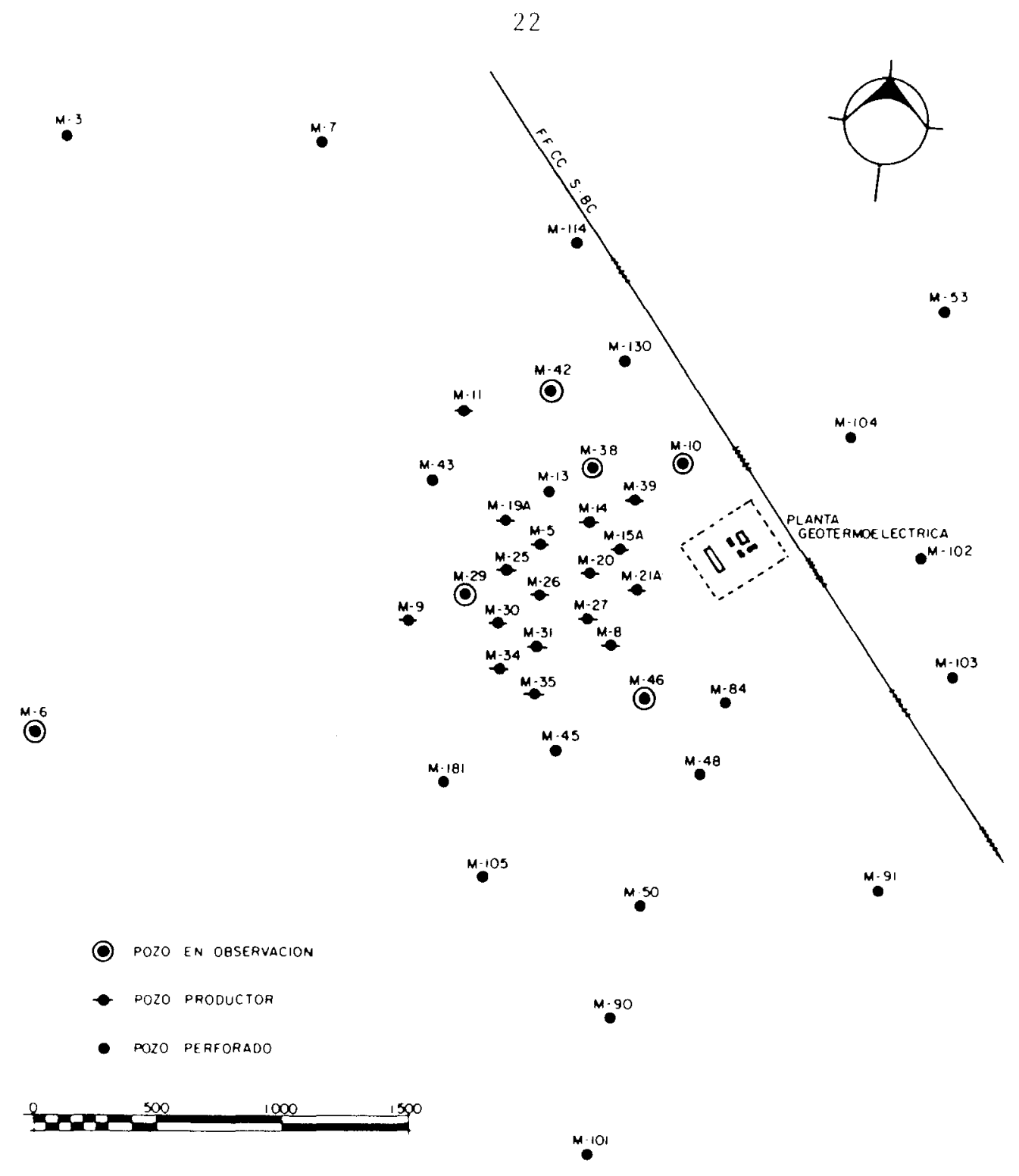

FIG. 13b. Location of wells in the Cerro Prieto Field.

about 1.0. The exponential and hyperbolic curves only start diverging at about $\mathrm{t}_{\mathrm{Dd}}=0.2$, so with rough data we would like the last point to have $t_{D d}=2.0$, at least. We could not reproduce the fits reported by Rivera-R. (1977, 1978) using Cerro Prieto data. None of the data from liquiddominated fields fit very well, but this is probably much more a function of data scatter than of the efficacy of the methods. See below for a discussion of data scatter. The only fair fits were for several wells from Larderello. Successful use of type curves with rough data may require a great deal of insight on the part of the analyst.

We tried two other kinds of type curves, Figs. $10 \mathrm{a}$ and $10 \mathrm{~b}$, with no more success than with Fetkovich's curves. Scatter and small dimensionless time caused problems again.
Gentry and McCray (1978) proposed the use of several different graphs, Figs. $9 a, 9 b$, and $9 c$, for decline curve analysis. We had difficulty with the plots involving $a_{i}$ because the data scatter gave $a_{i}$ a very large uncertainty. We plotted $\mathrm{N}_{\mathrm{p}} / \mathrm{q}_{i} \mathrm{t}$ vs. $\mathrm{q}_{i} / \mathrm{q}$ for several wells and got very peculiar results which were of no use. Again, the data are far more problematical than the models.

We tried plotting $\mathrm{p} / \mathrm{z}$ vs. Q for The Geysers data using pressure from Cobb Mountain \#1 we11 and yearly total production data from Finn (1975) and from the California Dept. of Oil and Gas (see Figs. 14a and b). Brigham (1979) analyzed some Larderello data using $p / z$ vs. $Q$, but as mentioned above he cautions against expecting linearity after one-third to one-half of the fluid has been produced (see Figs. 15a and 1.5b for plots of the data). 


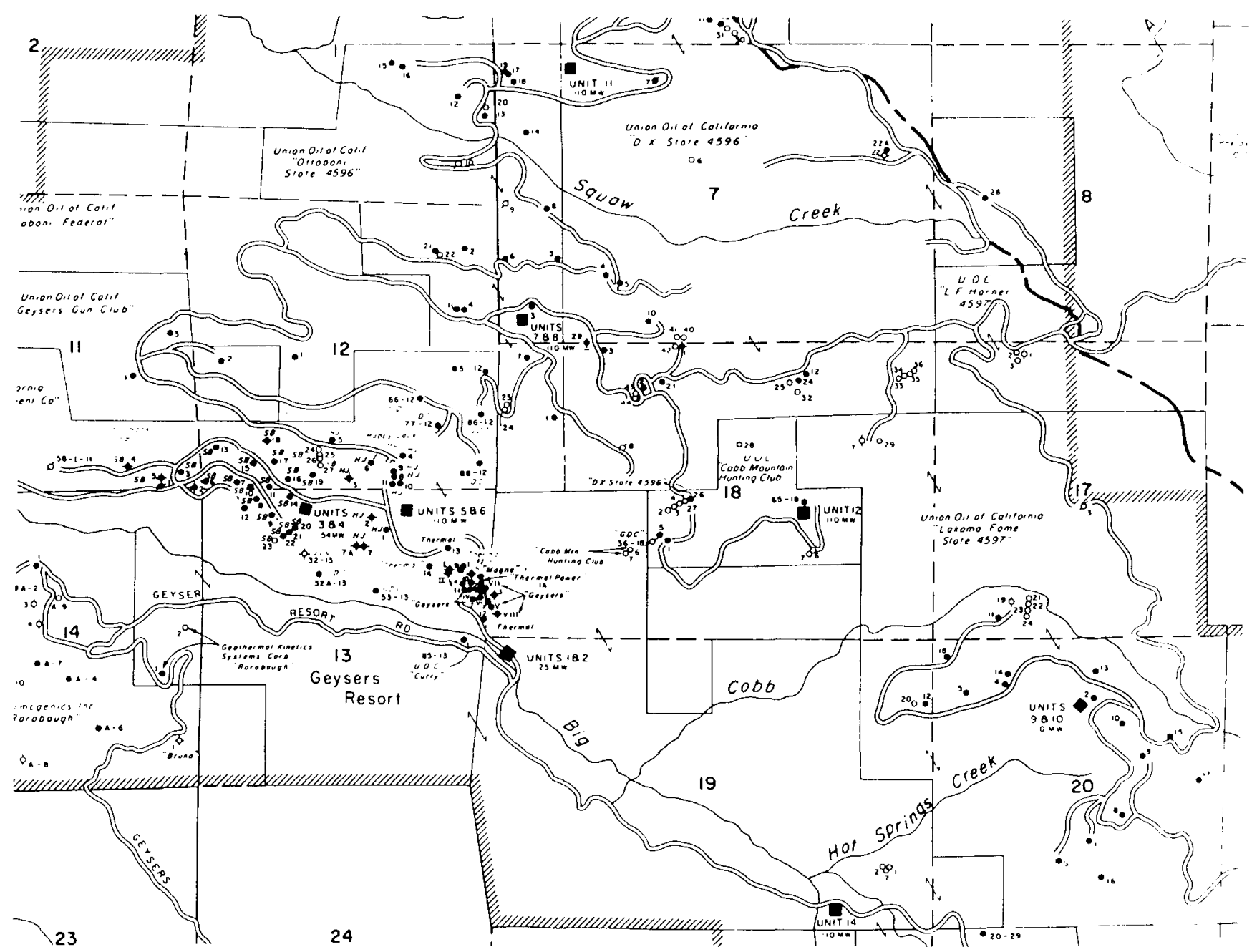

FIG. 13c. The Geysers, California (from California Dept. of Conservation, Division of Oil \& Gas, 1978).

\section{Statistica1 Treatment of Data}

Most of the data sets had so much scatter that statistical treatment was the only reasonable approach. We used SPSS (Statistical Package for the Social Sciences) to reduce the data. See Appendix for discussion of SPSS and for the programs we used. SPSS is available at many computer centers and it requires a minimum of data handling.

We used SPSSPLOT to generate cartesian plots of the $q$ vs. $t$ data for all the wells. From the plots we chose wells to analyze further. Some of the wells had drastic rate changes in their histories so only selected parts of their histories were analyzed. We used a non-linear least squares regression subroutine to analyze the exponential equation

$$
q(t)=q_{i} e^{-a t}
$$

The program requires initial estimates of $q_{i}$ and $a$, and it returns $\hat{q}(t)$, the predicted value of $q$, and best estimates $\hat{a}$ and $\hat{q}_{i}$ for the fractional decline and the initial flow rate. A fit to the linear equation

$$
q(t)=q_{i}+k t
$$

is also generated. The primary statistic generated is $\mathrm{R}^{2}$ defined as

$$
\begin{aligned}
\mathrm{R}^{2}= & \frac{\mathrm{SSR}}{\mathrm{SST} 0}=\frac{\text { regression sum of squares }}{\text { total sum of squares }}= \\
& 1-\frac{\mathrm{SSE}}{\mathrm{SSTO}}=1-\frac{\text { residual sum of squares }}{\text { total sum of squares }} \\
\text { SSTO }= & \sum_{i=1}^{n}\left(\mathrm{q}_{1}-\overline{\mathrm{q}}\right)^{2} \text { where } \overline{\mathrm{q}}=\frac{\sum \mathrm{q}_{i}}{\mathrm{n}} \\
\mathrm{SSR}= & \sum_{i=1}^{\mathrm{n}}\left(\overline{\mathrm{q}}-\hat{\mathrm{q}}_{\mathrm{i}}\right)^{2}
\end{aligned}
$$




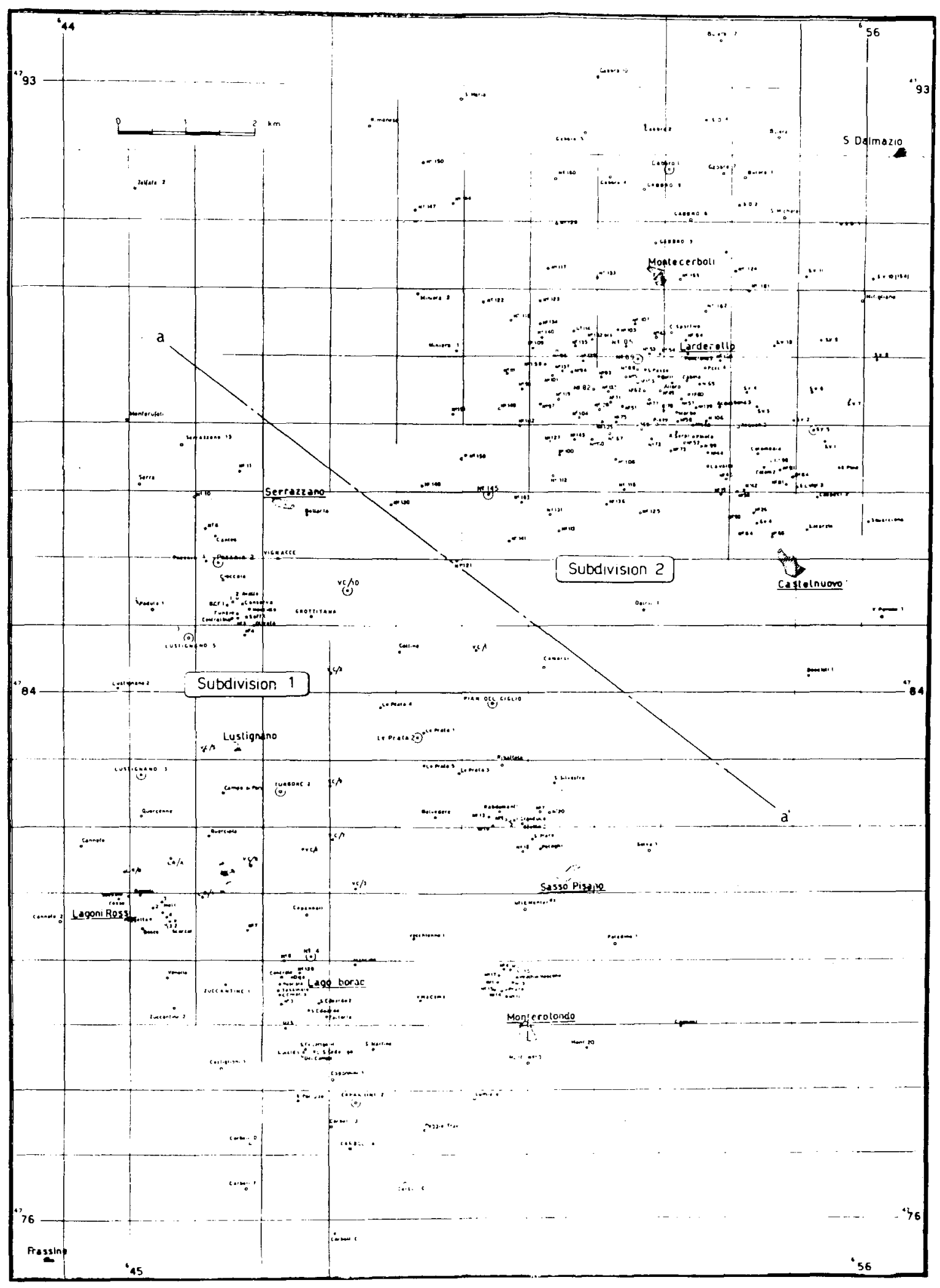

FIG. 13d. Larderello geothermal area (from Sestini, 1970). 


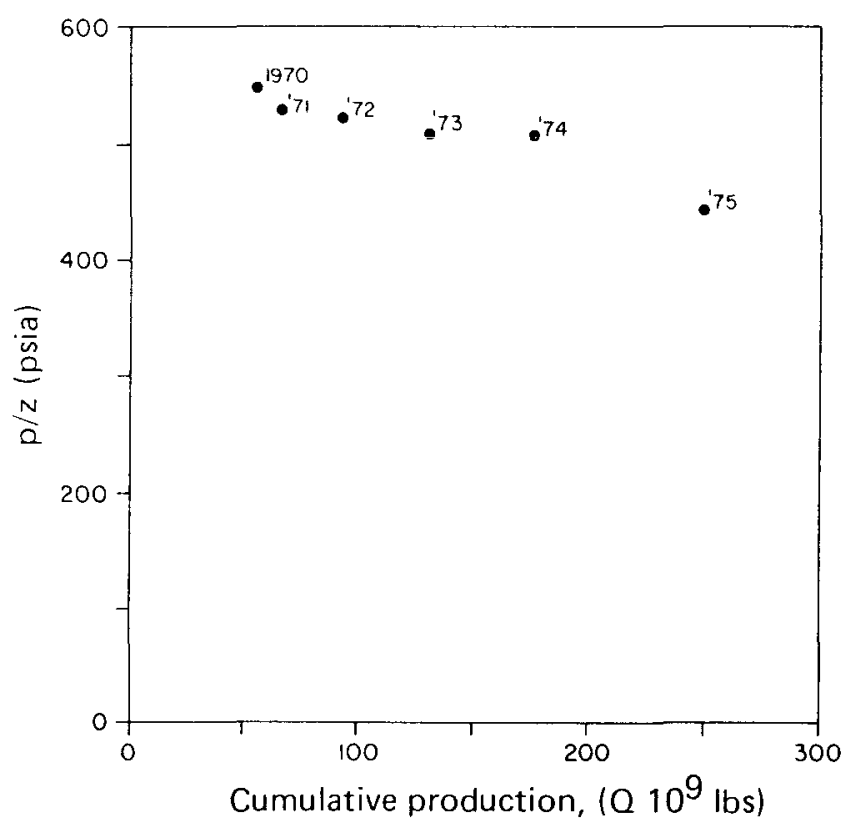

FIG. 14a. The Geysers p/z vs cumulative production, total field (pressure from Cobb Mt. No. 1 and Curry 85, ENEL Proceedings 1977, Strobel et al; production data from Finn, 1975).

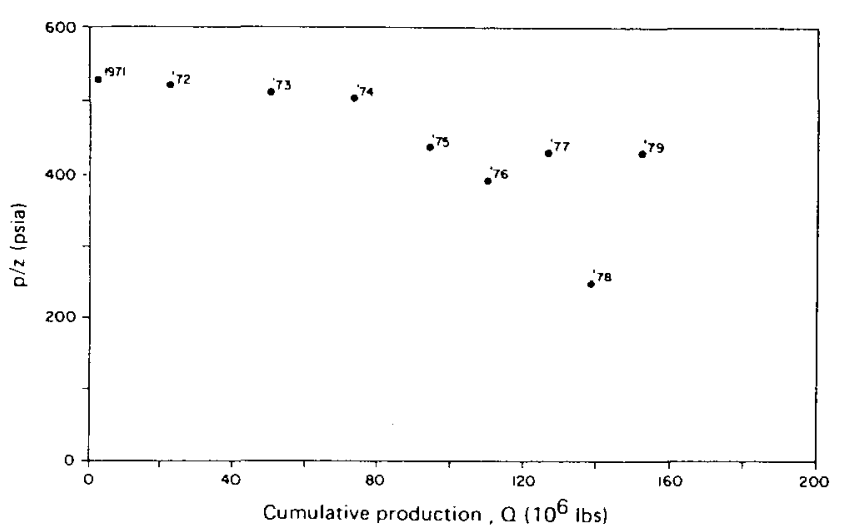

FIG. 14b. The Geysers $\mathrm{p} / \mathrm{z}$ vs cumulative production, 20-30 wells. (pressure data from ENEL Proceedings 1977; production data from California Division of Oil \& Gas, 1971-1979 data on 20-30 selected wells).

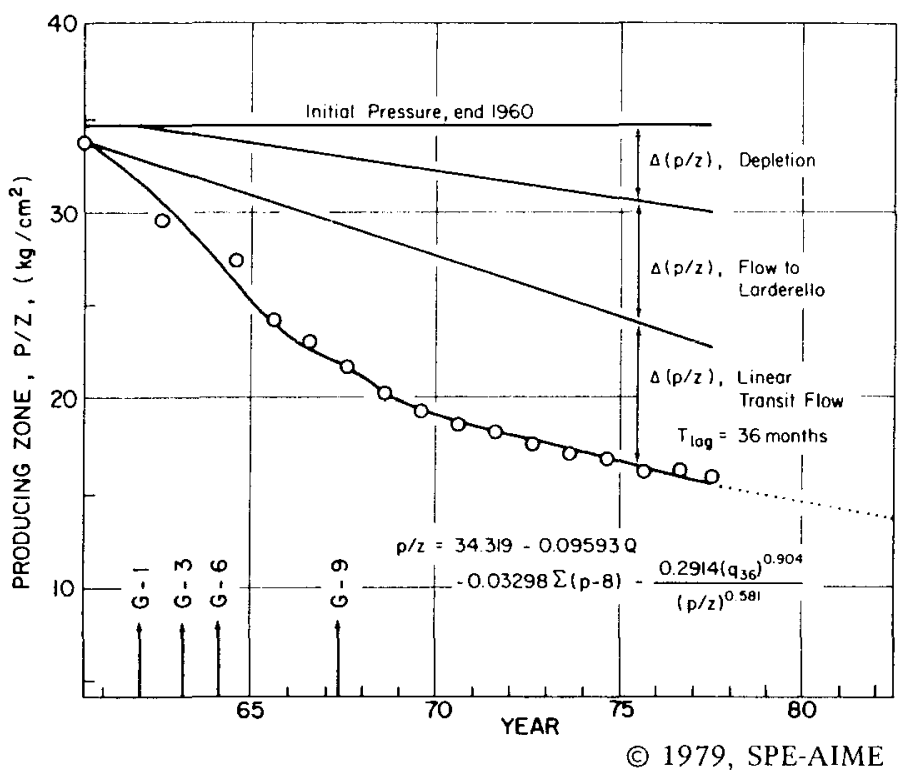

FIG. 15a. Gabbro Zone pressure-production history match, lag time $=36$ months (from Brigham, 1979).

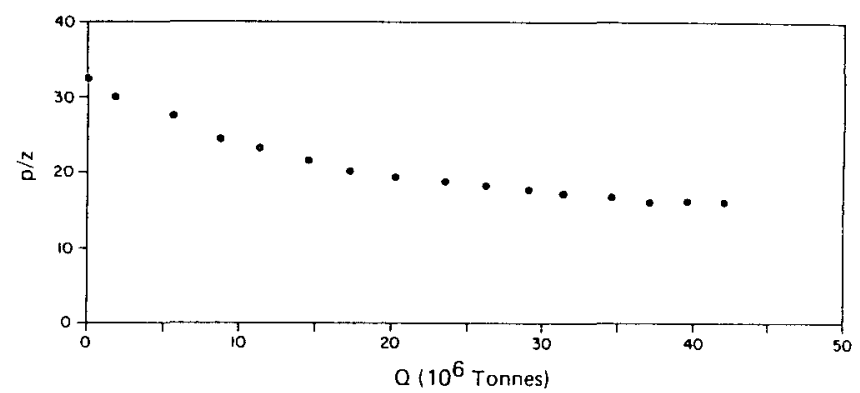

(C) 1979, SPE-AIME

FIG. 15b. p/z vs Q-Larderello data (from Brigham \& Neri, 1979).

$\mathrm{SSE}=\mathrm{SSTO}-\mathrm{SSR}$

Values of $R^{2}$ greater than 0.65 indicate a good fit which can be extrapolated with some confidence. The value 0.65 is arbitrary, but is generally considered to be a good fit for raw data.

For the influence function method, we developed a fitness measure, $\rho$, which is the average fractional deviation of computed pressure differences, $\hat{\Delta p}$, from observed pressure difference, $\Delta p=$ $\mathrm{p}_{i}-\mathrm{p}(\mathrm{t})$. For example, if $\rho=0.1$ and $\hat{\Delta p}=100$, the true value is between 90.91 and 111.11 because $\Delta p=$ $\hat{\Delta p} /(1+p)$. 
Discussion of Data Scatter

Field data often have a great deal of scatter in them which can cause difficulties in analyzing them. The scatter can be of two general types, reservoir related and operations related. Reservoir related scatter can be caused by
1) rainfall
2) recharge
3) earthquakes
4) subsidence.

Production related scatter can be caused by
1) changes in production schedules
2) bad well completions
3) workovers
4) poor calibration techniques
5) poor data gathering techniques

Little can be done to prevent reservoir related scatter, but operations related scatter can always be reduced. Methods for reducing the chance of scatter are discussed in the Standard Operating Procedure section. Scattered data can be analyzed with the following techniques:
1) averaging the data
2) least squares fitting
3) subtracting our known effects and trends
4) using insight and experience.

We tried averaging data from several Wairakei and Cerro Prieto wells to see whether we could use Guerrero's method for Arps's equations. We could not get reasonable values for the decline exponent. See Fig. 16 for a graph of six month average production vs. time for Bore 18 .

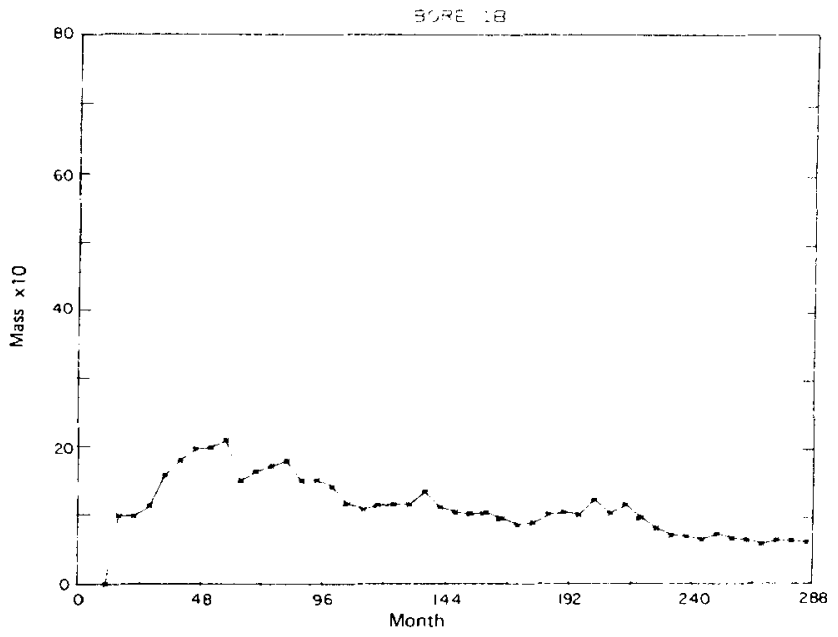

FIG. 16. Six month average production, Bore 18, Wairakei, New Zealand.

The easiest known effects to take into account are periodic shut downs. The annotated production graphs from Wairakei showed that many of the wells were shut in for periods of about 1 month every $1-2$ years. The monthly production during these shut-in months is obviously much lower than the preceding and following month's production. If the other data are on a smooth trend, the low values can effectively be ignored in fitting an equation to the trend line. Since these points represent production, however, they should be included in any calculation involving the cumulative production, Q. 


\section{RESULTS}

\section{Arps's Equations}

We tested Arps's exponential equation (73) on all individual well data, total field data and on several groups of wells. The results are summarized in Table 3 with complete results in the Appendix. $\hat{\mathrm{D}}$ is the average calculated monthly fractional decline. $\hat{D}$ based on total field production from Wairakei, The Geysers, and Cerro Prieto ranges from 0.003 for Wairakei to 0.0115 for The Geysers. This converts to yearly declines of $3.6 \%$ and $13.8 \%$, respectively. $\mathrm{R}^{2}$ for individual wells ranges from 0.0004 for a well at Otake to 0.9712 for a well at Larderello. Eight of the ten wells and groups at Larderello had $\mathrm{R}^{2}$ 's greater than 0.87 , indicating a very good fit to the equation. Also, all three wells at Matsukawa had $\mathrm{R}^{2}$ 's greater than 0.76 . The wells from The Geysers did not fit as well as the wells from Larderello and Matsukawa, so we cannot draw definite conclusions about vapor-dominated fields and the exponential equation.

Cerro Prieto and Wairakei are both liquidcominated fields, and their data did not fit the exponential equation quite as well as the vapordominated fields. However, for all the fields the equation fit at least several of the well's data quite well. See Figures $17 \mathrm{a}-\mathrm{g}$ for a fit of the exponential equation to total Wairakei production and to several individual wells.
We only tested a few wells using the hyperbolic equation and got $\mathrm{R}^{2}$ 's greater than 0.989 in all cases. This indicates that the equation is either nearly perfect or that it is a very poor model and will fit virtually any data set. We hold the latter view. Because the equation has no physical basis, we recommend against using it. However, if a particular data set fits a hyperbolic type curve well over a long stretch of dimensionless time, the curve can be used to extrapolate production.

\section{Type-Curve Methods}

None of the data sets fit any of the type curves well. The scatter is so high that no value of $b$ can be picked with confidence. Some of the Larderello data fit Fetkovich's exponential curve for up to 80 months but then develop constant production which takes them of $f$ the curve. See Figure 18a. Figure 18b shows typical Cerro Prieto data plotted on the same curve. No value of $b \mathrm{ca}$. reasonably chosen.

Coats' Influence Function Method

Coats' method can be used with any but the most bizarre data because the derivative constraints imposed on the solution method guarantee that either a meaningful solution or no solution is generated. The fitness measure tells how useful

TABLE 3. SUMMARY RESULTS FOR FITS TO EXPONENTIAL EQUATION

\begin{tabular}{|c|c|c|c|c|c|}
\hline Field & $\underline{D}$ & $R^{2}$ & \# of Wells & $\begin{array}{c}\text { Range on Individual } \\
\mathrm{R}^{2} \mathrm{~S} \\
\end{array}$ & $\begin{array}{l}\# \text { of Wells at } \\
R^{2}>0.65\end{array}$ \\
\hline $\begin{array}{l}\text { Wairakei, NZ } \\
\text { total prod. }\end{array}$ & 0.0030 & 0.7847 & 36 & $0.0016-0.9049$ & 11 \\
\hline $\begin{array}{l}\text { Cerro Prieto } \\
\text { B.C., Mexico }\end{array}$ & & & & & \\
\hline $\begin{array}{l}\text { Liquid prod. } \\
\text { Total prod. }\end{array}$ & & & $\begin{array}{l}17 \\
19\end{array}$ & $\begin{array}{l}0.0066-0.8524 \\
0.0405-0.9409\end{array}$ & $\begin{array}{l}6 \\
8\end{array}$ \\
\hline $\begin{array}{l}\text { The Geysers, } \\
\text { CA., USA }\end{array}$ & 0.01151 & 0.8103 & 26 & $0.0126-0.8127$ & 6 \\
\hline $\begin{array}{l}\text { Larderel 1o, } \\
\text { Italy }\end{array}$ & & & 10 & $0.0416-0.9712$ & 8 \\
\hline $\begin{array}{l}\text { Matsukawa, } \\
\text { Japan }\end{array}$ & & & 3 & $0.7609-0.8633$ & 3 \\
\hline $\begin{array}{l}\text { Otake, } \\
\text { Japan }\end{array}$ & & & & & \\
\hline $\begin{array}{l}\text { Liquid } \\
\text { Vapor }\end{array}$ & & & $\begin{array}{l}4 \\
4\end{array}$ & $\begin{array}{l}0.1528-0.7043 \\
0.0004-0.7981\end{array}$ & 1 \\
\hline
\end{tabular}




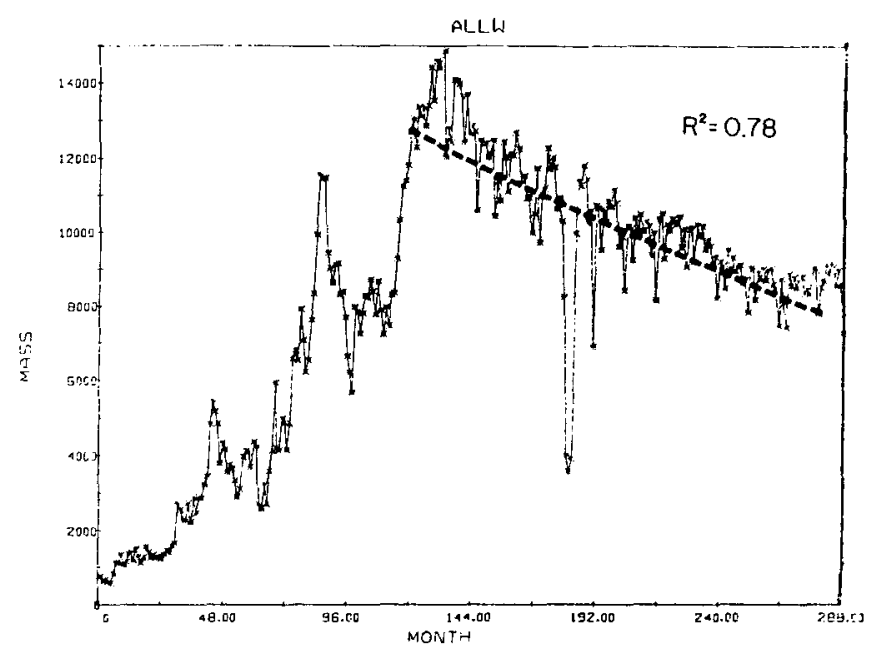

FIG. 17a. Wairakei total production, 1953-1976, with exponential fit 1964-1976.

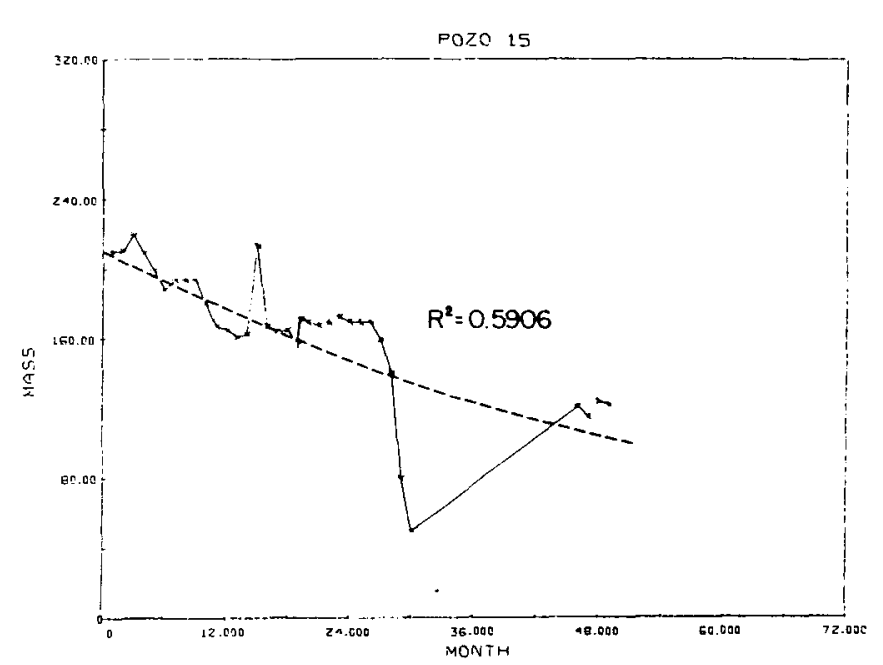

FIG. 17b. Pozo 15, Cerro Prieto, Mexico.

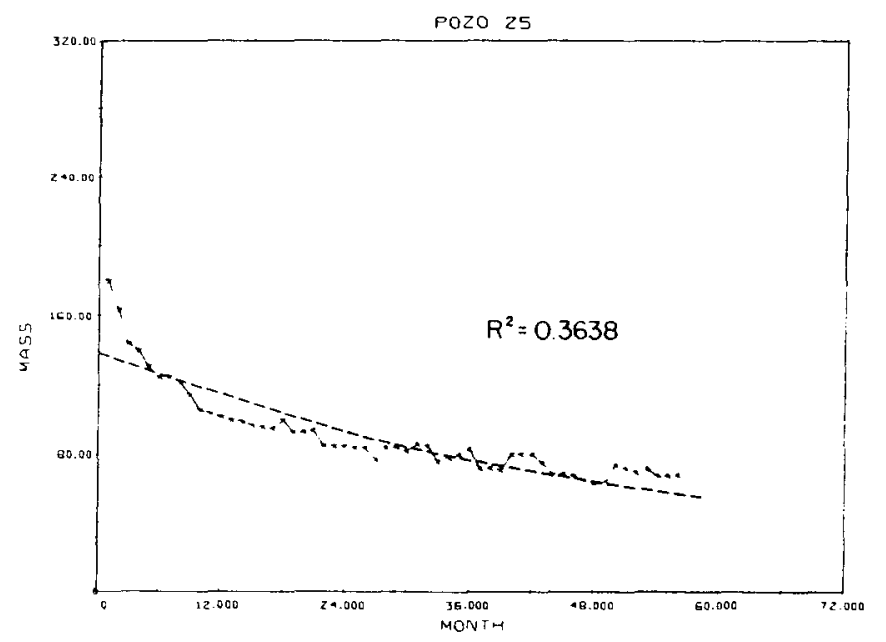

FIG. 17c. Pozo 25, Cerro Prieto, Mexico.

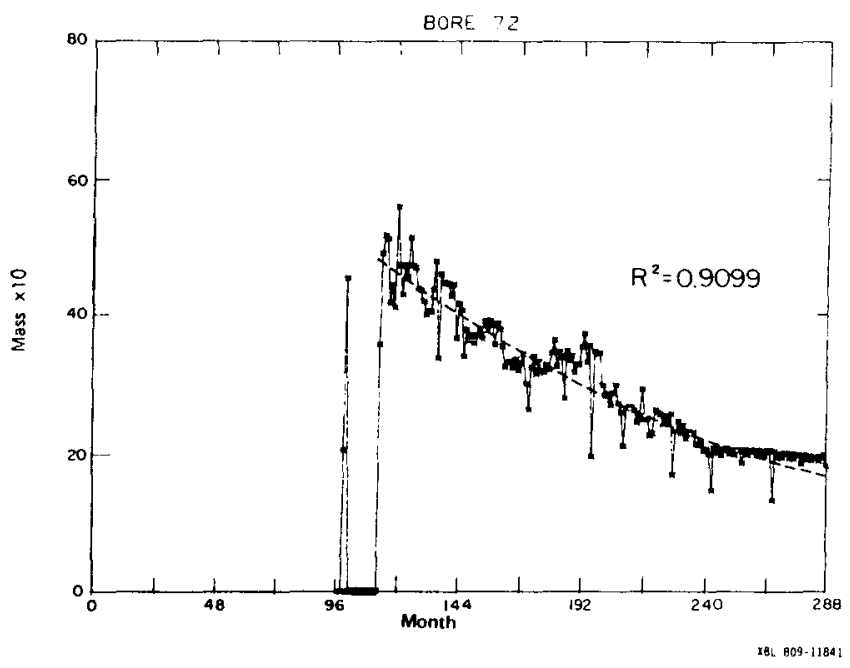

FIG. 17d. Bore 72, Wairakei, New Zealand.

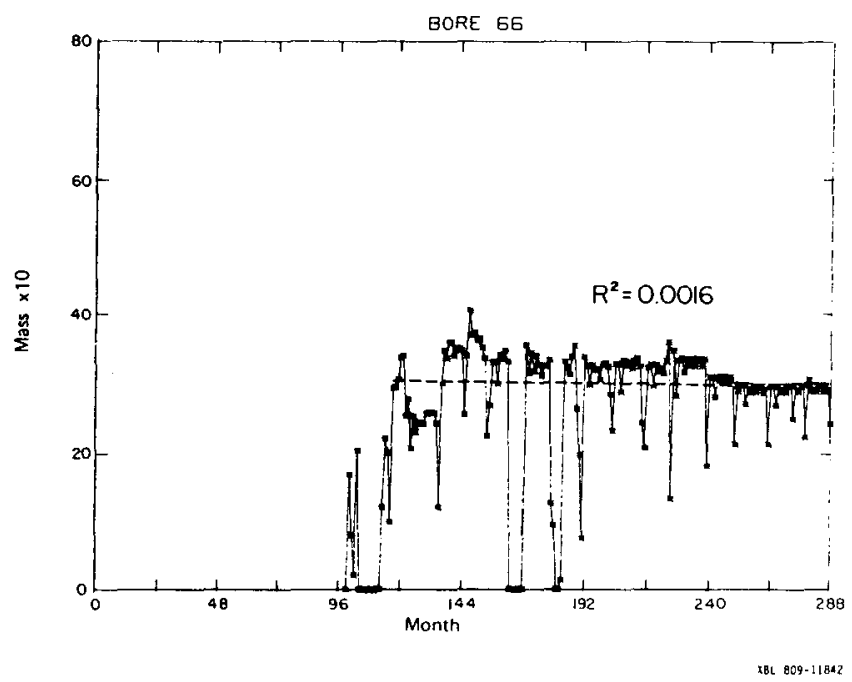

FIG. 17e. Bore 66, Wairakei, New Zealand.

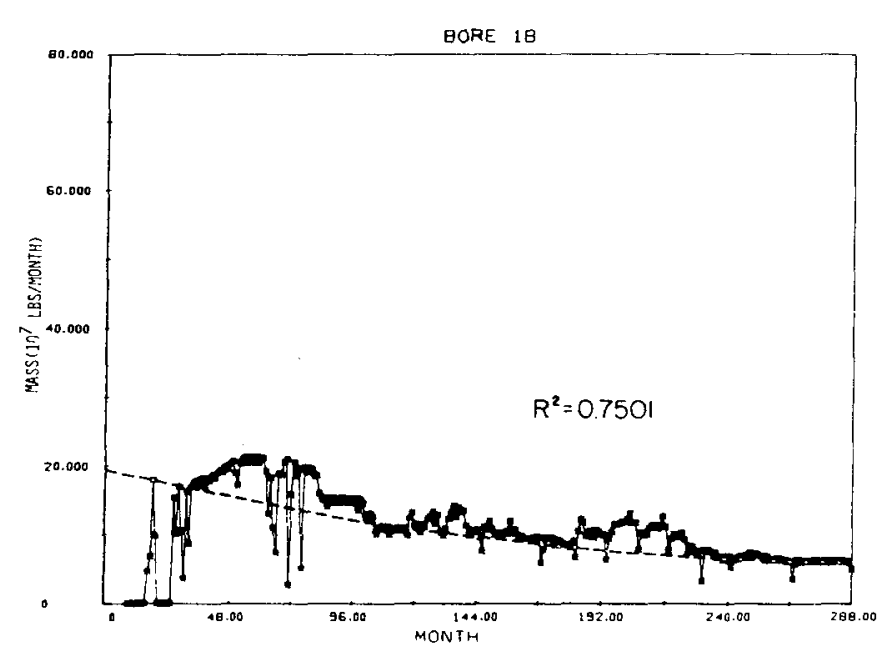

FIG. 17f. Bore 18, Wairakei, New Zealand. 


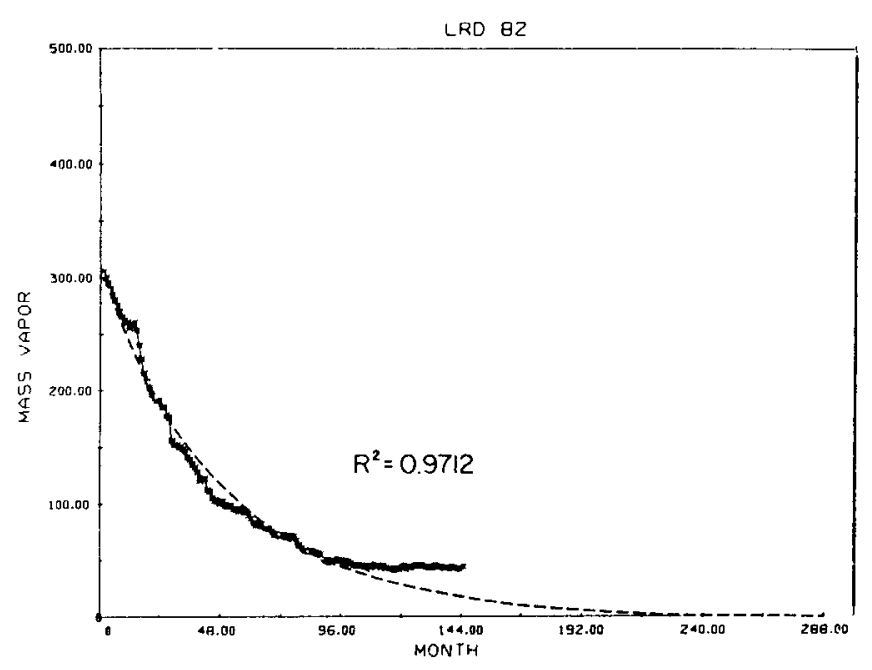

FIG. 17g. Larderello, Italy-Nella Sasso Rosso Nr. 82.

the solution is. We tried the method on Wairakei and Cerro Prieto total production and on Travale 22 from Larderello. The fitness measure, $\rho$ for Travale 22 was 0.038 indicating a very good fit (see Fig. 19). $\rho$ was 0.1001 and 0.3366 for Cerro Prieto liquid production and Wairakei total production, respectively. We tested the predictive value of the method by fitting Wairakei data from 1955-62 and then extrapolating. The pressures obtained using both the infinite and bounded aquifer approximations are shown in Table 4 along with the actual pressures. The pressure drop is calculated as

$$
\Delta p=\frac{Q F}{t}
$$

Where $Q$ is cumulative production, $F$ is the influence function and $t$ is time. Figure 20 shows the calculated influence functions for Wairakei 19551962. The high fitness measure indicates very rough data. The observed pressures fall within the fitness measure for the infinite aquifer case.

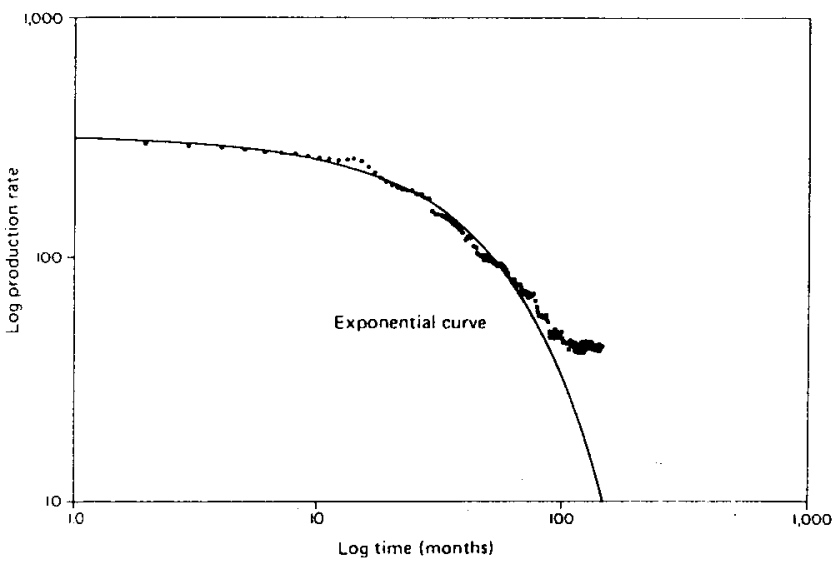

FIG. 18a. Larderello 82 (Nella Sasso Rosso Nr. 82) fit to Fetkovich type-curve.

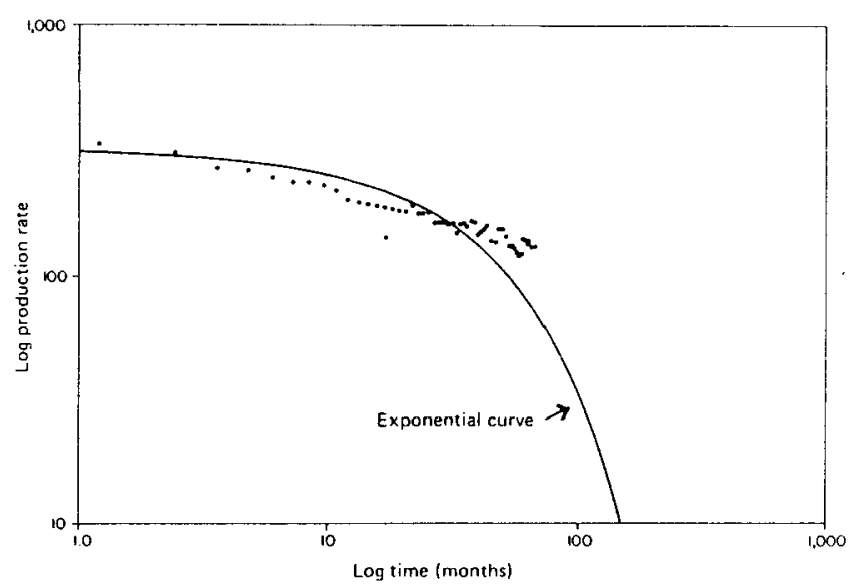

FIG. 18b. Pozo 25, Cerro Prieto, fit to Fetkovich type-curve.

In an infinite aquifer the rate of pressure decline decreases with time as is the case for Wairakei.

\section{Bodvarsson's Linearized Free Surface Method}

We had enough data to try the linearized free surface method only with Wairakei. We divided the field into six regions and then assumed that the total production from each region was coming from a virtual well in the "center" of the region. The production depth for each virtual well was the production weighted average center of open zone for the wells in the region. A centroid was chosen for the entire field and then the pressure drawdown at the centrold was calculated for each virtual well and summed to get total drawdown. The drawdown curve obtained is shown in Figure 21 as Curve $\sharp 2$ with the actual drawdown as Curve 1 for comparison. By adding the term for a bottom as described in Chapter III and by adjusting the porosity, $\phi$, permeability, $k$, and depth, $\mathrm{H}$, we obtained Curve $\|_{3}$,

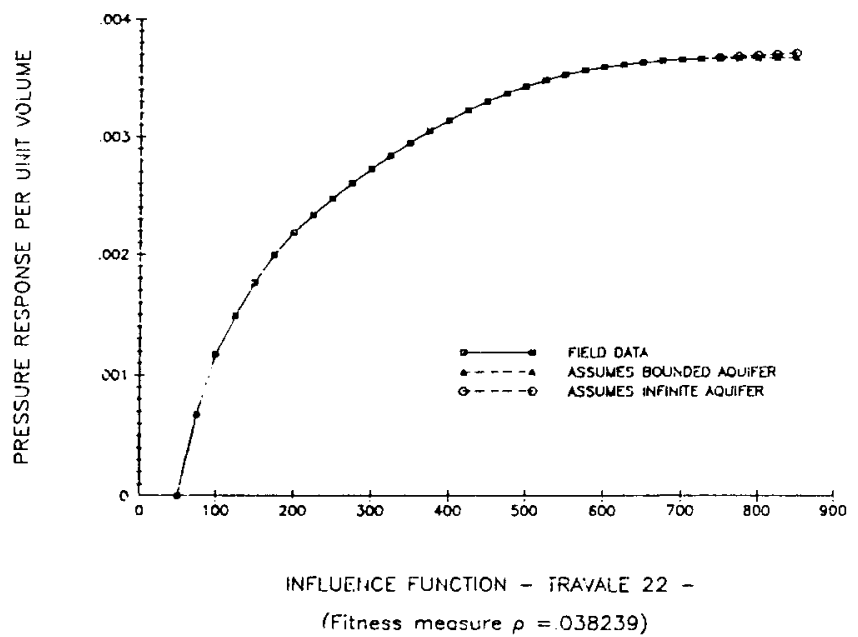

FIG. 19. Influence function-Travale 22. 


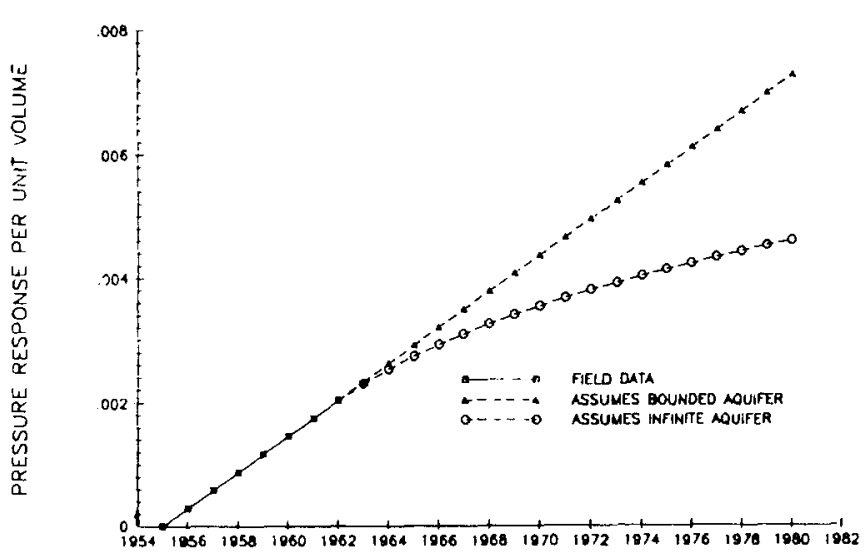

INFLUENCE FUNCTION - - WAIRAKEI TOTAL FIELD -.. 1955-1962

(Fitness meosure $\rho=.336597$ )

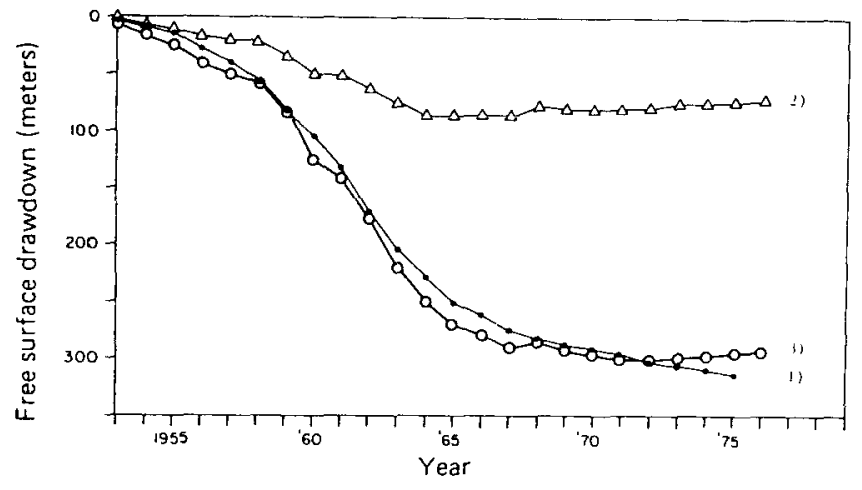

FIG. 21. Linearized free surface fits to Wairakei data. Curve 1, - $\bullet$ observed pressure drawdown Curve $2, \triangle-\triangle$ : LFS fit, 1 term Curve 3, O-O: LFS fit, 2 terms

FIG. 20. Influence function-Wairakei total field 1955-1962.

a plausible fit. This method is difficult to use because the necessary geologic and production data are usually lacking or sparse at best.

TABLE 4. CHECK OF EXTRAPOLABILITY OF COATS' METHOD USING WAIRAKEI DATA

(Values of the influence function are from Fig. 20)

$\begin{array}{cccccccccc}\text { Year } & \begin{array}{c}\text { Cumulative } \\ \text { Prod., Q }\end{array} & \begin{array}{c}\text { Producing } \\ \text { Time, } t, \text { yrs. }\end{array} & \mathrm{F}_{\infty} & \Delta \mathrm{p} & \mathrm{p} & \underline{F_{\text {bound }}} & \Delta \mathrm{p} & \mathrm{p} & \underline{\mathrm{p}_{\text {obs }}} \\ 1963 & 726276 & 8 & .0023 & 209 & 542 & .002334 & 212 & 539 & 543 \\ 1965 & 10283401 & 10 & .0027 & 278 & 473 & .002917 & 300 & 451 & 491 \\ 1970 & 1644585 & 15 & .0035 & 384 & 367 & .004376 & 480 & 271 & 427 \\ 1976 & 2295755 & 21 & .0042 & 459 & 292 & .006126 & 670 & 81 & 405\end{array}$


VI. STANDARD OPERATING PROCEDURE FOR DATA GATHERING AND ANALYSIS

\section{Data Gathering}

The most important step for the analysis of data is the proper collection of it. The data must be as complete and clear as possible so that "bad data" can be eliminated as a possible cause of unusual results in the analysis. Some steps for ensuring good data gathering are

1) Set up regular testing schedules and stick to them.

2) Set up calibration schedules for all instruments used such as pressure gauges and temperature bombs.

3) Keep an updated calibration $\log$ for each instrument.

4) Use clear standard forms for recording data.

A data chart for routine measurements should include at least the following information
1) Well name and location
2) Date and time
3) Pressure-we1l head, tubing, bottom hole, meter run, etc. gauge or absolute
4) Temperature
5) Flow rate
6) Location of test points
7) Units for all measured quantities
8) We11 statis
9) Type of test being conducted - buildup, interference, etc.
10) Zone being tested
11) Instrument numbers
12) Name of tester

\section{Data Analysis}

The data can be analyzed by wells, by groups of wells and by fields.

\section{Graphs}

Graphing the data provides an easy way of examining the data for unusual behavior such as occasional high, low or erratic production. Such data sets can be flagged for special attention. The data should be plotted and analyzed according to Arps (1945, 1956) using cartesian semi-log, and $\log -\log$ plots of production vs. time. However, this provides only a "quick look" and further analysis should be done. If the data are smooth enough, log-log type curves and Gentry's and McCray's curves can be used to fit current data and to extrapolate to future behavior. If the field is vapor dominated, $\mathrm{p} / \mathrm{z}$ vs. Q plots can be used but only with great caution.

\section{Least Squares Fits to Arps's Equations}

Production data ( $q$ vs. $t$ ) should be fit to Arps's exponential equation using a non-linear least squares program. The program should calculate $R^{2}$ to indicate goodness of fit. A reasonably high value of $R^{2}$, e.g., greater than 0.65 , allows extrapolation with some degree of confidence.

We recommend against using the computer to fit data to Arps's hyperbolic equation for the reasons described in Chapter V. However, if the data fall very well on a particular type curve then one may reasonably predict future production using that curve.

COMPLETE RESULTS FOR FITS TO EXPONENTIAL EQUATION

\begin{tabular}{|c|c|c|c|c|}
\hline $\begin{array}{l}\text { Field } \\
\text { Well }\end{array}$ & Start Date & End Date & $\begin{array}{l}\text { Calculated } \\
\text { Fractiona } 1 \\
\text { Decline, Dx } 10^{3}\end{array}$ & $R^{2}$ \\
\hline \multicolumn{5}{|c|}{ Wairakei - Total Production } \\
\hline 18 & $1-56$ & $12-76$ & 4.86 & 0.75 \\
\hline 20 & $4-59$ & $12-76$ & 6.00 & 0.32 \\
\hline 22 & $12-59$ & $12-76$ & 12.47 & 0.79 \\
\hline 24 & $1-60$ & $12-66$ & 7.52 & 0.60 \\
\hline 24 & $5-68$ & $12-76$ & 3.26 & 0.46 \\
\hline $26 \mathrm{~A}$ & $\begin{array}{l}3-00 \\
1-63\end{array}$ & $12-76$ & 5.38 & 0.52 \\
\hline 268 & $10-62$ & $12-76$ & 5.29 & 0.68 \\
\hline 27 & $8-58$ & $12-76$ & 2.05 & 0.20 \\
\hline 28 & $1-64$ & $12-76$ & 1.74 & 0.19 \\
\hline 30 & $3-57$ & $12-76$ & 4.90 & 0.72 \\
\hline 39 & $1-64$ & $12-76$ & 3.69 & 0.53 \\
\hline 41 & $1-59$ & $12-66$ & 7.02 & 0.43 \\
\hline 42 & $1-60$ & $12-66$ & 17.48 & 0.80 \\
\hline 43 & $12-58$ & $12-66$ & 5.04 & 0.40 \\
\hline 44 & $7-62$ & $12-76$ & 5.10 & 0.78 \\
\hline 46 & $12-58$ & $12-76$ & 4.86 & 0.74 \\
\hline 47 & $3-59$ & $12-76$ & 1.34 & 0.14 \\
\hline 47 & $1-63$ & $11-67$ & 7.87 & 0.40 \\
\hline 47 & $6-68$ & $12-76$ & 0.47 & 0.01 \\
\hline 48 & $5-62$, excl 5-58-3-69 & $12-76$ & 11.22 & 0.80 \\
\hline 55 & $5-62$ & $12-76$ & 3.05 & 0.52 \\
\hline 56 & $8-62$ & $12-76$ & 9.81 & 0.86 \\
\hline 57 & $9-62$ & $12-76$ & 6.01 & 0.69 \\
\hline 58 & $8-61$ & $12-76$ & 2.84 & 0.45 \\
\hline 66 & $5-64$ & $12-76$ & 1.03 & 0.06 \\
\hline 67 & $8-60$ & $12-76$ & 4.67 & 0.61 \\
\hline 70 & $1-65$ & $12-76$ & 1.94 & 0.38 \\
\hline 71 & $5-63$ & $12-76$ & 1.77 & 0.20 \\
\hline 72 & $7-62$ & $12-76$ & 5.97 & 0.90 \\
\hline 74 & $12-63$ & $4-66$ & 2.50 & 0.27 \\
\hline 76 & $12-62$ & $12-76$ & 5.72 & 0.59 \\
\hline 80 & $1-53$ & $12-76$ & 6.81 & 0.72 \\
\hline 81 & $12-60$ & $5-62$ & 3.99 & 0.59 \\
\hline 82 & $1-66$ & $12-76$ & 3.40 & 0.33 \\
\hline 83 & $9-63$ & $12-76$ & 2.54 & 0.38 \\
\hline 88 & $1-54$ & $12-76$ & 0.45 & 0.01 \\
\hline 108 & $8-64$ & $12-76$ & 2.87 & 0.51 \\
\hline ALL WELLS & $1-64$ & $12-76$ & 3.00 & 0.78 \\
\hline
\end{tabular}


COMPLETE RESULTS FOR FITS TO EXPONENTIAL EQUATION (Continued)

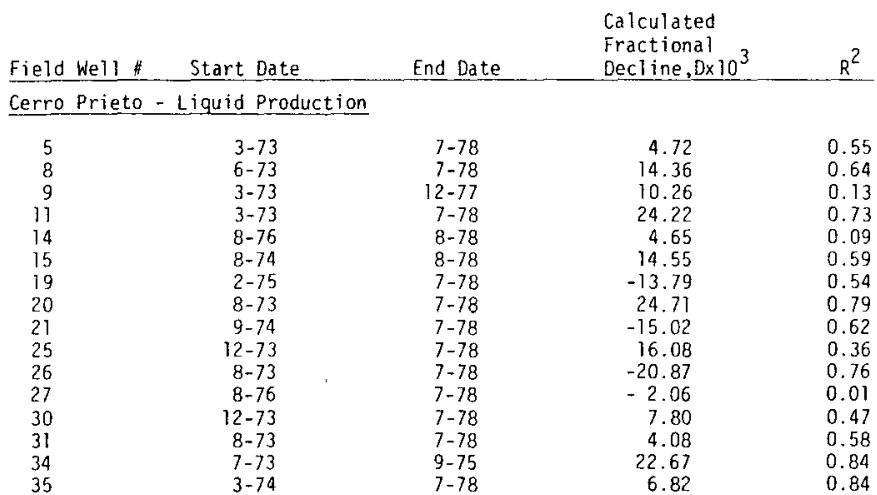

Cerro Prieto - Total Production

$\begin{array}{rrrrr}5 & 1-73 & 12-79 & 8.01 & 0.81 \\ 8 & 1-73 & 12-79 & 18.12 & 0.81 \\ 9 & 1-73 & 12-79 & 99.09 & 0.15 \\ 11 & 1-73 & 12-79 & 19.87 & 0.72 \\ 14 & 1-73 & 12-79 & 9.74 & 0.52 \\ 15 & 1-73 & 12-79 & 17.31 & 0.73 \\ 19 & 1-73 & 12-79 & -1.40 & 0.06 \\ 20 & 1-73 & 12-79 & 25.31 & 0.83 \\ 21 & 1-73 & 12-79 & 4.60 & 0.19 \\ 25 & 1-73 & 12-79 & 9.52 & 0.58 \\ 26 & 1-73 & 12-79 & -8.36 & 0.31 \\ 27 & 1-73 & 12-79 & 2.76 & 0.04 \\ 29 & 1-73 & 12-79 & 7.55 & 0.22 \\ 30 & 1-73 & 12-79 & 6.93 & 0.68 \\ 31 & 1-73 & 12-79 & 5.84 & 0.67 \\ 34 & 1-73 & 12-79 & 27.20 & 0.58 \\ 35 & 1-73 & 12-79 & 8.07 & 0.94 \\ 39 & 1-73 & 12-79 & 33.26 & 0.63 \\ 42 & 1-73 & 12-79 & 7.18 & 0.32\end{array}$

\begin{tabular}{|c|c|c|c|c|}
\hline $\begin{array}{l}\text { Field } \\
\text { Well \# }\end{array}$ & Start Date & End Date & $\begin{array}{l}\text { Calculated } \\
\text { Fract ional } \\
\text { Decline, } 0 \times 10^{3}\end{array}$ & $R^{2}$ \\
\hline \multicolumn{5}{|c|}{ Geysers - Total Production } \\
\hline$D x-2$ & $3-74$ & $11-79$ & 7.98 & 0.44 \\
\hline $0 x-3$ & $11-72$ & $11-79$ & 8.10 & 0.54 \\
\hline $0 x-4$ & $8-72$ & $11-79$ & 10.86 & 0.69 \\
\hline $0 \times-5$ & $8-71$ & $11-79$ & 1.16 & 0.01 \\
\hline $0 x-10$ & $8-71$ & $11-79$ & 5.00 & 0.16 \\
\hline $0 x-10$ & 3.74 & $2-78$ & 9.80 & 0.35 \\
\hline SUFBK3 & $8-71$ & $11-79$ & 11.59 & 0.49 \\
\hline GDC-32A & $12-72$ & $11-79$ & 9.94 & 0.54 \\
\hline GDC -53 & $3-72$ & $11-79$ & 19.01 & 0.32 \\
\hline$G D C-66$ & $4-73$ & $11-79$ & 9.56 & 0.54 \\
\hline GDC -77 & $5-72$ & $11-79$ & 9.85 & 0.31 \\
\hline GDC- 85 & $5-72$ & $11-79$ & 7.17 & 0.38 \\
\hline$G D C-85$ & $5-73$ & $12-74$ & 37.98 & 0.82 \\
\hline GDC-85 & $2-75$ & $11-76$ & 24.34 & 0.89 \\
\hline$G D C-86$ & $5-73$ & $11-79$ & 7.69 & 0.42 \\
\hline GDC-88 & $3-72$ & $11-79$ & 17.76 & 0.61 \\
\hline HAPYJKI & $11-71$ & $11-79$ & 36.10 & 0.61 \\
\hline HAPYJK2 & $1 \mid-71$ & $11-79$ & 13.17 & 0.60 \\
\hline HAPYJK 7 & $|1-7|$ & $11-79$ & 2.45 & 0.15 \\
\hline HAPYJK8 & $11-71$ & $11-79$ & 10.13 & 0.48 \\
\hline & $11-72$ & $11-79$ & 6.18 & 0.22 \\
\hline OS-1 & $6-73$ & $11-79$ & 9.66 & 0.59 \\
\hline $05-2$ & $9-72$ & $11-79$ & 6.03 & 0.23 \\
\hline $0 S-3$ & $9-72$ & $11-79$ & 13.70 & 0.46 \\
\hline $05-3$ & $6-75$ & $9-77$ & 25.36 & 0.89 \\
\hline $05-4$ & $1\}-72$ & $17-79^{\circ}$ & 11.64 & 0.54 \\
\hline $05-5$ & $7-74$ & $11-79$ & 23.99 & 0.63 \\
\hline $05-6$ & $8-72$ & $11-79$ & 9.58 & 0.59 \\
\hline OS -7 & $11-72$ & $17-79$ & 11.58 & 0.69 \\
\hline $05-8$ & $8-72$ & $11-79$ & 10.80 & 0.81 \\
\hline
\end{tabular}

Geysers Total Field

$\begin{array}{llll}11-72 & 11-79 & 11.51 & 0.81\end{array}$

Olkaria

$-$

$-$

10.84

0.85

\section{Influence Functions}

If adequate production and pressure data are available, they should be analyzed using Coats's influence function method and a computer program with the constraints described in Chapter III. Data preparation is straightforeward and data handling is minimal. The first half of a data set can be modeled and extrapolated in several different ways. Comparing the extrapolation with the second half of the data can give insight to the placement of reservoir boundaries such as faults or outcrops.

Bodvarsson's linearized free surface method should be tried if the reservoir has a free liquid surface, and if enough data are available to estimate a sinking velocity.

\section{REFERENCES}

Alonso E., H., B. Dominguez A., et al., 1978, Recent Activities at the Cerro Prieto Field, $\mathrm{LB}_{\mathrm{L}}-8538$, Dec., Lawrence Berkeley Laboratory.

Arps, J., 1945, Analysis of Decline Curves, Trans. AIME, 160

Arps, J., 1956, Estimation of Primary Oil Reserves, Trans. AIME, 207

Arps, J., F. Brons, A. van Everdingen, R. Buchwald, and A. Smith, 1967, A Statistical Study of Recovery Efficiency, Am. Pet. Inst. API Bull. D14, october

Bermejo M., F., C. Cortéz A., and A. Aragón A., 1979, Cambios Fisicos Y Termodinamicos Observados en el Yacimiento Geotermico de Cerro Prieto, in Proceedings First Symposium on the Cerro Prieto Geothermal Field, Baja California, Mexico, Sept. 20-22, 1978, LBL7098, Lawrence Berkeley Laboratory

Bodvarsson, G., 1977, Unconfined Aquifer Flow with a Linearized Free Surface Condition, Jokul1, 27

Bodvarsson, G., 1978, Mechanisms of Reservoir Testing, in Proceedings of the Fourth Workshop on Geothermal Reservoir Engineering, Dec. 1315, 1978, Stanford University, SGP-TR-30.

Bodvarsson, G., 1980, Personal Commication

Brigham, W. and G. Neri, 1979, Preliminary Results on a Depletion Model for the Gabbro Zone (Northern Part of Larderello Field) in Proceedings Fifth Workshop Geothermal Reservoir Engineering, H.J. Ramey, Jr. and P. Kruger, eds., Stanford, Dec. 12-14, SGP-TR-40.

Brigham, $W$. and $W$. Morrow, 1974, P/Z Behavior for Geothermal Steam Reservoirs, Soc. Pet. Eng. SPE 4899

Brons, F., 1963, On the Use and Misuse of Production Dedine Curves, Trod. Yonthly 
California Dept. of Conservation, Div. of Oil\& Gas, 1978, The Geysers, (geothermal map), G3-1

California Division of $0 i 1$ and Gas, Public Production Data on the Geysers Geothermal Field, Released 1979

Cerullo, R. and M. Romeo, 1970, A Review of the Curve-Fitting Method of Least Squares as Applied to Petroleum Engineering, USDI Bu. Mines Info. Circ. 8449

Coats, K., 1973, Elements of Reservoir Simulation, Intercomp/Human Resources Development Corp.

Coats, K., L. Rapoport, J. McCord, and W. Drews, 1964, Determination of Aquifer Influence Functions from Field Data, J. Pet. Tech., Dec.

Cohen, C., and J. Stein, 1977, Multipurpose Optimization System User's Guide, Version 4, Vogelback Computing Center, Northwestern University, Evanston, I1.

Duff, G. and D. Naylor, 1966, Differential Equations of Applied Mathematics, John Wiley \& Sons, Inc., New York

Earlougher, Jr., R. C., 1977, Advances in We11 Test Analysis, Monograph 5, Society of Petroleum Engineers of AIME

Economides, M., W. Brigham, et al., 1979, Influence Functions and their Application to Geothermal We11 Testing, in Geothermal Resources Council, Trans., 3, Sept.

Fetkovich, M., 1973, Decline Curve Analysis Using Type Curves, Soc. Pet. Eng. SPE 4629

Finn, D.F.X., 1975, Price of Steam at The Geysers, in Proceedings, 2nd UN Symposium on the Development and Use of Geothermal Resources, p. 2298

Garrison, L.E., 1972, Geothermal Steam in The Geysers - Clear Lake Region, California, GSA Bull., v. 83, p. 1449, May

Gennai, N. and G. Sestini, 1964, Studio sulle Cause del Decline delle Portate di Vapore Endogeno nel Tempo, Richerche di Termotecnica, Nr. 14

Gentry, R., 1972, Decline-Curve Analysis, J. Pet. Tech, Jan.

Gentry, R. and A. McCray, 1978, The Effect of Reservoir and Fluid Properties on Production Decline Curves, J. Pet. Tech., Sept.

Grant, Malcolm, 1979, Wairakei Production Graphs

Guerrero, E., 1961a, How to Determine Performance and U1timate Recovery by Exponential DeclineCurve Analysis, 011 and Gas J., May 22

Guerrero, E., 1961b, How to Determine Performance and Ultimate Recovery of a Reservoir Declining Hyperbolically, Oil and Gas J., July 17
Gurley, J., 1963, A Productivity and Economic Projection Method - Ohio Clinton Sand Gas Wells, J. Pet. Tech., Nov.

Higgins, R. and H. Lechtenberg, 1970, How to Predict 0il-Field Performance, Oil and Gas J., Sept. 14

Higgins, R, and H. Lechtenberg, 1969, Merits of Decline Equations Based on Production History of 90 Reservoirs, Soc. Pet. Eng. SPE 2450

Hutchinson, T. and V. Sikora, 1959, A Generalized Water-Drive Analysis, Trans. AIME, 216

Jargon, J. and H. van Poolen, 1965, Unit Response Function from Varying-Rate Data, J. Pet. Tech., August

Katz, D. and K. Coats, 1968, Underground Storage of Fluids, Ulrich's Books, The U. of Michigan

Katz, D., M. Tek, et a1., 1963, Movement of Underground Water in Contact with Natural Gas, American Gas Assoc., New York

Lamb, H., 1932, Hydrodynamics, 6th ed., Dover, New York

Lefkovits, H., C. Matthews, 1958, Application of Decline Curves to Gravity-Drainage Reservoirs in the Stripper Stage, Trans. AIME, 213

Lindstrom, F., 1980, FUNMIN: An Online-Interactive Mixed Simplex-Marquardt Least Squares or Likelihood Minimization Algorithm, Tech. Rep. 73, Dept. of Stat., OSU, Corvallis

Locke, C., L. Schrider, and M. Romeo, 1968, A Unique Approach to Oil-Production Decline Curve Analysis with Applications, Soc. Pet. Eng. SPE 2224

Mannon, R., 1965, Oi1 Production Forecasting by Decline Curve Analysis Soc. Pet. Eng. SPE 1254

Matthews, C. and H. Lefkovits, 1956, Gravity Drainage Performance of Depletion-Type Reservoirs in the Stripper Stage, Trans. AIME, 207

Muskat, M., 1949, Physical Principles of Oil Production, McGraw-Hill

Nie, N., C. Hull, J. Jenkins, K. Steinbrenner and D. Bent, 1975, Statistical Package for the Social Sciences, 2nd Edition, McGraw-Hill

Onodera, S., T. Masukawa, M. Fukuda, and K. Aosaki, 1977, The Inclination of Flow Rates of Steam and Hot Water from Otake Production Wells, and the Effect of Reinjection, Nihon Koogyoo Kaishi (Japan Mining Journal), 931069 (177?-3)

Palama, A., 1976, Funzioni di Influenza in Campi Geotermici, ENEL Provvisorio 511-Z 18, Ottobre

Pirson, S., 1946, Mathematical Methods of Decline Curve Extrapolation and Reserve Calculation, The Oil Weekly, Sept. 9 
Pritchett, J., L. Rice, and S. Garg, 1978, Reservoir Engineering Data: Wairakei Geothermal Field, New Zealand, SS-R-78-3597-1, Systems, Science and Software

Pruess, K., G. Bodvarsson, R. Schroeder et a1., 1979 Simulation of the Depletion of Two-Phase Geothermal Reservoirs, Lawrence Berkeley Laboratory LBL-9606, August

Pruess, K. and R. Schroeder, 1979, Basic Theory and Equations Used in the Two-Phase Multidimensions1 Geotherma1 Reservoir Simulator, SHAFT79, Lawrence Berkeley Laboratory LBL9464, Ju1y

Pruess, K., J. Zerzan, R. Schroeder, and P. Witherspoon, 1979, Description of the ThreeDimensional Two-Phase Simulator SHAFT78 for Use in Geothermal Reservoir Studies, Lawrence Berkeley Laboratory LBL-8802, January

Rivera R., J., 1977, Decline Curve Analysis - A Useful Reservoir Engineering Tool for Predicting the Performance of Geothermal Wells, Geotherma1 Res. Council, Trans, 1

Rivera-R., J., 197\%, Application of Type Curve Procedures for the Analysis of Production Data from Geothermal Wells, Geothermal Res. Council, Trans., 2

Robinson, B., 1977, SPSS Subprogram NONLINEAR Nonlinear Regression, Manual No. 433, Vogelback Computing Center, Northwestern University, Evanston, IL, August

Sánchez, R., J. and A. de la Peña, 1979, Preliminary Geohydrological Study of the Cerro Prieto Geothermal Field, in Abstracts of Second
Symposium on the Cerro Prieto Geothermal Field, Baja California, Mexico, Lawrence Berkeley Laboratory

Sestini, G., 1970, Superheating of Geothermal Steam, Proc. of the U.N. Symposium on the Development \& Utilization of Geothermal Resources, Pisa.

Shea, G., R. Higgins, and H. Lechtenberg, 1964, Decline and Forecast Studies Based on Performances of Selected California Oilfields, J. Pet. Tech., Sept.

Slider, H.C. 1968, A Simplified Method of Hyperbolic Decline Curve Analysis, J. Pet. Tech., January

Simon, B., 1974, Functional Integration and Quantum Physics, Academic Press, New York

Stakgold, I., 1967, Boundary Value Problems of Mathematical Physics, vol. 1, The MacMillan Co., New York

Sunde, E., 1968, Earth Conduction Effects in Transmission Systems, Dover, New York

Tsarevich, K. A. and I.F. Kuranov, 1956, Calculation of the Flow Rates for the Center Well in a Circular Reservoir Under Elastic Conditions, extract from Part I of Problems of Reservoir Hydrodynamics and Thermodynamics (Voprosy Gidrodinamiki i Termodinamiki Plasta), ed., E. M. Minskii, Ministerstvo Neftyanoi Promyshlennosti SSSR, Vsesoyuzni Neftegazovyi Nauchno-Issledovatelskii Institut (VNII), Leningrad Gostoptekhizdat

Tuccy, J., 1977, SPSS Subprogram PLOT: Digita1 (Calcomp) Plotting, Document No. 409 (Rev. A), Vogelback Computing Center, Northwestern University, Evanston, IL, October 


\section{APPENDIX}

Statistical Package for the Social Sciences SPSS

SPSS is a set of programs developed for general statistical analysis. We have used the two subprograms PLOT (Tuccy, 1977) and NON-LINEAR (Robinson, 1977) quite extensively. The listings for our SPSS main programs which used these subprograms are given below. SPSS2 will plot a set of data. SPSS4 will do a nonlinear least squares $\mathrm{fit}$ using the exponential equation. $B(1)$ and $B(1)$ are initial guesses for initial production, $q_{O}$, and monthly fractional decline, D. The other program names are self-explanatory. A complete description of SPSS is given in Nie, 1975.

\section{Multiple Purpose Optimization System MPOS}

MPOS is a linear programming package designed to solve a wide variety of linear programming problems. Coats' influence method can be formulated as a linear programming problem as follows.

$$
\begin{array}{rlrl}
\sum_{j=i}^{1} q_{i-j} x_{j}+u_{i}-v_{i}=0 & \text { (1) } i & =1,2, \ldots n \\
x_{j} & =F_{j}-F_{j-1} \\
x_{i} \geq 0 & \text { (2a) } i & =1,2, \ldots n \\
x_{n-1}-x_{n} \geq 0 & \text { (2b) } i & =1,2 \ldots n \\
x_{i+1}-2 x_{i}+x_{i-1} \geq 0 & \text { (2c) } i & =1,2 \ldots n
\end{array}
$$

$\mathrm{n}$

Objective function $\sum\left(u_{i}+v_{i}\right)=$ minimum where $u_{i}$ and $v_{i}$ are slack variables, $b_{i}$ is the observed pressure change $\Delta p$, and $q_{i-j} X_{j}$ is the calculated pressure change. MPOS generates a tableau for the calculation which looks like the following for $\mathrm{n}=4$.

$\begin{array}{lllllllllllll}x 1 & x 2 & x 3 & \times 4 & \text { u1 } & \text { u2 } & \text { u3 } & \text { u4 } & \text { v1 } & \text { v2 } & \text { v3 } & \text { v4 } & \text { b }\end{array}$

$$
\begin{aligned}
& \begin{array}{lllllllll}
\text { Objective function } & 1 & 1 & 1 & 1 & 1 & 1 & 1 & 1
\end{array}
\end{aligned}
$$

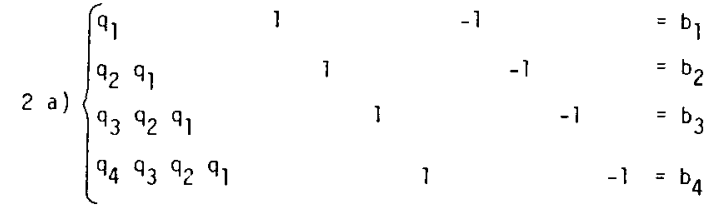

$$
\begin{aligned}
& \text { 2c) } 1-1 \quad \geq 0 \\
& 2 \text { d) }\left\{\begin{array}{rrrrrr}
1 & -2 & 1 & & \geq 0 \\
1 & -2 & 1 & \geq 0
\end{array}\right.
\end{aligned}
$$

Values for $u$, and $v$, are given in the output so that the fitness mieasures, $\rho$, can be calculated directly as

$$
\rho=\frac{1}{n} \sum_{i=1}^{n} \frac{1}{b_{i}}\left(u_{i}+v_{i}\right) .
$$

The listing for program INFUNC is given below. 
COMPUTER LISTINGS AND EXAMPLES

SPSS PROGRAMS

: : $=====$ SPSS
PAGESIZE
PUN NAME
YAPIARLE LIST
INPUT FOQMAT
NOF CASES
READ INPUT DATA
PLOT

OP TIONS
NOF JFCT

PLOT ONLY - POZO 5

MONTH53, MASS

FIXEO $(24 x, F 3.0,27 \times, F 7.0)$

UNKNOWN

PLOTS=MASS $(0,320)$ WTTH MONJH53 $(0,72)$

IILE $=P O Z O 5$

TIT LE $X=M O N T H$,

SIZE $=10.5,8.0 \%$

$\times \mathrm{DIV}=12$

$Y D T=B$

$S Y M 9 O L S=-7$,

1.10

$$
====\text { SPSS4 }====
$$

187

PAGESIZE

PUN NAMF

VARIABLE LIST

INPUT FORMAT

$N$ OF CASES

SOMPUTE

YISSING VALUES

IF

GOMPUTE

READ INPUT

* RE JECT IF

NONLINEAR

४OEL

DERIVAT IUES

DARAMETERS

REGRESSION

I O I

OA TA

NOF NEC

NONLINEAR REGRESSION - DORE 10A

MONTH53, AMONITH, YEAR, MASS

FIXED $(9 X, F 5,0,5 X, 2 F 5,0, F \geq 0.2)$

159

PMASS = MASS

MASSIO)

IYEAO LT 1964) MASS $=0$

IYEAE EQ 1964 AND AYONTH LT B) MASS $=0$

MONTHR=MONTH $3-140$

(MASS EO D)

VARTAQLES =MASS WITH MONTHR, NB=2

YHAT $=10 C 000 C$ B $(1) * E X P(B(2) *$ COOO1*MONTHP)

$G(1)=E X P(B(2) * .00001 * M O N T H R ; 1000000$

$G(2)=10^{*}$ MONTHR* $\left.9(1) * E X P(A) * .00001 * M O N T H R\right)$

$R(1)=435.299562$

Q ( 2$)=-302.55$

VAF IA BLES MASS.MONTHR/

PLOTS=PMASS (O.80OOCOCOU) WITH MONTH53(0.2A9),

TITLE = QCRE 10.8

TTTLEX MONTH

TITLE $Y=M A S S$

SI $P E=10.5 .8 .01$

XDT $V=121$

YOIV $=9 /$

OPTIONS

SYMROL $S=-7$,

FINTSH

1,10 


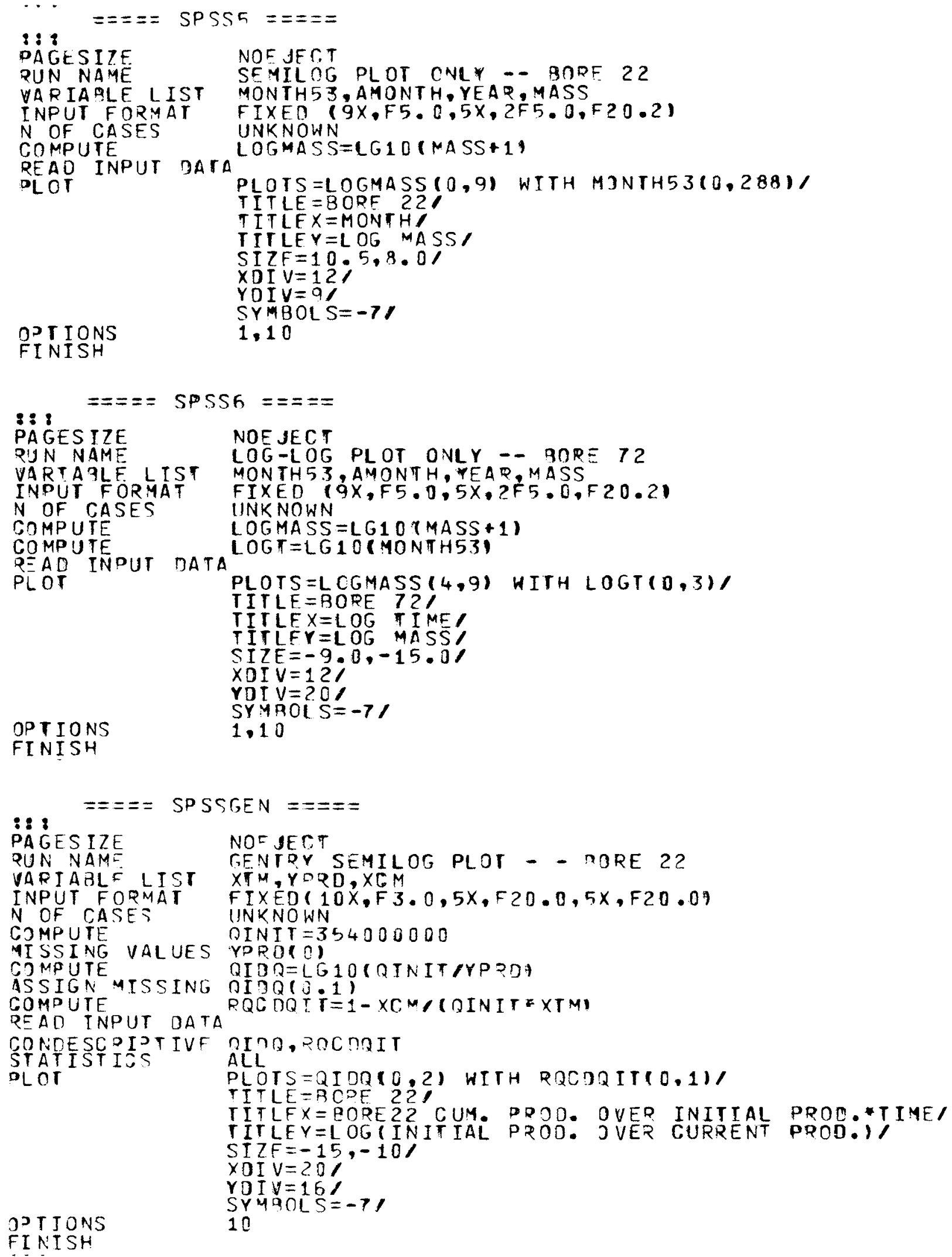

FINISH$$
== \pm= \pm \text { SPSSGEN }== \pm==
$$

\section{$:: 1$}

PAGESIZE

QUN NAME

VAFIABLE LIST

INPUT FORMAT

$N$ OF CASES

CJMPUTE

MISSING VALUES CD MPUTE

ASSIGN MISSING COMPUTE

READ INPUT DATA

CONDESCOIJTIVF OIND, POC ORIT

STATISTIES ALL

口L OT

NOE SECT

TENTRY SEMILOG PLOT - - NORE 22

$X T M, Y O Q D, X G M$

FIXED( $10 X, F 3,0,5 X, F 20,0,5 X, F 20.07$

UNKNOWN

DINTT $=354000000$

YPRO(O)

QIOR=LG10(RINIT/YPPDA

DITQ $(0.1)$

RQCDQT $T=1-X C M,(D I N T T=X T M)$

PLOTS=QIDQ $(0,2)$ WITH RQCDQIT $(0.1) \%$

IITLFX = PORE22 CUM. PROD. OVER INITIAL PROC. TIMEI IITLEY =LOG (INITIAL PROD: JVER CURRENT PROD:) SIZF $=-15,-10 /$ $X 0 I V=2.0 \%$

YDT $V=16 /$

JPT TONS

SYM $9015=-7 /$

FINISH 
$: 1:$

$====$ SPSEN2 $====$

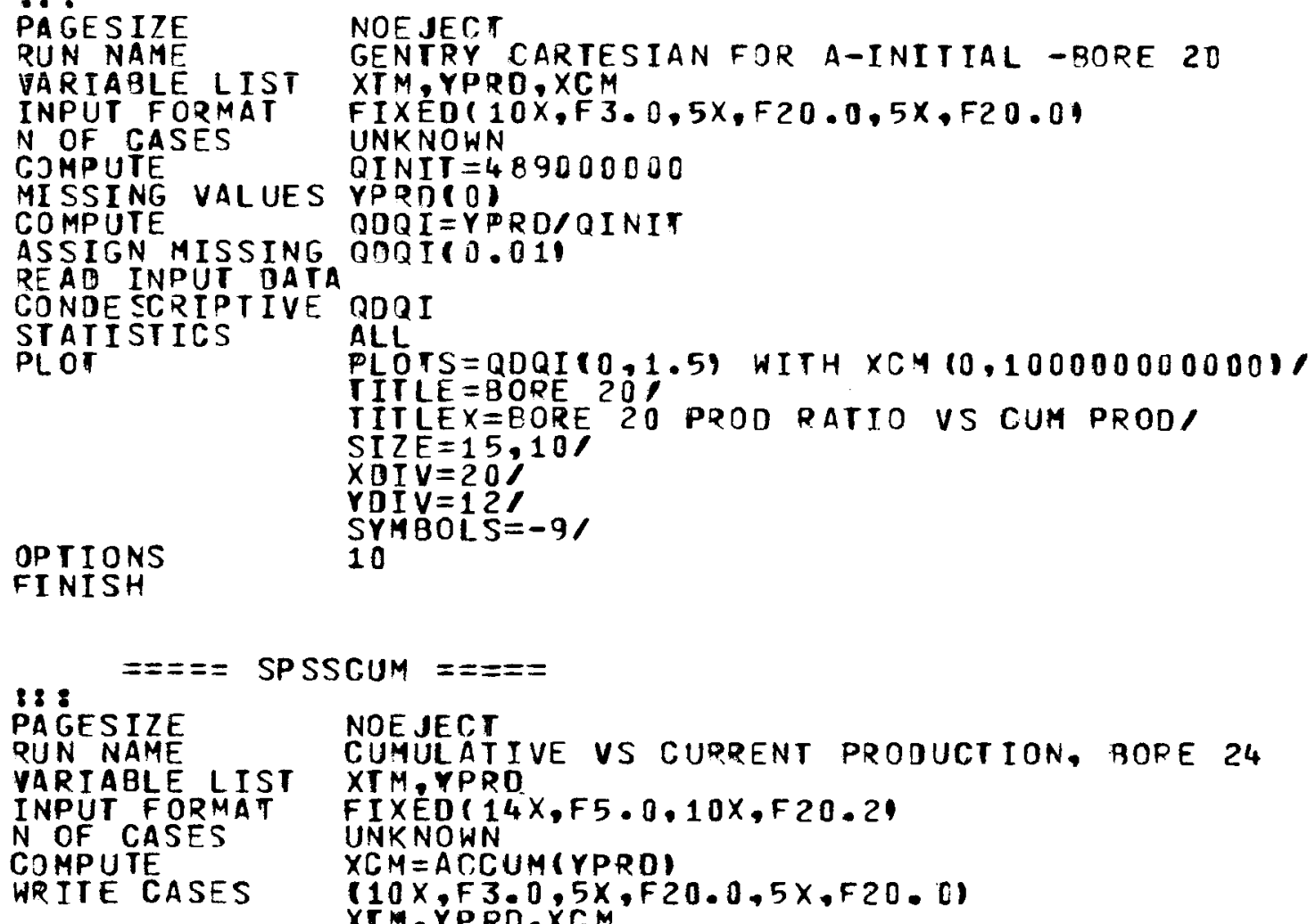

FI NISH

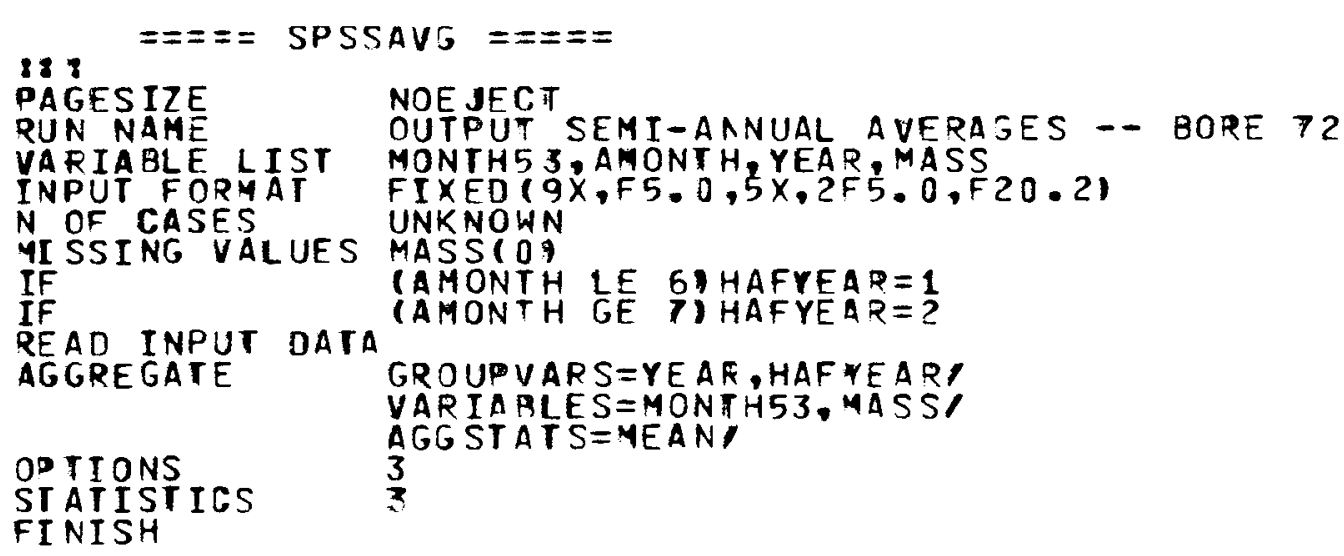




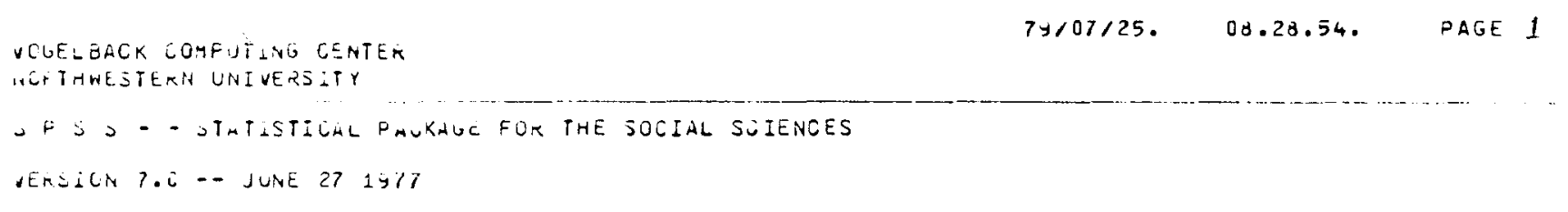

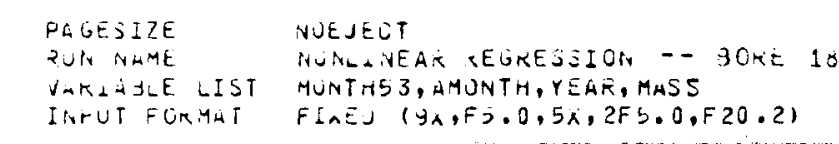

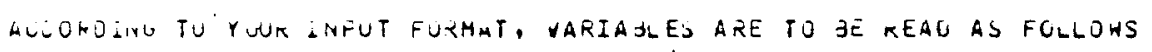

VARIMLLE FORYGT TELORO COLUANS

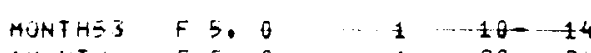

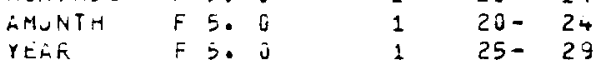

$\begin{array}{lllll}\text { YEAR } & F 5.0 & 1 & 25-29 \\ \text { MALS } & F 20.2 & 1 & 30-49\end{array}$

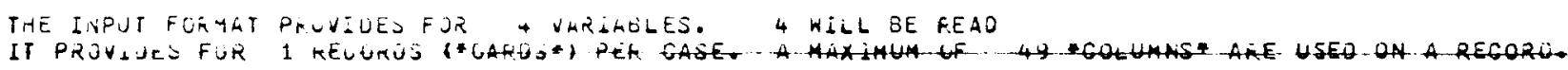

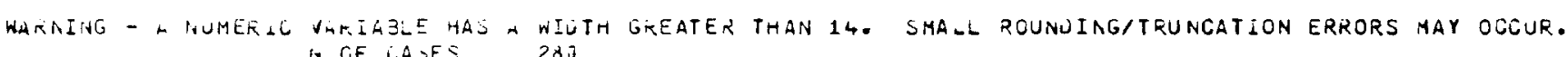

$$
\begin{aligned}
& \text { iv CF LADES } 28 \\
& \text { IF (REAK LT 195O)MASS }=0 \\
& \text { UUMPUTF HUTFHR=AUNTA33-37 } \\
& \text { AOSIGN IISSLIHG MUNTHR }(-1) \\
& \text { REEJECT IF IMASS EQ J }
\end{aligned}
$$

XEAL INPUT ITIA

SPSS RELUMLEO 


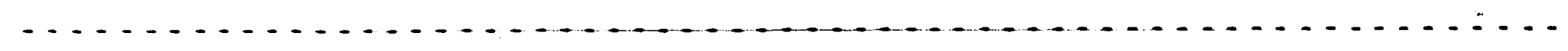

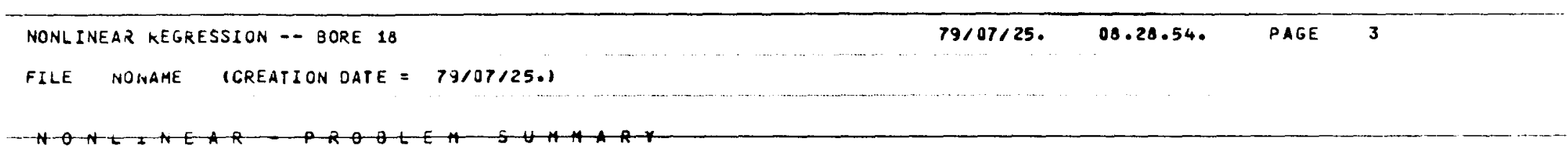

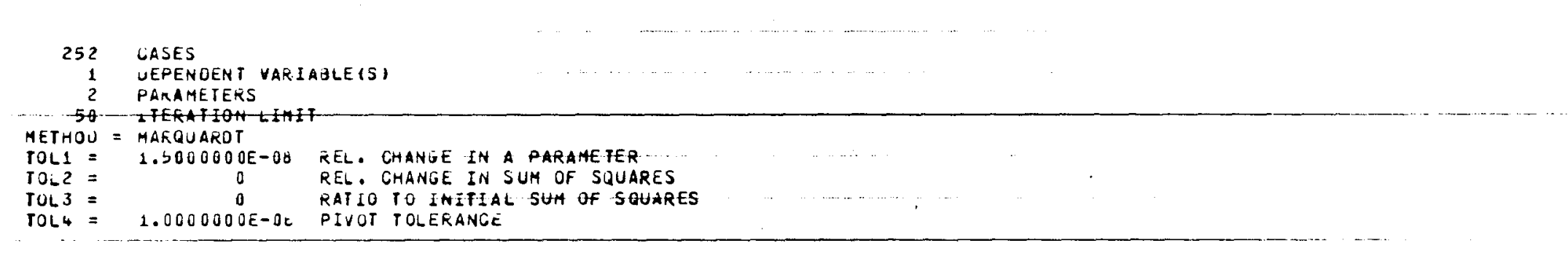

\section{PARAMETERS}

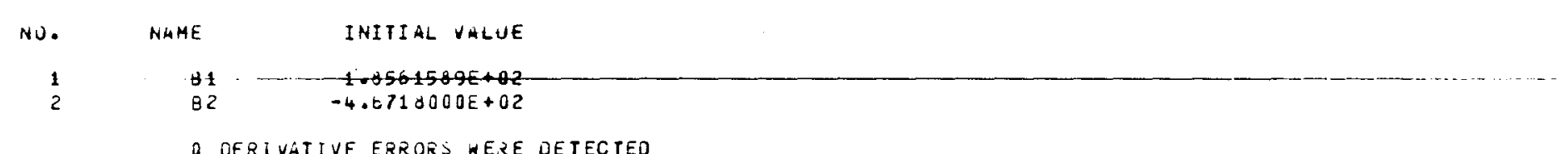

SETUP FIHE $=\ldots$. . TOWOSE SOS

THELAST ITERATIUN

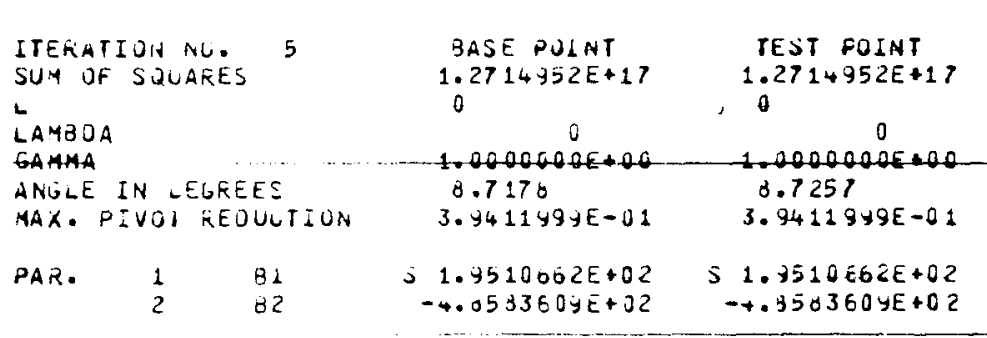

CUMULATIVE NO. OF FUNCTION CALLS $=6$

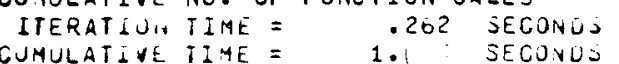


ITERATION TERMINATES

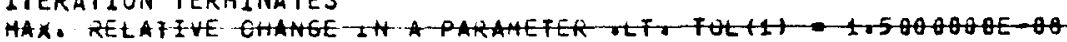

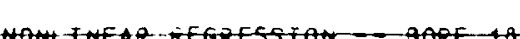

$19707+25,-0828.54 .-16 E$

FILE NONAME ICREATION OATE = 79/07/25.1

FINAL PARAMETER̈ VALUES

final VALUE

SHM OF SQUARES $=1.2714952 E+17$

$R^{2}=.7501$

PAR. $\quad$\begin{tabular}{rrr}
1 & 31 & $1.951 \theta 662 E+\theta 2$ \\
\hline
\end{tabular}

NGINLINEAR KEGRESSIUN -- 3ORE 18

$79 / 07 / 25$

08.28 .54$.

PAGE

FILE NUNAME (CREATION DATE = 79/07/25.)

FINAL FUNGTION VALUES ANO RESIOUALS

ROOT MEAN SQUARE RESIOUAL $=2.2552119 E+07$

J.F.: =

250

THIS IS THE SCALE UAIT IN THE GEAPH UF THE RESIOUALS.

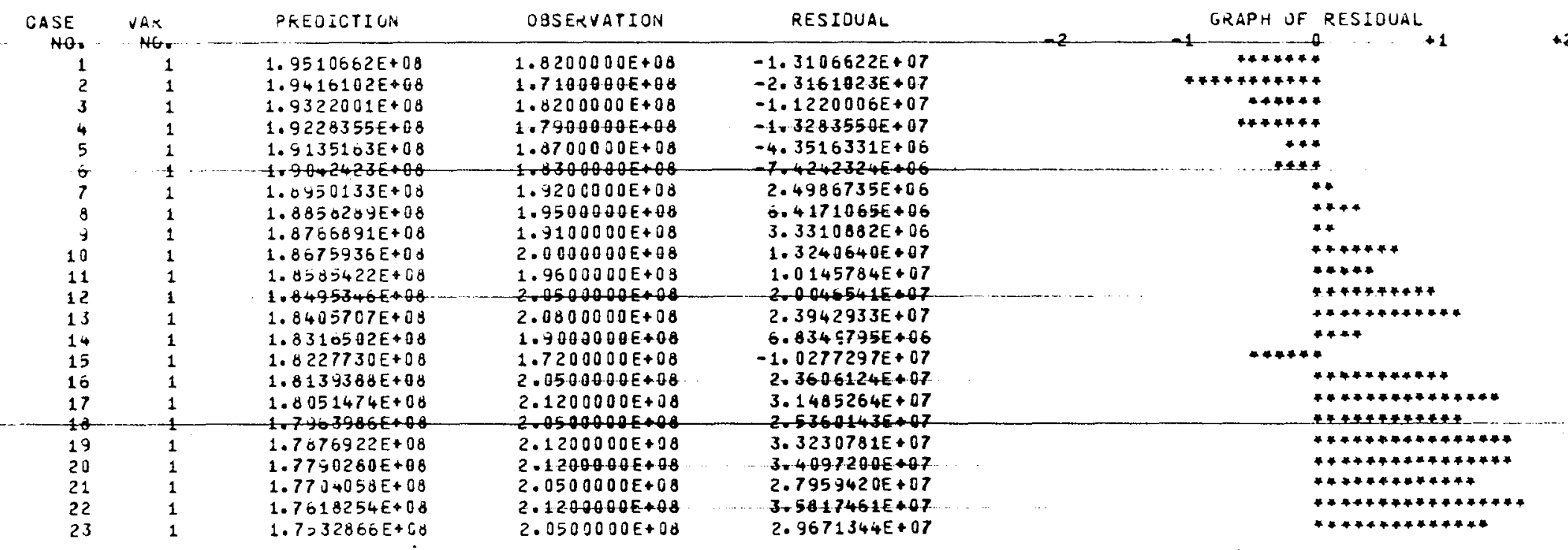




\begin{tabular}{|c|c|c|c|c|c|c|}
\hline 24 & 1 & $1.7447891 E+08$ & $2.1200000 E+08$ & $3.7521088 E+07$ & & $* * * * * * * * * * * * * * * * * *$ \\
\hline 25 & 1 & $1.7363329 E+00$ & $2.1200000 E+08$ & 3. $3305713 E+\theta 7$ & & 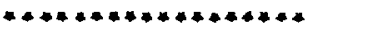 \\
\hline $\begin{array}{l}26 \\
27\end{array}$ & 1 & $\begin{array}{l}1.7279176 \mathrm{E}+08 \\
1.71954+08\end{array}$ & $1.9200000 E+08$ & 1.9208241E+07 & 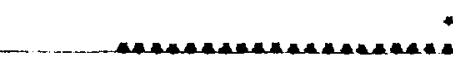 & $*+*+*+*+* *$ \\
\hline 28 & 1 & $1.7112092 E+08$ & $1.3400000 E+08$ & $1.2879079 E+07$ & & $* * * * * *$ \\
\hline 23 & 1 & $1.702 Y 157 E+08$ & $1.1000000 E+00$ & $-6.0291570 E+07$ & 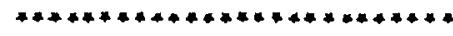 & \\
\hline 30 & 1 & $1.0946624 E+00$ & $7.3000000 E+07$ & $-9.6+60238 E+07$ & 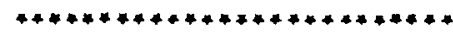 & \\
\hline 31 & 1 & $1.6864491 E+8 y$ & $1.9000000 E+00$ & $2.1355093 E+07$ & & $+\infty++++\infty+\infty$ \\
\hline 32 & 1 & $1.0782750 E+\cup 8$ & $1.8800000 E+08$ & $2.0172444 E+07$ & & $* * * * * * * * * *$ \\
\hline 33 & 1 & $1.0701647 E+90$ & $2.070000 E 00$ & $3.9905033 E+07$ & - & 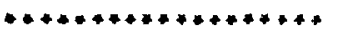 \\
\hline 34 & 1 & $1.0020+72 E+08$ & $2.1100000 E+08$ & $4.4795280 E+07$ & & $* *+* * *+* * * * * * * * * * * * *$ \\
\hline 3j & 1 & $1.0539920 E+00$ & $2.7000000 E+07$ & $-1.3839920 E+08$ & 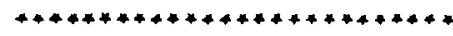 & * \\
\hline 30 & 1 & $1.6459750 E+C 3$ & $1.6000000 E+08$ & $-4.5975754 E+06$ & 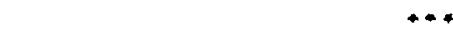 & * \\
\hline 37 & 1 & $1.0379904 E+33$ & $C .0700000 E+J 8$ & $4.3200100 E+07$ & & $*+*+*+* * 4 *+*+* * *+* * *$ \\
\hline 38 & 1 & $1 . E 3005975+00$ & $1.0600000 E+00$ & $2.2994026 E+07$ & & $*+*+*+*+*+*$ \\
\hline 37 & 1 & $1.02215 y 5 E+00$ & $1.77 \theta \theta \theta \theta \theta+98$ & $3 .+78+050 E+07$ & & $* *+* * *+* * * * * * * * * *$ \\
\hline+0 & 1 & $1.0142976 E+08$ & $3.1000000 E+07$ & $-1.1042976 E+0 B$ & 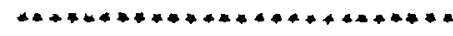 & 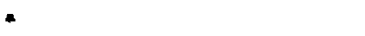 \\
\hline 41 & 1 & $1.0004738 E+00$ & $1 . \rightarrow \rightarrow 00000 E+00$ & $3.8352624 E+B 7$ & & $*+*+*+*+* * 4+*+*+*+*$ \\
\hline 42 & 1 & $1.5306079 E+00$ & $1 . \$ 100000 E+20$ & $3.1131214 E+07$ & & $4 * * * * * * *+* * *+* *$ \\
\hline 43 & 1 & 1.5 y $9337 \equiv+00$ & $1.7000000 E+00$ & $3.690603 \mathrm{JE}+07$ & & $* *+*+*+* * * * *+* * * * *$ \\
\hline+4 & 1 & $1.30322915+C 8$ & $1.3500000 E+08$ & $3.60770+2 E+U 7$ & & $-x+\infty+x+x+4+\infty+4+\infty$ \\
\hline 4) & 1 & $1.575>550 E+00 d$ & $1.0 \Rightarrow 00 \theta \theta \theta E+00$ & 2. $7 \rightarrow+4+10 E+67$ & & $*+*+*+*+*+4+* *$ \\
\hline 40 & 1 & $1.507 y 1 y \theta E+0 d$ & $1.0700000 E+08$ & $3.0208022 E+07$ & & $\omega++\infty+\infty *+\infty, \ldots$ \\
\hline
\end{tabular}

\begin{tabular}{|c|c|c|c|c|}
\hline $\begin{array}{l}\text { UASE } \\
\text { NO. }\end{array}$ & $\begin{array}{l}\text { VAR } \\
\text { NU. }\end{array}$ & PAEOICIICN & OBSERVATIOA & RESIOUAL \\
\hline 47 & 1 & $1.5003207 E+00$ & $1.0100000 E+03$ & 4. $3073262 E+56$ \\
\hline 43 & 1 & $1.5527535 E+i 3$ & $1.5300000 E+00$ & $-2.2750522 E+C 0$ \\
\hline 43 & 1 & $1.5-52330 E+00$ & $1.536 \theta \theta \theta \theta E+78$ & $-1.5232956 E+00$ \\
\hline 50 & 1 & $1.337743 y E+08$ & $1 .+300000 E+08$ & $-1.077+30 \sigma E+07$ \\
\hline 51 & 1 & $1.5302911 E+C 0$ & $1.5300000 E+03$ & $-2.9105781 E+04$ \\
\hline 52 & 1 & $1.522 C 7+4 E+C 3$ & $1.4 .500000 E+J 0$ & $-4.2 d 74393 \mathrm{E}+06$ \\
\hline 53 & 1 & $1.5154 y 37 E+03$ & $1.5300000 E+08$ & $1.4506337 \mathrm{E}+06$ \\
\hline 54 & 1 & $1.50814 .57 E+73$ & $1.4 J 0 J 0 \cup 0 E+J 8$ & $-2.3140704 E+O 6$ \\
\hline 55 & 1 & $1.5000393 \bar{E}+88$ & $1 .>300000 E+08$ & $-2.7160656 E+06$ \\
\hline 50 & 1 & $1.4935654 E+08$ & $1.5300000 E+j 0$ & $3.6434592 E+J 0$ \\
\hline 57 & 1 & $1.4003267 E+00$ & $1 .+000000 E+00$ & $-0.3267269 E+05$ \\
\hline 58 & 1 & $1.4791231 E+08$ & $1.5300000 E+\square 8$ & $5.0876872 E+06$ \\
\hline 53 & 1 & $1.471+2+4 E+08$ & $1.4000000 E+00$ & 8.0455577E+C5 \\
\hline 60 & 1 & $1.4040205 E+00$ & $1.5300000 E+28$ & $0.5179500 E+66$ \\
\hline 61 & $1 \cdots$ & $1.4577241 E+f Q$ & 1.52000000 .08 & $-0.24788675+06$ \\
\hline 62 & 1 & $1.4506502 E+08$ & $1.3700000 E+j 8$ & $-8.0656174 E+06$ \\
\hline 63 & 1 & $1.4436255 \varepsilon+08$ & $1.5200000 E+08$ & $7.037+545 E+0 b$ \\
\hline 04 & 1 & $1.4306288 E+08$ & $1.4700000 E+08$ & $3.3371189 E+06$ \\
\hline 65 & 1 & $1.4290061 E+08$ & $1.2800000 E+08$ & $-1.4966608 E+67$ \\
\hline 66 & 1 & $1.4227371 E+08$ & $1.2700000 E+08$ & $-1.5273709 \mathrm{~g}+07$ \\
\hline 67 & & $1 .+158+17 E+00$ & $1.3200000 E+08$ & $-7 \rightarrow \rightarrow 841683 E+06$ \\
\hline 68 & 1 & $1.40097 y 7 E+08$ & $1.2700000 E+08$ & $-1.3897970 E+07$ \\
\hline 69 & 1 & $1.4021510 E+08$ & $1.0100000 E+08$ & $-3.9215076 E+\theta 7$ \\
\hline 70 & 1 & $1.39(53 \mathrm{E}+0 \mathrm{~d}$ & $1.1300000 E+08$ & $-2.6535(B E+07$ \\
\hline 71 & 1 & $1.388>926 E+08$ & $1.0700000 E+08$ & $-2.9859 \div 03 E+07$ \\
\hline 72 & 1 & $1.3018627 E+98$ & $1.1200000 E+08$ & $-2.618 \in 271 E+67$ \\
\hline
\end{tabular}

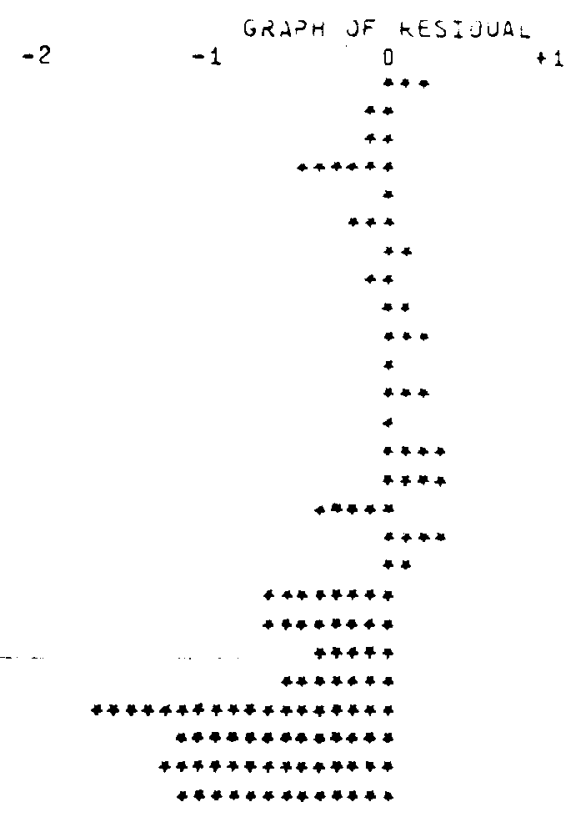




$\begin{array}{ll}1 & 1.37 ., 54 E+08 \\ 1 & 1.3685006 E+08 \\ 1 & 1.3018680 E+08 \\ 1 & 1.3552676 E+08 \\ 1 & 1.3486992 E+08 \\ 1 & 1.3421626 E+08 \\ 1 & 1.3350577 E+08 \\ 1 & 1.3291044 E+08 \\ 1 & 1.3227424 E+08 \\ 1 & 1.3163316 E+08 \\ 1 & 1.3099519 E+08 \\ 1 & 1.3036031 E+08 \\ 1 & 1.29720511+08 \\ 1 & 1.2909477 E+08 \\ 1 & 1.2047403 E+08 \\ 1 & 1.2785142 E+08 \\ 1 & 1.2723178 E+08 \\ 1 & 1.2061514 E+08 \\ 1 & 1.2600149 E+08 \\ 1 & 1.2539081 E+08 \\ 1 & 1.2478309 E+08 \\ 1 & 1.2417832 E+08 \\ 1 & 1.2357640 E+08 \\ 1 & 1.2297756 E+08\end{array}$

\begin{tabular}{|c|c|}
\hline \multicolumn{2}{|l|}{$1.1200000 E+08$} \\
\hline $1.0100000 E+00$ & $-3.5850056 E+67$ \\
\hline $1.1100000 E+00$ & $-2.5186001 E+07$ \\
\hline $1.0700000 E+08$ & \\
\hline $1.1000000 E+08$ & $-2.486 \subseteq 920 E+07$ \\
\hline $\begin{array}{l}1.0600000 E+00 \\
1.0900000 E+08\end{array}$ & $-2.8216 .263 E+07$ \\
\hline $1.0900000 E+08$ & $-2.4565773 E+07$ \\
\hline $1.0900000 E+00$ & $-2.3918436 E+87$ \\
\hline $9.7000000 E+07$ & $-3.3274236 E+07$ \\
\hline $\begin{array}{l}1.2500000 E+08 \\
1.3400000 E+08\end{array}$ & $-5.6331590 E+\theta 6$ \\
\hline $1.3400000 E+08$ & $3.0048114 E+06$ \\
\hline $1.1200000 E+00$ & $-1.836031 \theta E+07$ \\
\hline $1.1600000 E+U \Delta$ & $-1.372850 Y E+C 7$ \\
\hline $1.0300000 E+08$ & $-2.6099769 E+07$ \\
\hline $1.1400000 E+08$ & $-1.4474077 E+07$ \\
\hline $1.1200000 E+08$ & $-1.5051+10 E+87$ \\
\hline $1.2400000 E+G 8$ & $-3.2317757 E+06$ \\
\hline $\begin{array}{l}1.2000000 E+08 \\
1.3500000 E+0 d\end{array}$ & $\begin{array}{l}1.3848631 E+06 \\
8.3985132 E+06\end{array}$ \\
\hline $1.1600000 E+08$ & $-9.3908107 E+06$ \\
\hline $\begin{array}{l}1.3000000 E+08 \\
1.0300000 E+28\end{array}$ & $\begin{array}{r}5.2169057 E+06 \\
-2+17323 E+07\end{array}$ \\
\hline $9.9000000 E+07$ & $-2.4576483 E+07$ \\
\hline $1.0900000 E+08$ & $-1.3977560 E+07$ \\
\hline
\end{tabular}

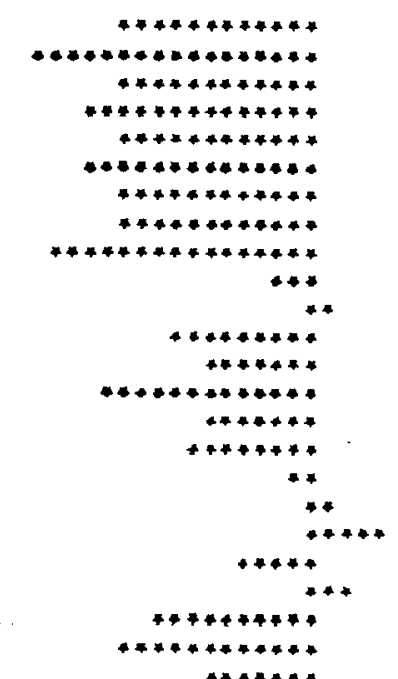

NONL INEAR TEGRESSION -- 3ORE 10

$79 / 07 / 25$

FILE NUIAME (CKEMTION DATE = 7H/07125.)

FINA-FUNCTIUN VALUES ANO RESEOUALS

$\begin{array}{rr}\text { IASE } & \text { VAK } \\ \text { NOA } & \text { NC. } \\ 97 & 1 \\ 98 & 1 \\ 93 & 1 \\ 100 & 1 \\ 101 & 1 \\ 102 & 1 \\ 103 & 1 \\ 104 & 1 \\ 105 & 1 \\ 100 & 1 \\ 107 & 1 \\ 108 & 1 \\ 109 & 1 \\ 119 & 1 \\ 111 & 1 \\ 112 & 1 \\ 113 & 1 \\ 11+ & 1 \\ 115 & 1 \\ 115 & 1 \\ 117 & 1 \\ 110 & 1 \\ 119 & 1 \\ 129 & 1 \\ 121 & 1\end{array}$

\begin{tabular}{|c|c|c|}
\hline PREOILTION & OJSERVATIUN & RESIDUAL \\
\hline $\begin{array}{l}1.223812+E+00 \\
1.217884 E+O A\end{array}$ & $\begin{array}{l}1.2+00000 E+08 \\
1.3402020 E+02\end{array}$ & $\begin{array}{l}1.0184601 E+06 \\
1.2211532 E+07\end{array}$ \\
\hline $1.2119815 E+08$ & $1.4+00000 E+08$ & $2.2801849 E+07$ \\
\hline $1.2001075 E+08$ & $1.2600000 E+08$ & $5.3892451 E+06$ \\
\hline $1.2002021 E+08$ & $1.4100000 E+00$ & 2. $0973795 E+07$ \\
\hline $1.19+4+49 E+08$ & $1.3502000 E+08$ & $1.5555511 E+07$ \\
\hline $1.1086553 E+000$ & $1.3700000 E+08$ & $1.813+408 E+07$ \\
\hline $1.162+950 E+02$ & $-1.14020008+22$ & $-+28 \times 5006 E+00$ \\
\hline $1.1771620 E+0 y$ & $9.9000000 E+07$ & $-1.8716201 E+07$ \\
\hline $1.1714508 E+08$ & $1.0200000 E+08$ & $-1.5145681 E+07$ \\
\hline $1.16577,2 E+0 d$ & $1.0600000 E+08$ & $-8.5779248 E+06$ \\
\hline $1.1001292 E+68$ & $1.0000000 E+03$ & $-1.0012921 E+07$ \\
\hline $1.15+5000 E+05$ & $9.0000000 E+07$ & $-1.9450655 E+07$ \\
\hline $1.1409111 E+08$ & $7.0020000 E+07$ & $-3.0891114 E \pm 67$ \\
\hline $1.1+33429 E+C d$ & $1.1200000 E+08$ & $-2.3342857 E+C 6$ \\
\hline $1.1378016 E+00$ & $1.0700000 E+08$ & $-6.7801556 E+06$ \\
\hline $1.1322871 E+03$ & $1.2100000 E+08$ & $7.7712888 E+06$ \\
\hline $1.12079 y+E+08$ & $1.0900000 E+00$ & $-3.6799394 E+06$ \\
\hline $1.1213383 E+00$ & $1.0100000 E+08$ & $-1.1133827 E+07$ \\
\hline $1.1154036 E+08$ & $1.01200005 * 08$ & $=1.0590362 E+07$ \\
\hline $1.11044 E 3 E+69$ & $1.0100000 E+08$ & $-1.0049531 E+07$ \\
\hline $1.1051132 E+00$ & $1.0300000 \mathrm{JE}+00$ & $-7.5113203 E+06$ \\
\hline $1.0 y 97572 E+00$ & $1.0100000 E+00$ & $-8.9757185 E+06$ \\
\hline $1.09+4271 E+00$ & $1.0500000 E+08$ & $-4 .+427126 E+06$ \\
\hline $1.00+122 y \equiv+03$ & $1.2100000 E+08$ & $1.2087710 E+07$ \\
\hline
\end{tabular}

$-2$

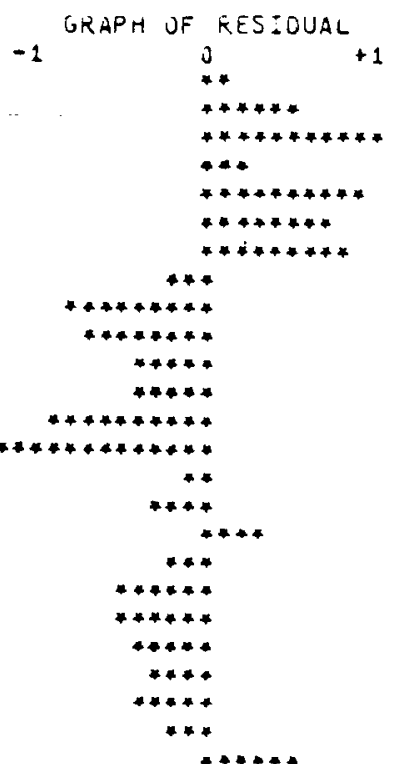




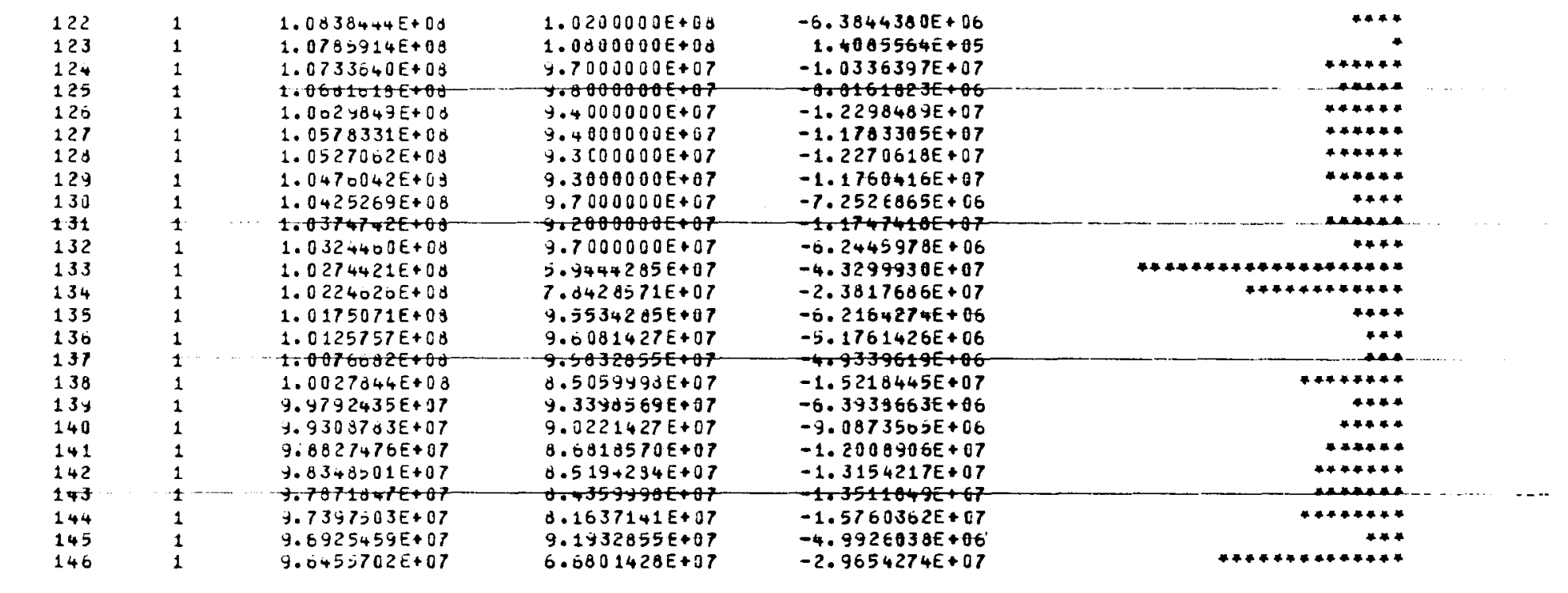

FILE NONAME (IKEATION DATE = 79/J7/25.)

FINAL FUNCTION VALUES A HO RESIOUALS

$\begin{array}{cr}\text { CASE } & \text { MAR } \\ \text { NO } & \text { NC. } \\ 147 & 1 \\ 140 & 1 \\ 149 & 1 \\ 150 & 1 \\ 151 & 1 \\ 152 & 1 \\ 153 & 1 \\ 154 & 1 \\ 153 & 1 \\ 156 & 1 \\ 157 & 1 \\ 158 & 1 \\ 159 & 1 \\ 150 & 1 \\ 161 & 1 \\ 162 & 1 \\ 163 & 1 \\ 164 & 1 \\ 165 & 1 \\ 166 & 1 \\ 167 & 1 \\ 168 & 1 \\ 167 & 1 \\ 170 & 1\end{array}$

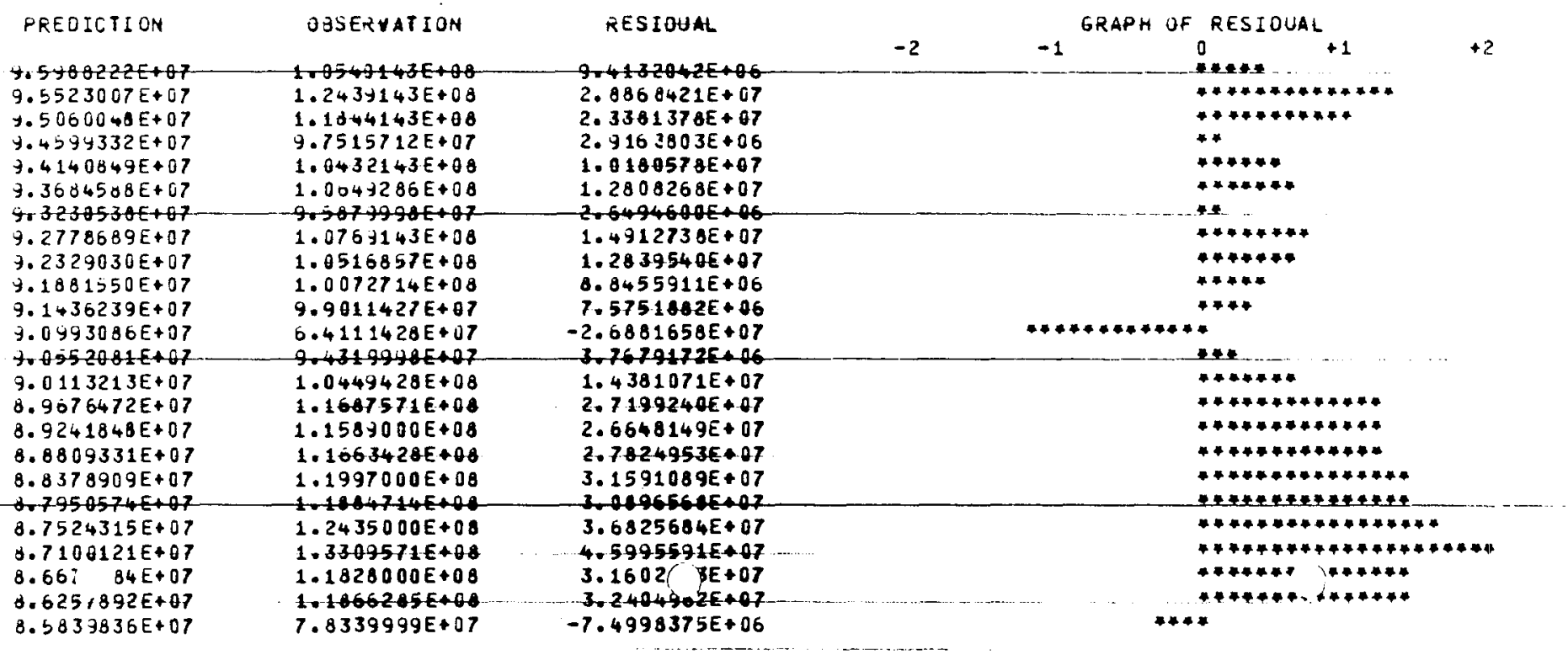




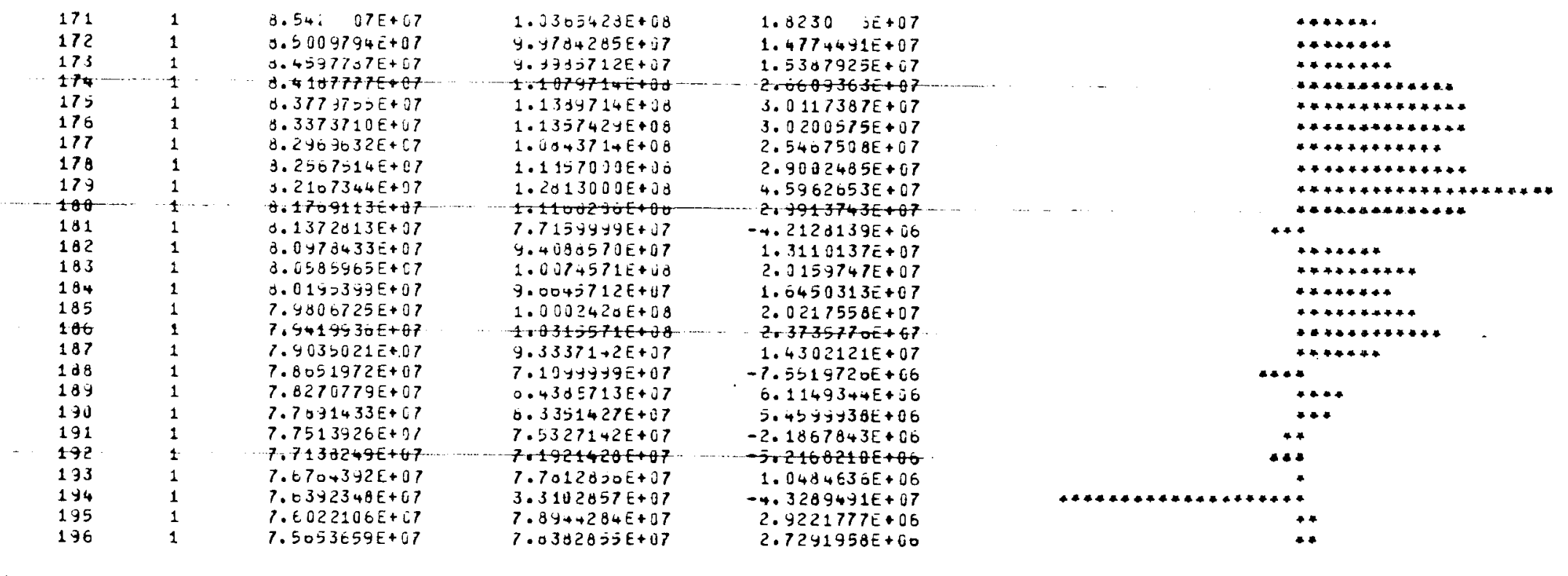

HONLINEAR REGKESSIGN -- BUFE 18

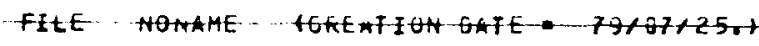

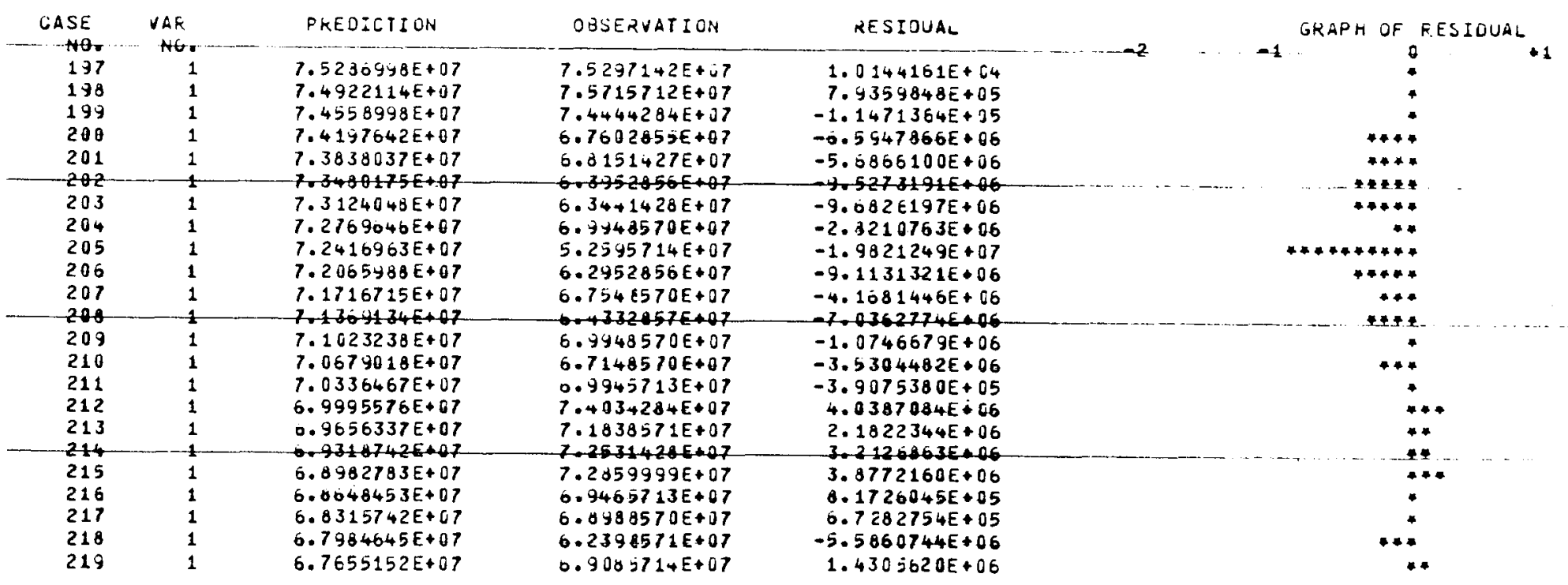




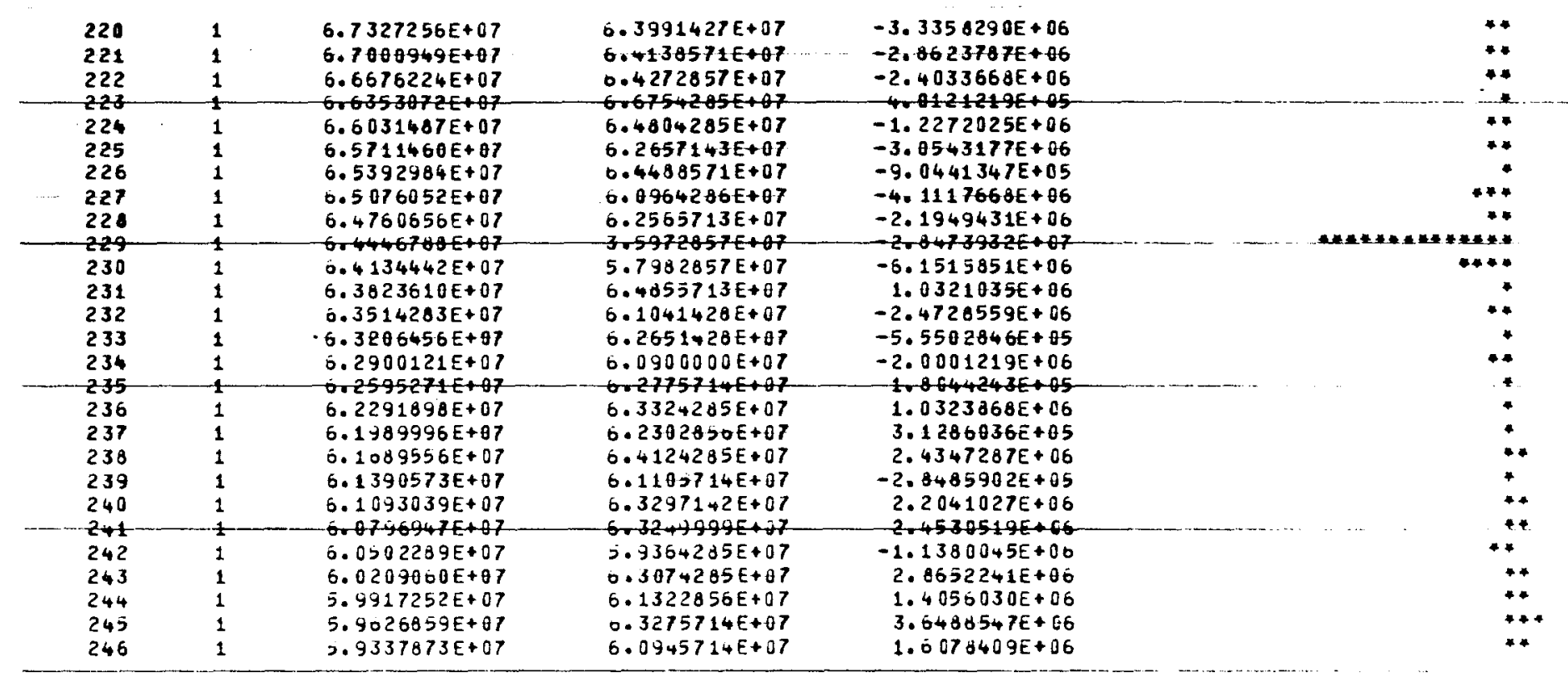

NCNLINEAR REGRESSICN -- BOKE 10

$79 / 07 / 25.08 .28 .54 . \quad$ PAGE

FIle NUNAME (CKeatiun DATE = 7y/07/25.)

$F I N A L$

$F \cup N O T I \cup N$

$\checkmark A L U E S$

A N O

RESIOJA I S

\begin{tabular}{|c|c|c|c|c|}
\hline NO. & NU. & & & \\
\hline 247 & -1 & $5.9030207 E+07$ & $6.3087143 E+07$ & $+.0308555 E+36$ \\
\hline $\begin{array}{l}248 \\
249\end{array}$ & $\begin{array}{l}1 \\
1\end{array}$ & $\begin{array}{l}2.8704045 E+07 \\
5.8+79290 E+07\end{array}$ & $\begin{array}{l}0.3228570 E+07 \\
6.0707142 E+87\end{array}$ & $\begin{array}{l}4 .+E+47+9 E+00 \\
2.2878517 E+06\end{array}$ \\
\hline 250 & 1 & $5.8195806 E+07$ & $0.1303571 E+07$ & 3. E927051E+00 \\
\hline 251 & -1 & $-5.7413815 E+87-$ & $6.05771+2 E+87$ & $2.0633269 E+06$ \\
\hline 252 & & $3.7633131 E+07$ & $5.0198572 E+07$ & $-7.4345597 E+06$ \\
\hline
\end{tabular}

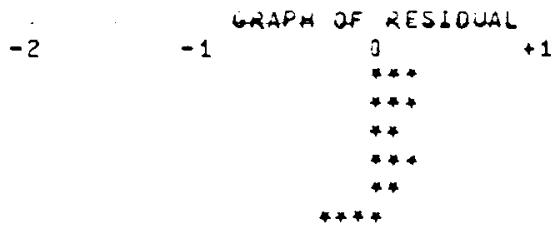

TIME SINCE END OF THE LAST ITERATION = 1.533 SECUNOS

$\begin{array}{lll}\text { TOTERATION } & 1.533 & \text { SECUNIOS } \\ \text { TOLTIAE } & 3.363 & \text { SELUNGS }\end{array}$


The linear progranning technique of Coats, Rapoport, HcCord and Irews (JPT, Dec.,1964), is used to deternine the aquifer influence functions fron field data. Several prograns have been written to take raw data and convert it into a tableau used by the K.P.0.S linear frogranning package, then extract the results and refornat it. The procedure is as follows:

1. INPUT DATA

The infut data nust follow the following arrangenent:

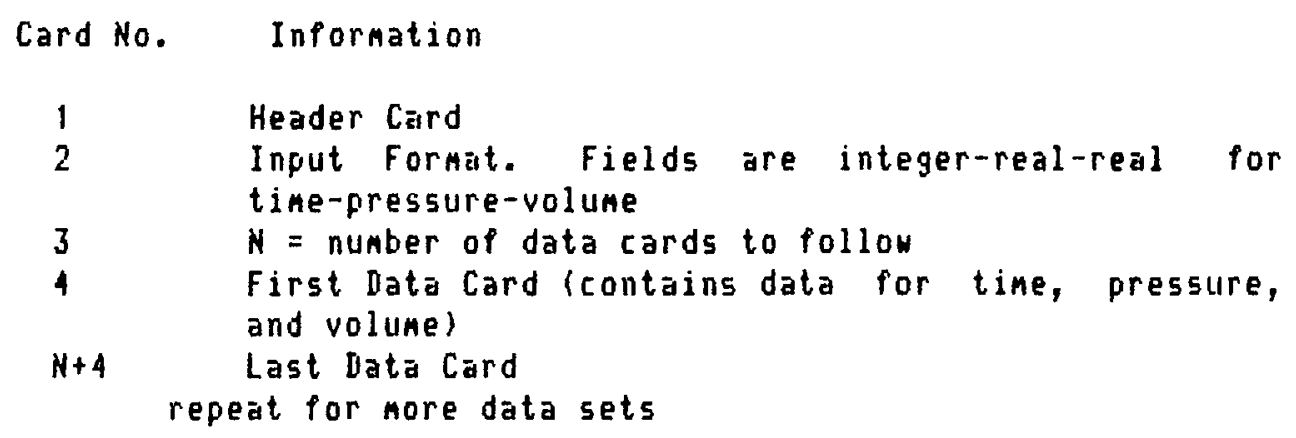

2. GENERATING THE INFLUENCE FUNCTION

The procedure to do this is sinfly:

GET, INFUNC. Or GET, INFUNC $/ U N=B K 0 Q 5 C$.

INFUNC, IN.

where iN is the file containing the input data as descritied above.

The results will be found in file OUT and are arranged as follows:

1) header card

2) card containing number of data points and fitness value RHO in $(15,5 X, F 17.0)$ field

3) N data cards in the format $(15,5 \times, 4 F 17.7)$ in order of tine, $F$, delta-F, $F, Q$.

4) E-0-F nark.

5) repetition of 11 to 3) for each data set

These results should be saved for future plotting. There is also a file named RESULTS generated which contains output from the H.P.O.S. frackage which should be sent to the line printer uith carriage control. 
3. PLOTTING THE INFLUENCE FUNCTION

To plot the influence functions generated atove, it is necessary to use the INFPLOT progran. The necessary libraries and object decks will trave been gotten by INFUNC. All that is necessary is to enter

\section{INFPLOT, OUT}

where OUT is the file generated in step 2 ) above. The progran should tie run fron a graphics terninal. Output can be sent to the GERBER filotter or plotted on a 4662 plotter. The progran will pronpt the user for the necessary information. 
Influence Function Programs

- PKOC, INFUNC, IN, OUT, RESULJS.

* THIS PFOCEOURE WILL TAKE RAW TIMEIPKESSURE JjLJME OATA ANO

- the lanear programing mlgokithm uf loats, ef́lal (1904).

* calling sequences begin, injuidc, jpricc, in, uut, fejults.

* WHERE:

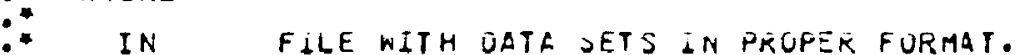

: ONT FILE WITH OATL DETS LN PROPER FURMATE

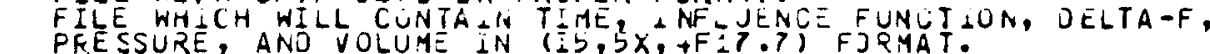

RESULT FILE WHICH WILL COHTAIN OUTBJT'FROY M.P.O.S. IINEAR FROGRAMMING PAC KAGE.

* COPAT INF4, OUTFUT.

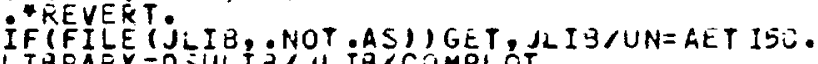

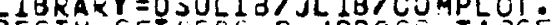

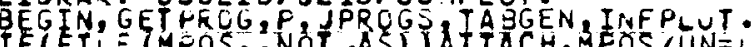

REWIND INP

SETTL, IOOD.

RETUZN,ZTAB.

TABGEN (IN,ZTAB)

COPY INF1.

MPOSIZTAB;RESULISI

CQPYINF? OA, JPF OC, RESULTS, IN, OUT .

IF (FILEIZ1Z3Z, ASIIFEVERT. ERROR ENCOUNTEREO.

CCPYIINF3.

RETURN, INF 1 , I NF 2 , INF 3 .

REVERT INFEUCINFUNC.

- OATA INFI

D.P. TABLEAU GeNEKATEU EIN LOCAL FILE CLTAB>

ENTERING H.F.O.S.

DATA, INF $\angle$.

M.P.O.S. RUA COMPLEIE. ERESULTS ARE EIN LOUAL FILE 〈QESU_TS〉

BEGIN D ATM

REFORMAT CCMPLETE, ¿NFLUENCE FUNOTZON PLUS ORIUINGL JATH ARE NOW

IN LOCAL FILE COUT D OATA SETS ARE EEPARATED GY E-J TF MAFKS.

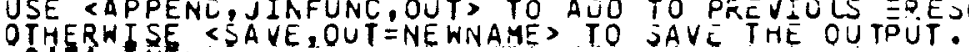

DATA. INF 4 .

PKUGRAHS ARE NOT HOKKING TEMPURARILY. CALL JEFF HT $75+-+515$ OR -4299 
- TABGEN

C

PRDGRAM TABGEN(INFUT, OUTFUT, TAPES=INPJT, TAPEG = OUTFUT) DIMENSION P $(300), Q(300), 3 U F F(8)$, FORMI $(0)$

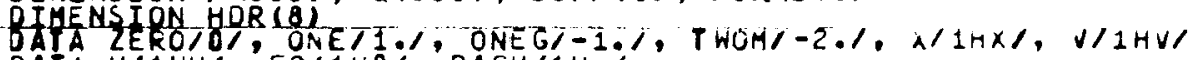
DATA U/1HU/, EQ/1HO/, DASH/1H-/

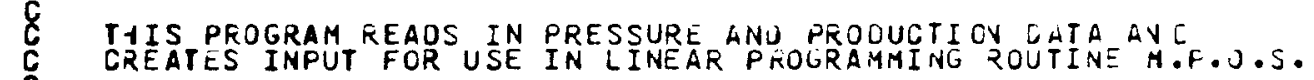

1 REAO(5,101) HCR

IF (EOF Y 51$) 99,2$

2 REAO (5,101) FORMI

101 FORMATIBAIO)

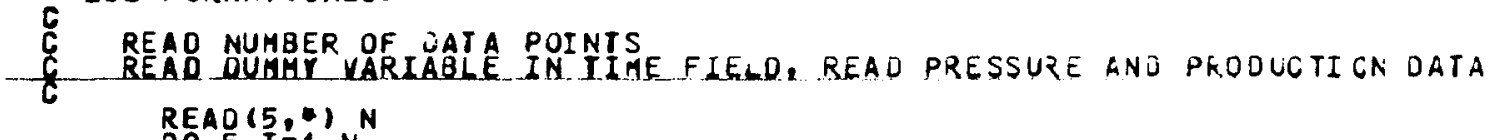
5 CONTINUE R.M I) IOUM, P(I), Q(I)

¿ SETUP INDEXES

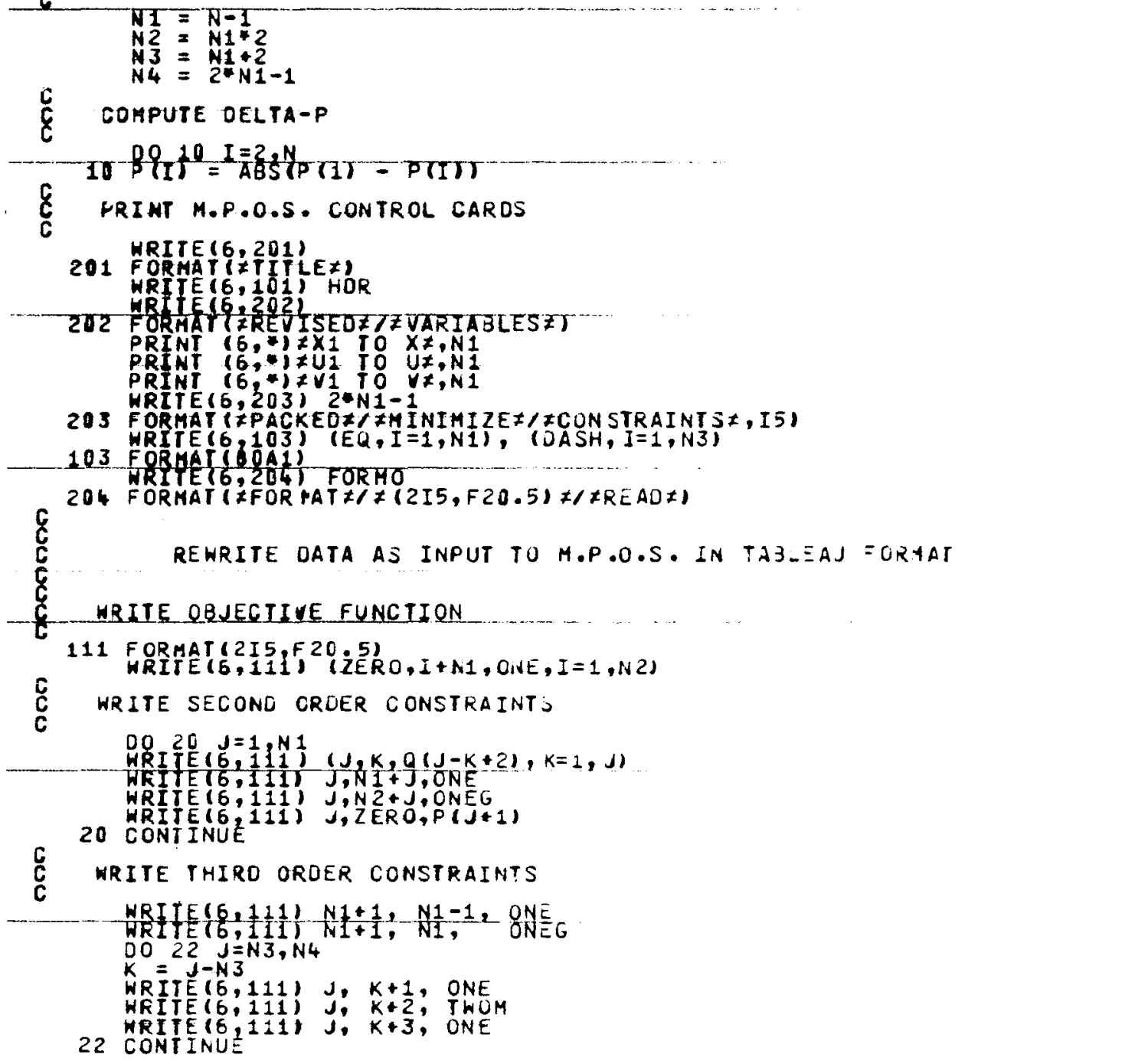


c

WRITE $(6,111)$ ZEKO, ZERO, ZERO

205 FOR MAT ( $X$ CPT IMIZE

99 REINO 6

STOP 
- INFPLO

PROGRAM INFPLOTIOUT, EXTFAP, INFUT, OU TPUT, TAPE1C=L, TAPES = INFUT,

* TAPEA=OUT, TAPET=EXTRAP,TAPEÓOUUTPUT,

PLOTS THE INFLUENCE FUNCT $A$ ON FOR GEOTHEZMAL FIELJ

TIME ANO VALUE OF THE FUNCTION AS GENERATED OY PROGRAM CLFM) ARE REAL ANO PLCTTEO ON TEKTRONIX 4662 PLOTTER

LQGICAL UNITS FOR INPUT IOUTPUT!

LUN O REACS INFLUENCE FUNCTION AS GENERATED $3 Y$ PROCEDURE CREFORM>

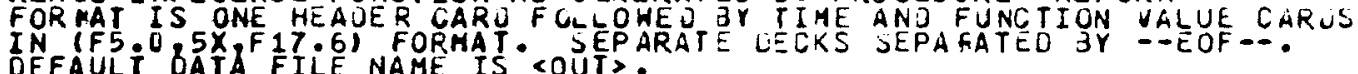
DEFAULT BATA FILE NAME IS <OUT>

LUN 6 WRITES HESSAGES TO OPERATUR ON FILE SCUTPUT,
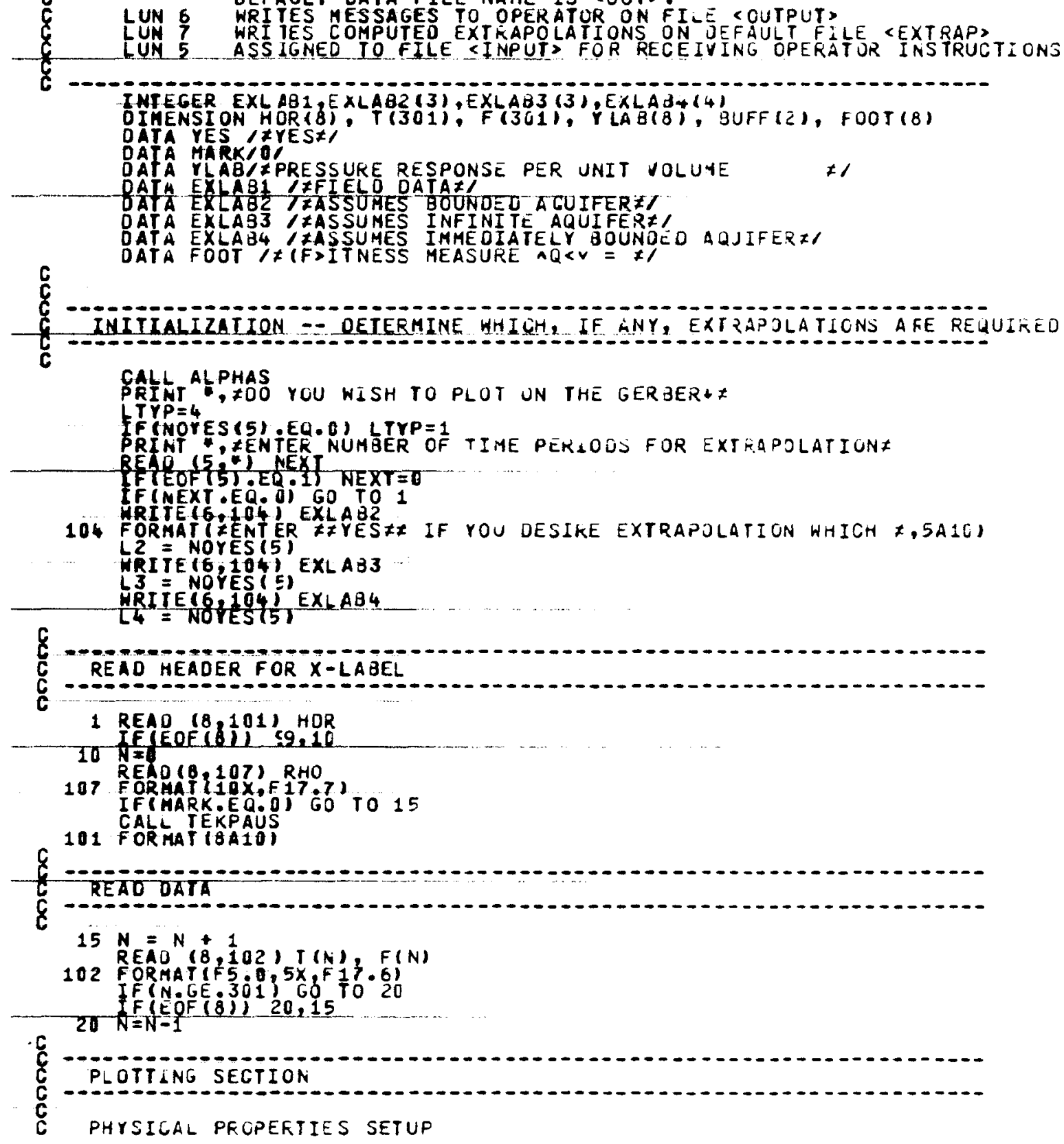


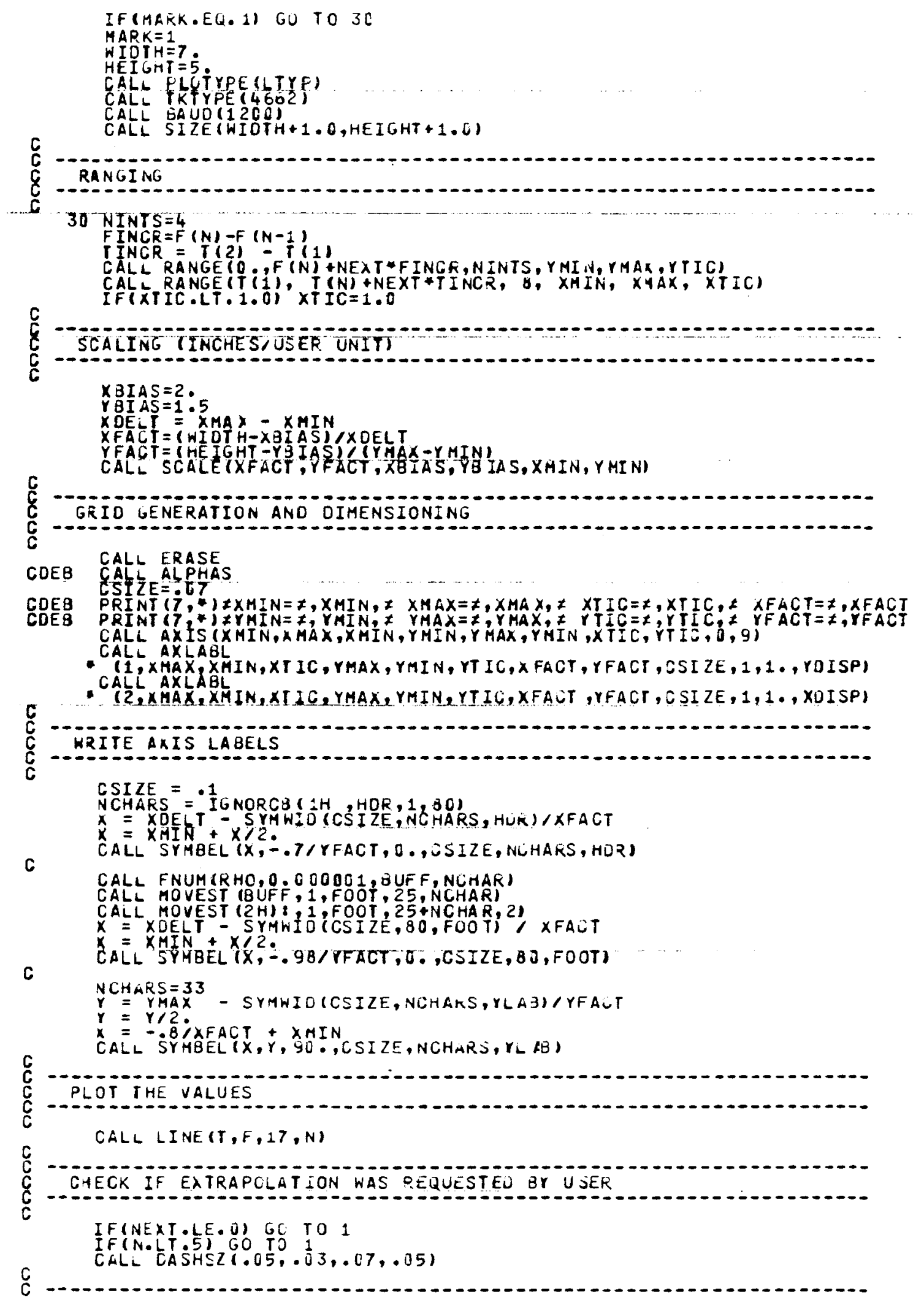




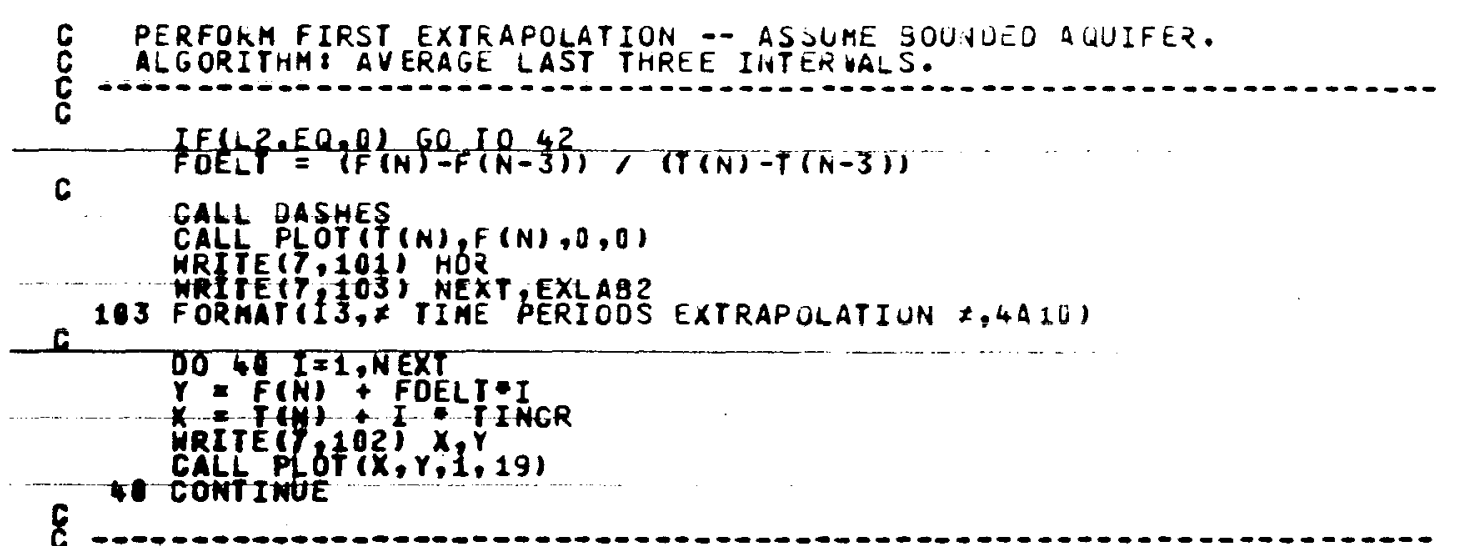

PERFORH SECONO EXTRAPOLATION ASSUAE INFINTT TQUIFER

ALGORITHA HUTCHINSON A SIKORA, 1959, P. 172, EQN. 16

42 J (L3.ER.OU) 60 10 52

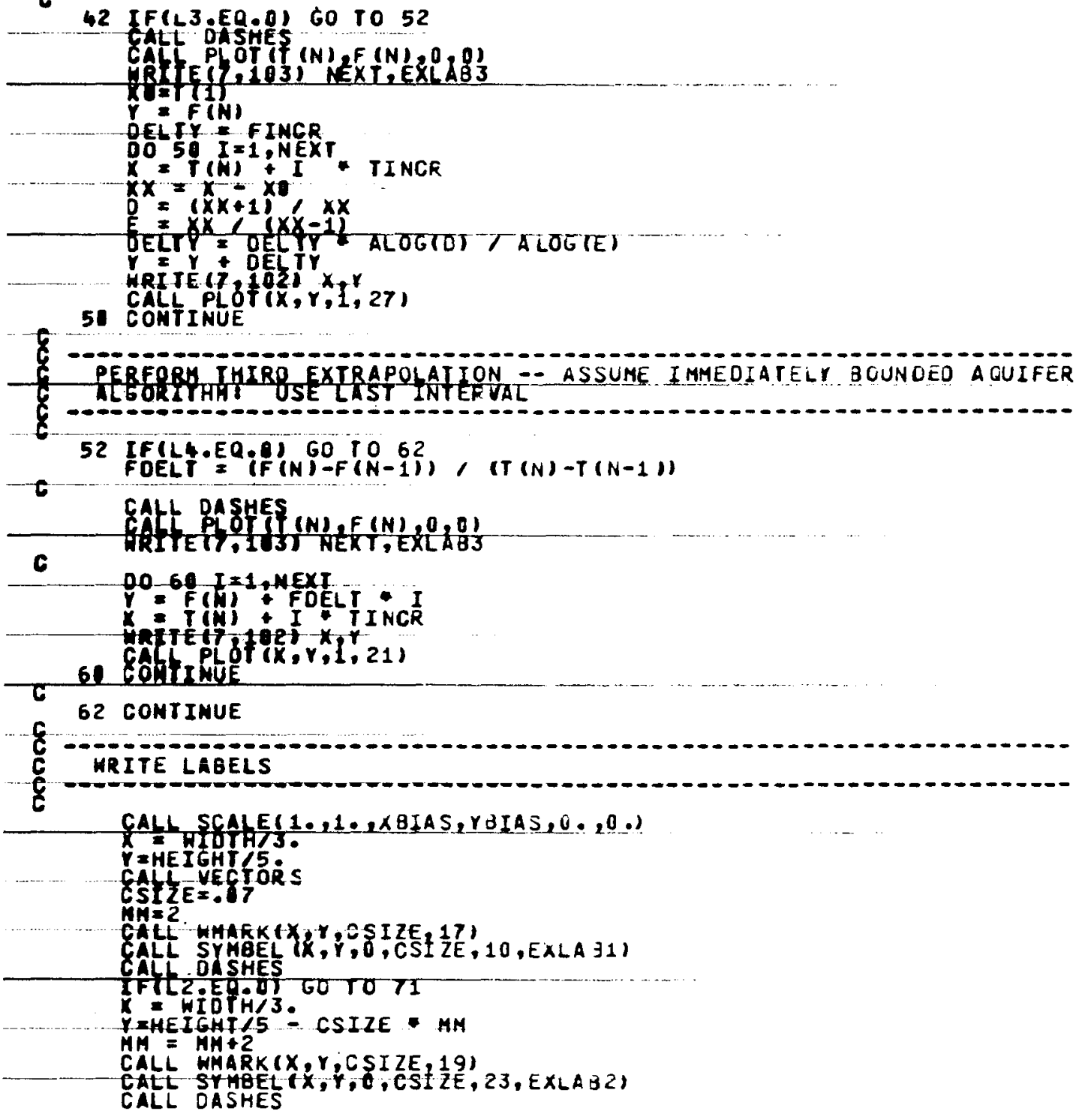


71 IF (L3.EQ.O GO TO 72 $X=$ HIOTH/3. $M M=H E I G H T$

CALL WMARKIX,Y,CSIZE, 27 CALL JASHES

72 IFIL4.EQ.0) 60101 $X=$ WIOTH/3

$\hat{Y}=$ HEIGHT/5 - CSLZE* MM

CALL WYARK $X, Y, O S I Z E, 2 I$

CALL SYMBEL $(\lambda, Y, O, C S \perp Z E, 35, E X L A B 4)$

C ENO

99 CALL PLOTENC

999 STOP XENO INFPLOTF 


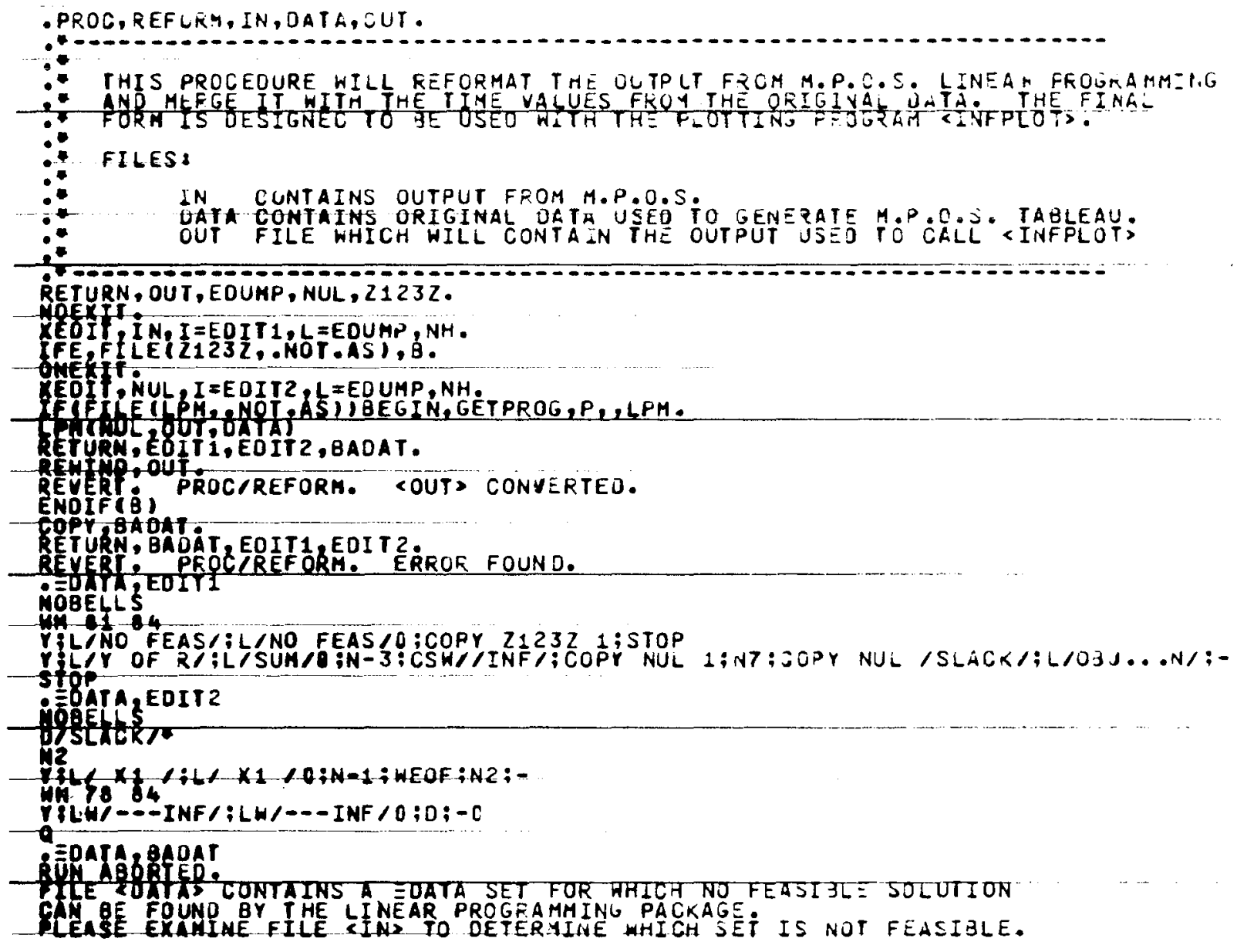




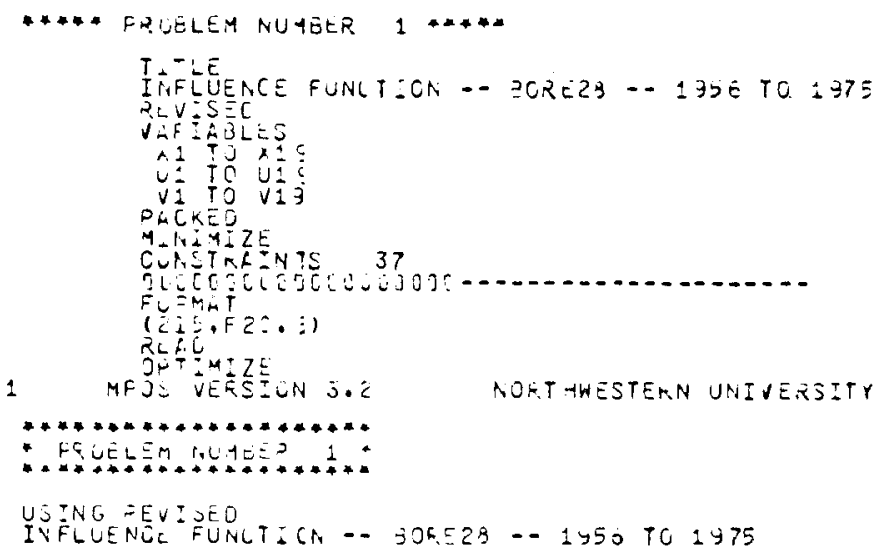

\begin{tabular}{|c|c|c|c|}
\hline 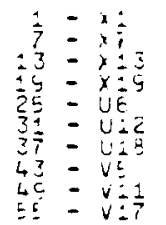 & 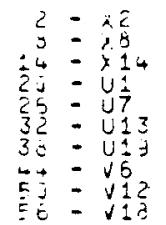 & 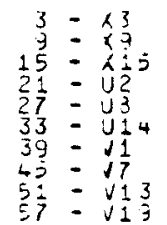 & 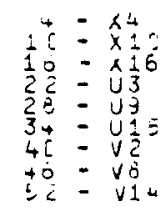 \\
\hline
\end{tabular}

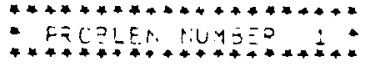

USANG FEUISEQ

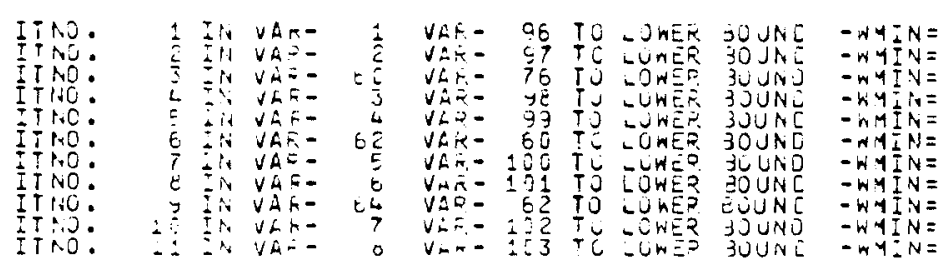




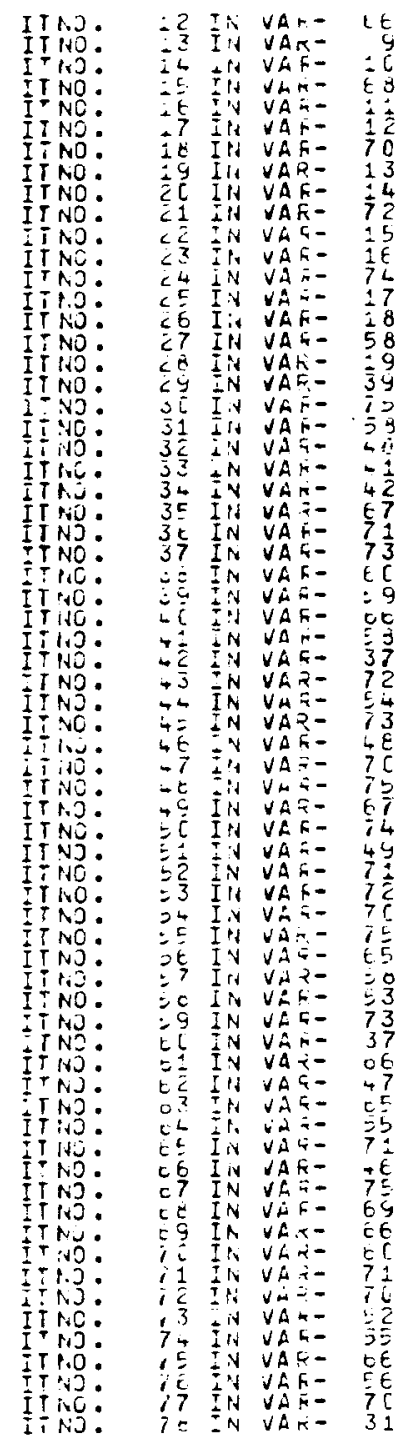

VEP- EU TO LOMEP JUUND

VAE= 1 C4 TU LUhEO DOUND VAT- ES IU LOWEE JOUND VAF= 106 TL LUWE 30 UNAC VAL- 167 IC LUNER BOUNL VAK- IC 3 TO LUWER TOUN VAD - IOS TO DOWER BOUNO VAR- 70 TU LORER BOUNJ WALE - 123 TC ZOWER JUUNO VAF - 72 TO UWEP 30 WN VAK= $1 \frac{2}{9}$ TH LUWER BOUNC VAF - 74 TO LOWER JOUNE VAF- 54 TO LGWER JOUN MAF= 34 IU EOhER 3OURA VATE- 75 TS LOWER JOUND VAT= 79TS LUWE $30 \cup N E$ VAR- 93 TL ECWER 30 JNO VAF- 92 TO LCWER JOUND VAE- 80 TC LOWER EDUNE WLN- O5 TO LOWER JOJN VAF- 60 TC LOWEP 30 UND VAF- 57 TL LOWEF $3 U$ JNL VA-E 73 TJ LUWEO BOUNL VÄ - 5 S TU LUWER 30 UN VAF $7 \frac{1}{2}$ TO LUWER ZOUND VAT:- T2 TU LOWER JJUND Jiri- EÓ TE LUWEa JUURO TEX - $7 D$ TU - UNEP 30 UN var= 73 tJ LOnER joUñ VAR- 67 TU LUWER 3DUNO VAC- 75 IO LUWER JOUN VAFE 37 TU -CWER 30 UN

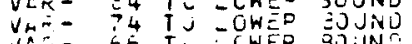
VAF= 75 IU LCNER OUJNO VAF- 75 TU LOWER BUUND AAFE 58 TC - LWER JULNC MAF- 65 TOLOWER 30 UNO VAF- $\rightarrow 3$ IC -OWE $3 J U N O$ HE- t6 T. - JWE 30UND VA- 37 I L LOWEX JUUNJ VA Z 55 TC LOWEP 3OUND YAE- 71 TU LONEF JOUNE VAE- 81 IU $=O \mathrm{HER}$ 3OUNC VAR: ES TU -OWER BJUNE VIE: $5 Y$ TOLOWE उUUNE SAE- 7O TUL LUWEP DOUNE VAT- 65 TJ LUWEK BOUND VAF: 66 TO LCHEQ 30UND

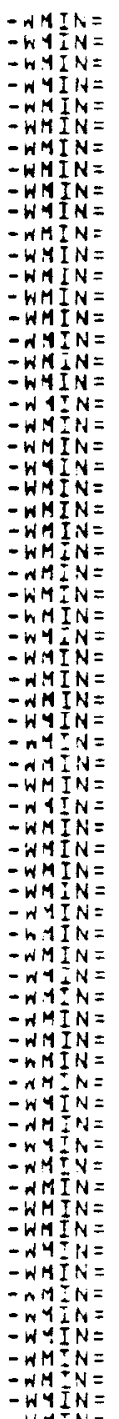

$-.0969 E 2$ -.096962
-.090962 $-.084+25$

$-.0844<5$

$-.078604$

$-078604$

$=: 078644$

$-.073500$

-.069205
-.0692005

$=.366265$

$-.065625$

$\because 035495$

-.03284

$=-1328131$

$\because-\because 19 y 15$

$-.009395$

$=: 084806$

$-.0033 y 4$

$-.003148$

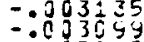

$\because 30072$

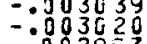

-

$\because 001733$

$\because 0314 y 3$

$\because 001321$

-.001276

$\because 001174$

- $0020 y 3$

$\because 301 j 76$

$-.00105 \mathrm{C}$

$-0.1020$

-.0j1013

$\because j 00 y y z$

$\because 0009$

-.00807

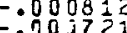

$\because 000706$

- 0 บे 6

$-.0005 \% 1$

$\because 000024$

- 007400

$\because 000403$ EATERING FHESE I =

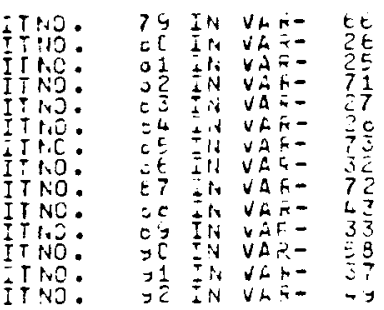

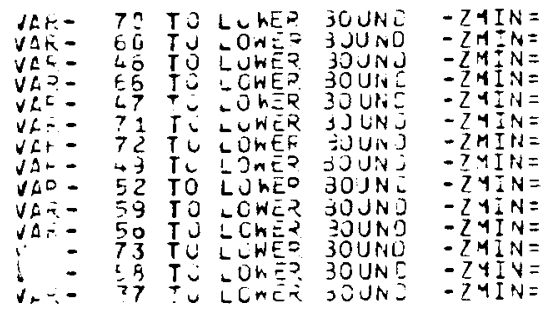

-239.326532
-281.505300 -247.772803
$-2+7.727205$

- $51.7041 \mathrm{e}$

$-241010305$

$-224.513152$

- 21 E. 595545

- ic. 


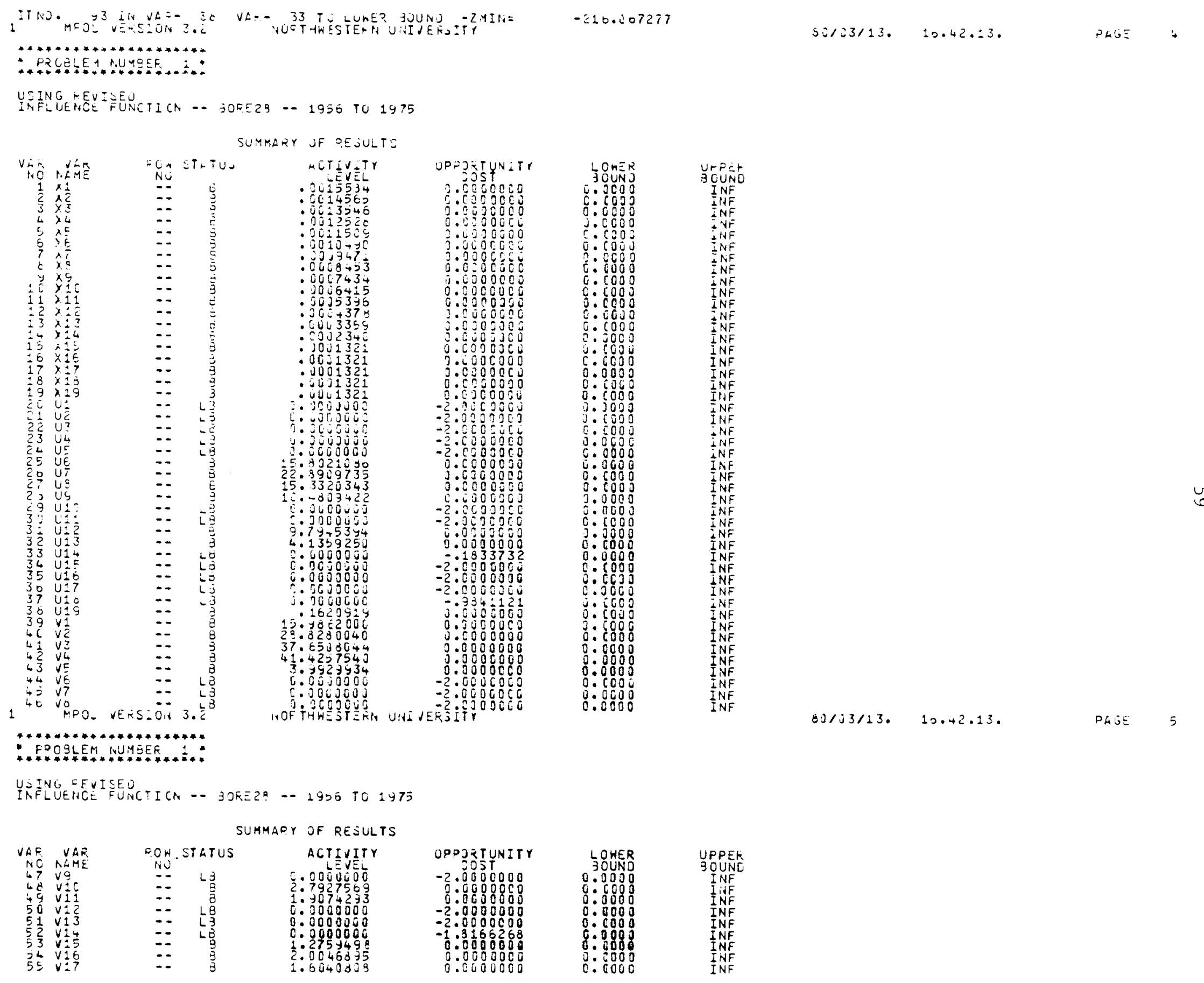




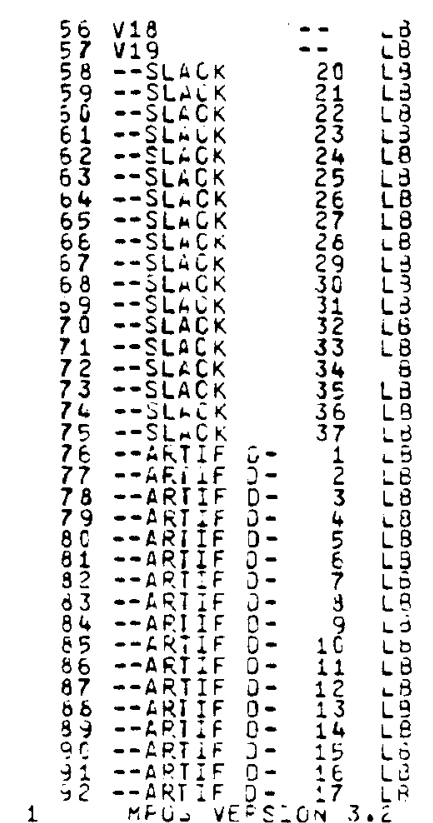

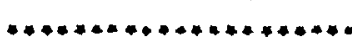
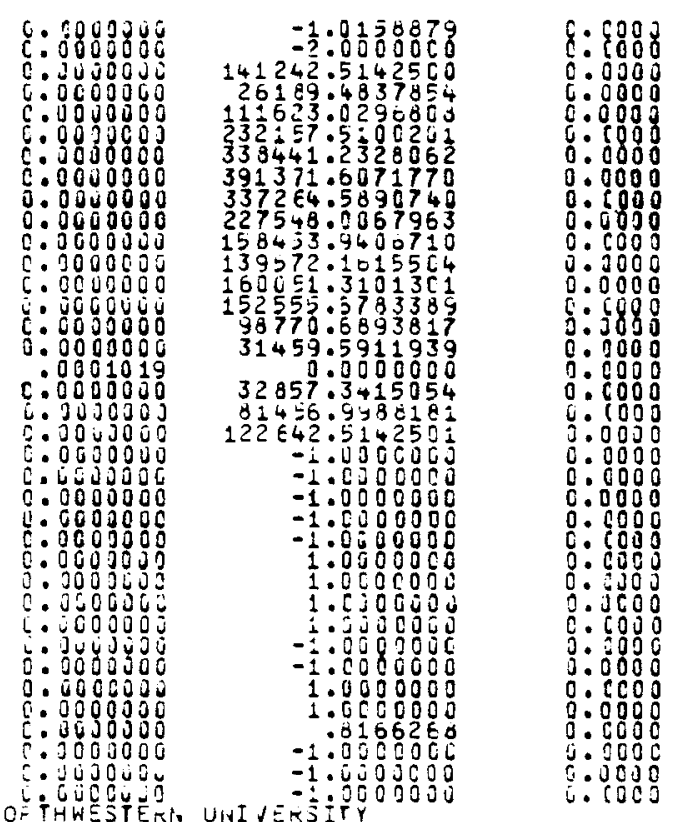

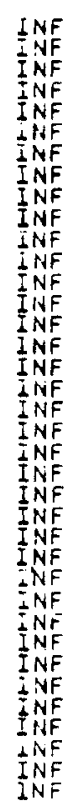

$80 / 63 /: 3 . \quad 10 .+2.13$

PAGE

USING REEIDED

\section{SUMYARY OF RESULTS}
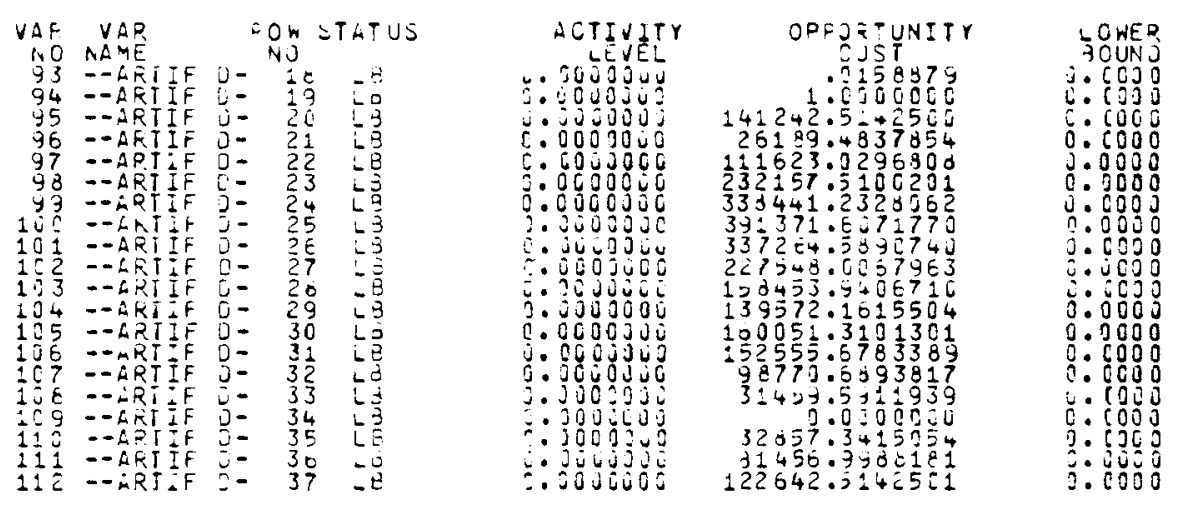

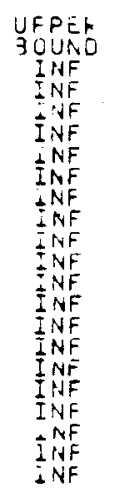

YINEMUM VALUE OF THE OBJECTIVE FUAUTION=

216.067277

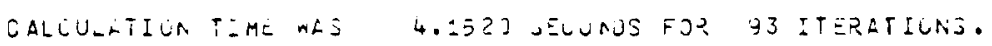

OATA DTCRAGE MERUMYY $=0.04564$ (OCTA-) TOTA: MEMORY $=245003$ (OCTAL) 
Linearized Free Surface Programs

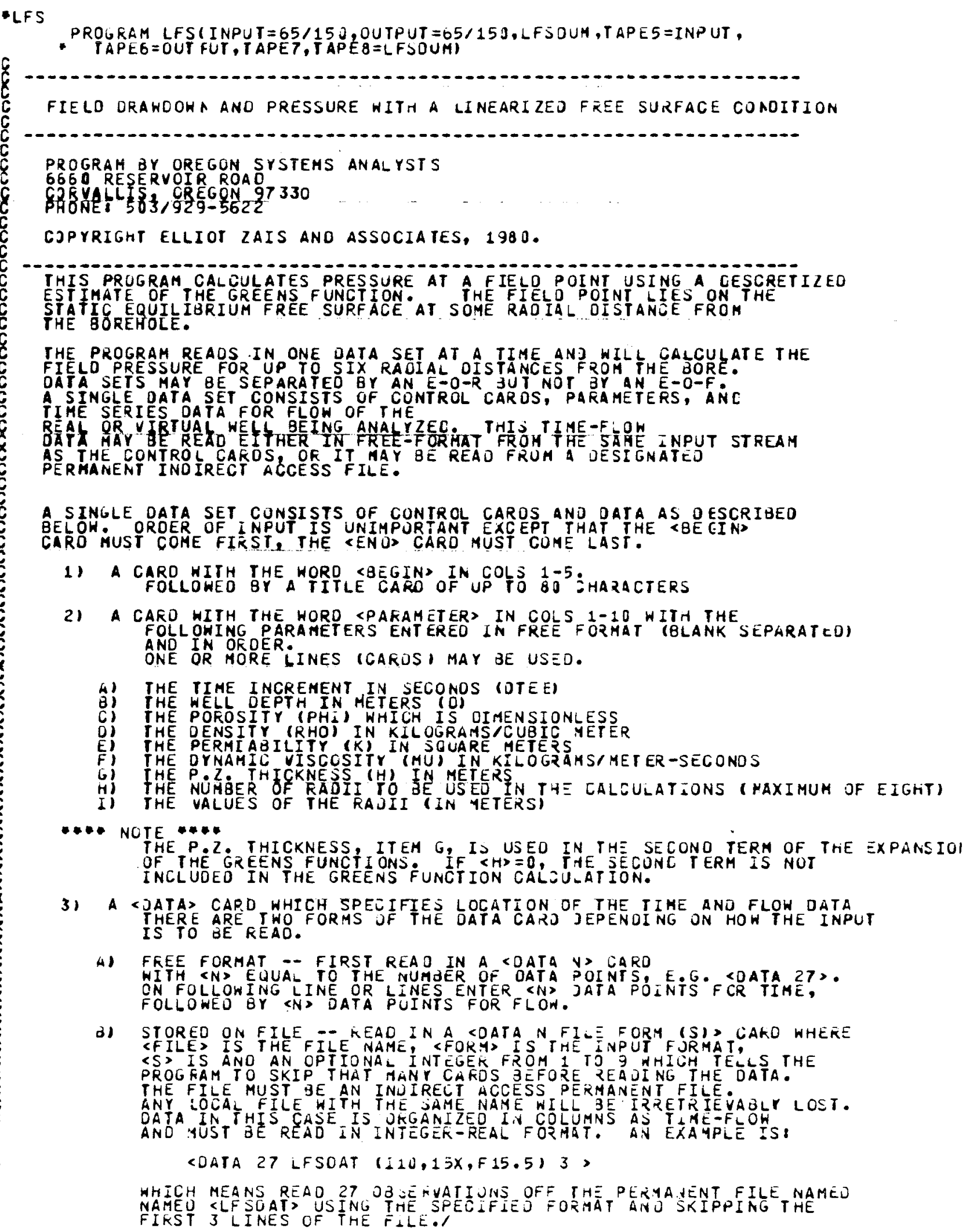

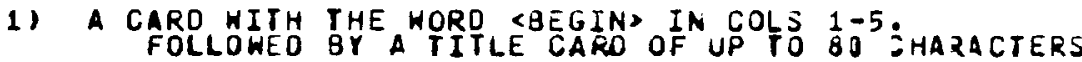

2) A CARO WITH THE WORO SPARAMETER> IN COLS 1-10 WITH THE FOLLOHING PARAMETERS ENTEREO IN FREE FORMAT (BLANK SEPARATCO) AND IN ORDER. ONE OR MORE IINES ICARUSI MAY BE USED.

A) THE TIME INCREMENT IN SECONOS (DTEE)

Q) THE WELL DEPTH IN METERS (O)

C) THE POKOSITY (PHI) WHICH IS OIMENSIONLESS

D) THE OENSITY (RHO) IN KILOGRAMSICUBIC METER

E) THE PERMIABILITY (K) IN SGUARE METEZS

F) THE DYNAMIC VISCOSITY (MU) IN KILOGRAMSIMETER-SECONOS

G) THE P.Z. THTCKNESS (H) IN METERS

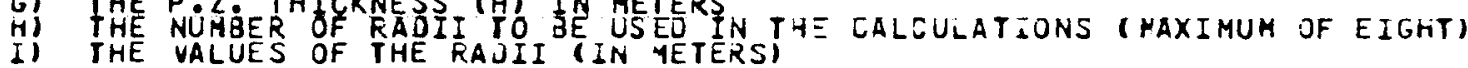

$* * *$ NOTE ****

THE P.Z. THICKNESS, ITEM G, IS USED IN THE SECONO TERA OF THE EXPANSIOI OF THE GREENS FUNCIIONS O IF CH> OO. THE SECONE TERM IS NOT

3) A CDATA> CARD WHICH SPELIFIES LOCATION OF THE TIKE ANO FLOW DATA ISERE ARE TWO FORMS OF THE DATA CARD JEPENOING ON HOW THE INPUT

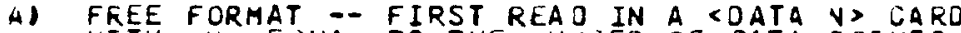
WITH ¿N> EQUAL TO THE NUMJER OF OATA POINTS, E.G. ¿DATA 27>. ON FOLLOWING LINE OR LINES ENTER KN> JATA POINTS FCR TIME, FOLLOWEO BY SN D DATA PUINTS FOR FLON.

3) STORED ON FILE -D KEAD IN A COATAN FI E FORM (SID CAKO WHEKE ¿FILED IS THE FILE NAME, CFORMP IS THE INPUT FURMAT, ¿S? IS ANO AN OPTIONAL INTEGEK FROM 1 TD 9 WHICH TELLS THE PROG FAM TO SKIP THAT MANY CAFDS 3 EFORE REA UI NG THE DATA. THE FILE MUST BE AN INUIRECT ACCESS PERHANENT FILE ANY COCAL FILE HITH THE JAME NAME WILL 3E IRRETRIEVAOLV LOST.

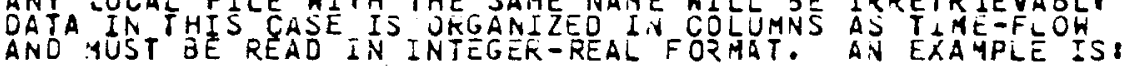
CDATA 27 LFSOAT (I10,15X,F 15.5) 3)

WHICH MEANS READ 27 OZ SERVATIUNS OFF THE PERMA.HENT FILE NAMED NAMEU SLF SGAT> USING THE SPECIFIED FORHAT AYU SKIPPING THE 


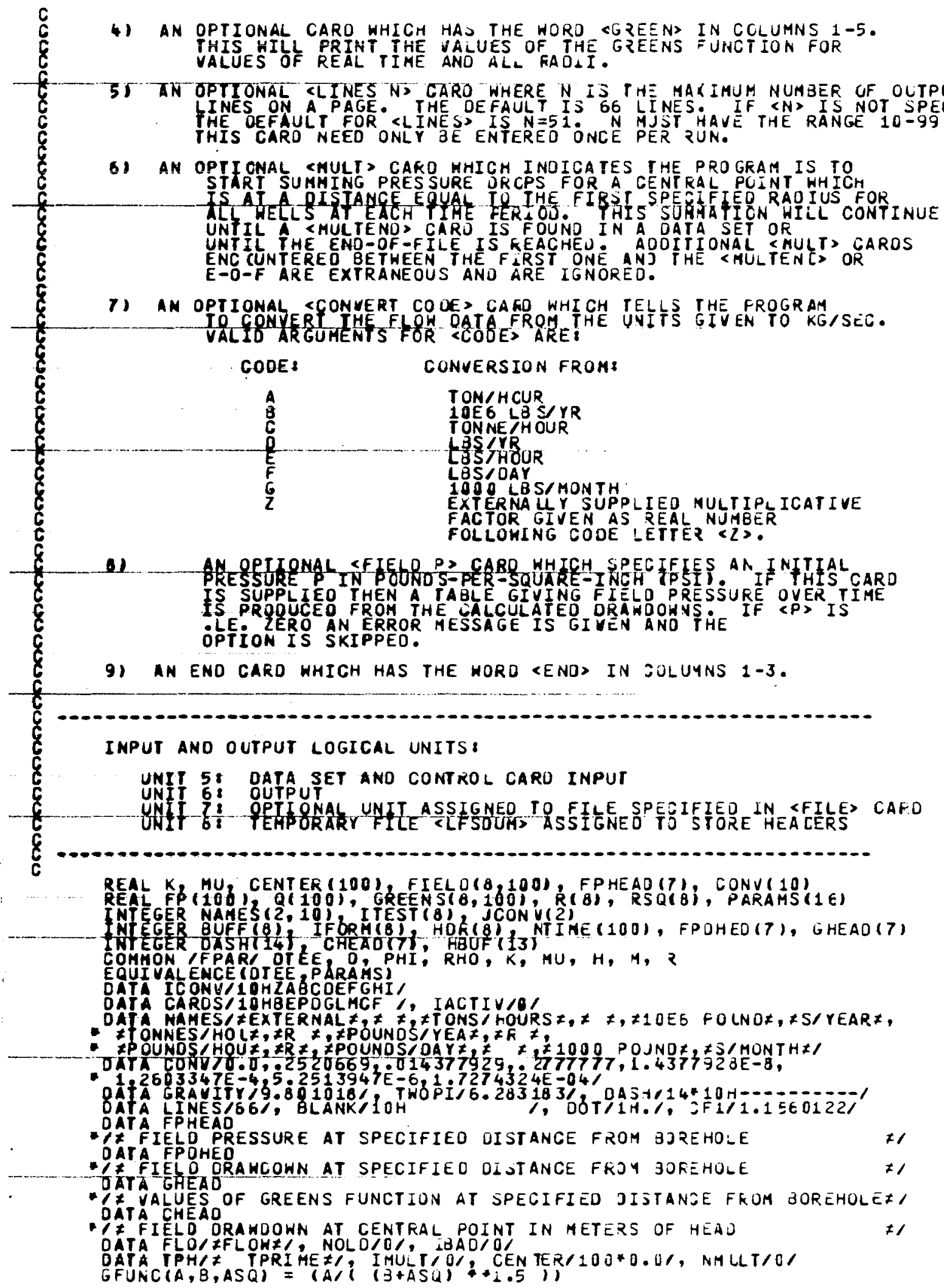




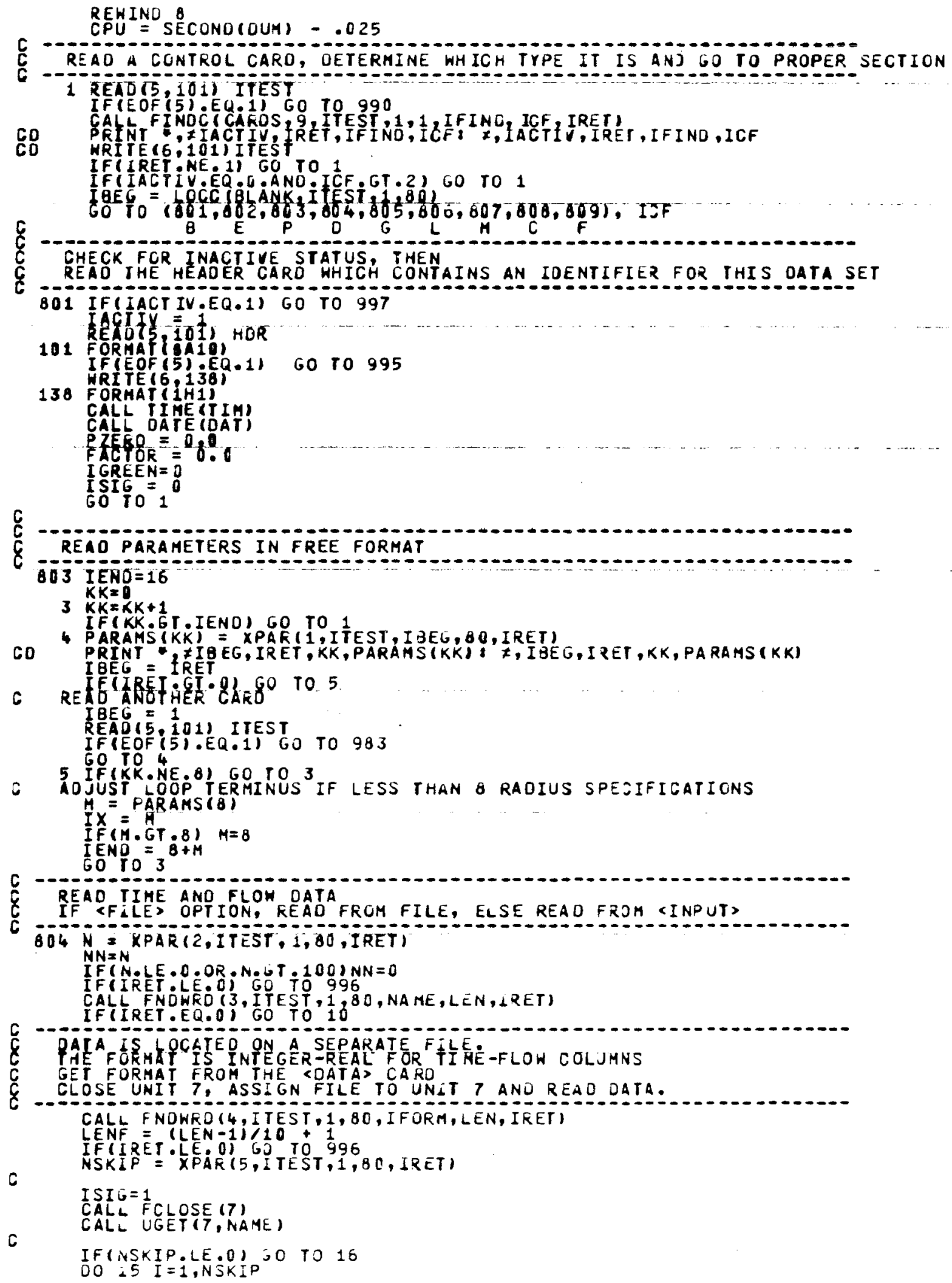

REHIND $\theta$ 
REAO (7, 101) DUMMY

15 CONTINUE

c

REAR (7FFEQRM) (NTIHE (I) $Q$ Q $(I), I=1, N)$

GO To 1

c

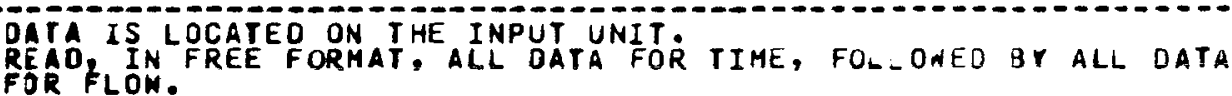

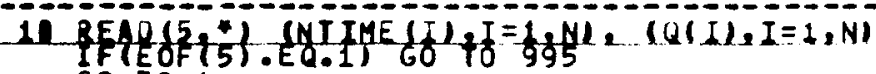
60 To 1

C
C
CGREEMI CARD

OA I GREEN $=1$

005 IGREEN=1

C

806 LINES $=$ XPAR(2,ITEST, 1,80, IRET)

\&

IF (I COMPAR(7HMULTENO, 1, ITEST, 1,7).EQ.0) I MULT =2

$$
\text { (6. }
$$

G0 fo

CCONVERT> CARD

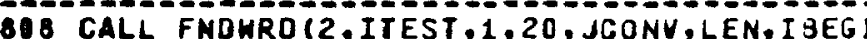

IF IIBEG.EQ.0.0R.LEN:GF.1) GO TO 998

CALL FINDCIICONV, 10, JCONV, 1, 1, I FIND, NAMEF, IRET)

IFTIREF GT I T GO TO 996

FAGTOR = GONY (NAHEF) 37

FACTOR = XPAR(3, ITEST 1,80, IRET)

37 IF TRET 36 LE

36 Q (I) $=Q(1)$. FACTOR

c. 60 10 1

SFIELOO CARO

809 PZERO = XPAG(2ITEST, 1 OO, IRET)

IFI IRET.LE.O) GO TO 986

GO TOE RO.LE.B) TO TO 980

$$
\frac{c}{c}
$$

AATOATORY CENDS CARD START ANAL YSIS

602 If IACTIV.E0.0) Go TO 997 IF IACTIV:LT:O) GO TO 1

\& CALCULATE SQUARE OF RAOIUS

C - IFINR.EQ.0) GO TO 390

DO 22 IRAD $=1, M$

22 RSQ(IRAD) = R(IRAD) * R(IRAD)

C CALCULATE SINKING VELOCITY, W.

C IF (HU,EQ,O,OR,PHI,EQ.0) GO TO 994

C $=$ (K GRAVITY RHO) (MU *PHI)

C CALCULATE GREENS FUNCTION FOR VALUES OF REAL TIME T ANU ALL RAOII. IFIRHO.EQ.OI GO TO 99 i

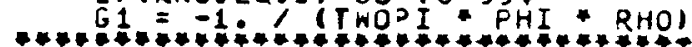

C LOOP DVER ALL TIME FERIOOS 
c

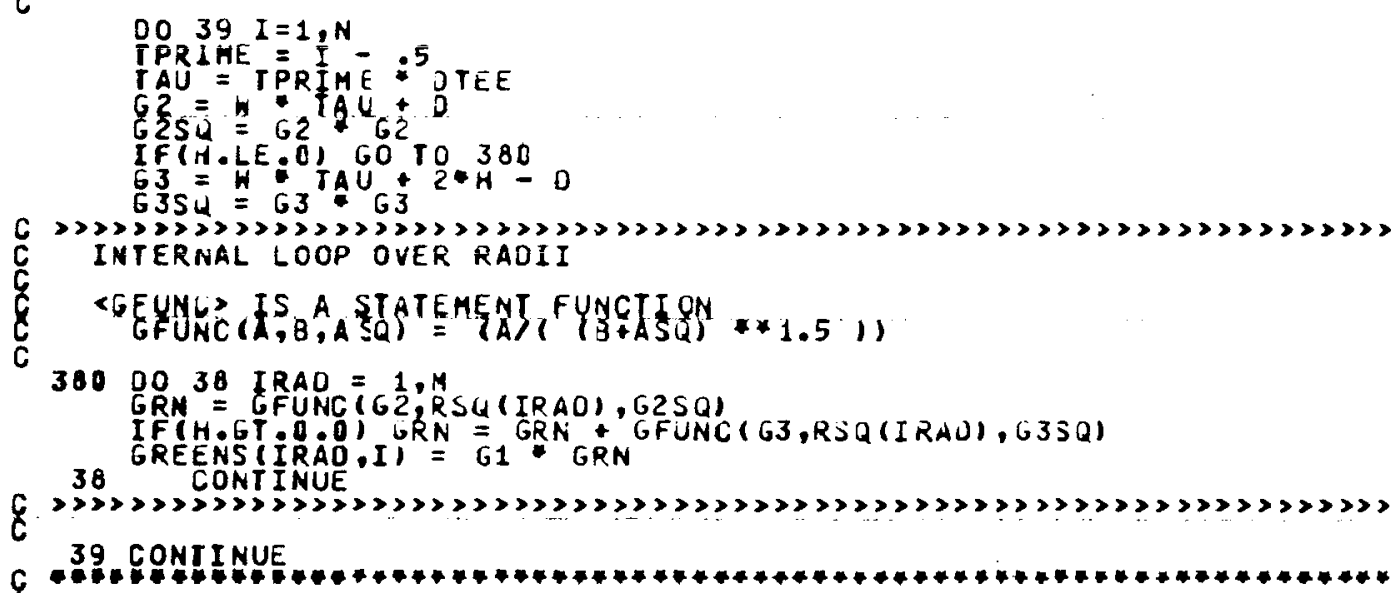

PRINT INITIAL TIME AND HEADER

398 CALL PEJECT (D)

NEEO $=27$

WRITE $(6,102)$ DASH(1), OASH(1), HOR

1 B 2 FORMAT

- I1X.A10,z FIELO POINT PRESSURES WITH LINEARIZEJ FREE SURFACE*,

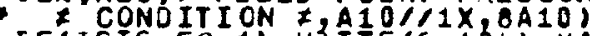

IF ISIG.EQ. 1) WRITE (6, I G 4) NAME, (IFORM(I), I =1,LENF)

104 FORHATY; I ME AND FLOW DATA REAO FROH FILE XEF,

IF (NSKIP.GT :O) PRINT *, \#FIRST $\neq$, NSKIP, $\neq$ CAZOS WERE SKIPPEOA

IF (ISIG.EQ.0) HRITE (6,105)

105 FORHAT I F TIME AND FLOW OATA READ FROM INPUT STREAYFI NAM = LOADCH (ICONV, NAMEF)

IF (FACTOR.NE.O) WRITE (6,130) NAM, (NAMES (I, NAMEF), I=1,2)

130. FORMAT IY FLOW DATA WERE CPNVERIEP FRQM TYPE Z2Z1,2H $(, 2 A 10,1 H 1$, IF(PZERO.GT.0.0) HRITE $(6,131)$ PZERO

131 FORMAT

* ijz fielo pressure tadle is baseo un an initial pressure atz,

- $\neq$ BOREHOLE AT TIME ZERO OF $, F 12.2,7$ PSI $\neq 1$

WRITE $(B, 103) N, O T E E, D, P H I, R H O, X, M(, H, H, I X, R R(I), I=1, M)$

103 FORMAT $\% 1 \%$ INPUT PARAMETEKS: $1 \% 1$ IP,

* TT5: :

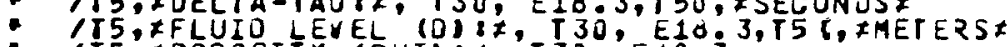

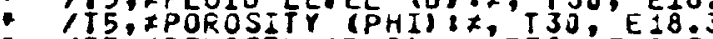

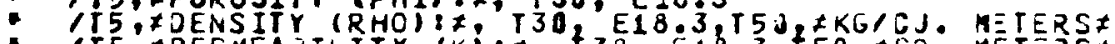

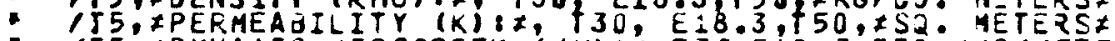

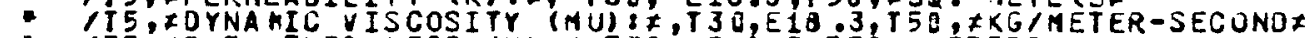

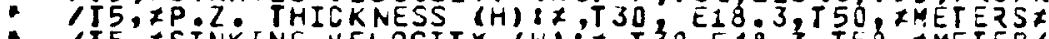

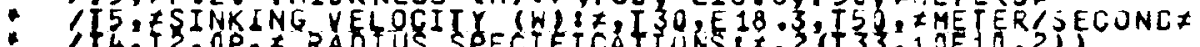

IF (IX G T

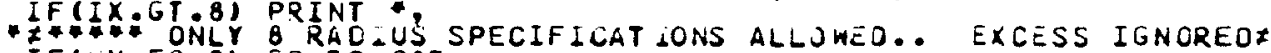

C IF (NN.EQ.C) GO TO 985

HRITE GREENS FUNCTION RESULTS

IFTIGEEN

WRITEIG, IIG)

$N E E U=N E E D+N+7$

CALL PEJECT (NEE), LINES, 6 )

WRITE $(5,118)$ HD?

WRT TE $(6,112)$ DASH

WRITE $(6,106)$ TPH, GHEAD

WRIIE (5:112) OASH

WRItE(E: II\}) (R (IRAD), IFAO =1,M)

WRITE $(6,1,12)$ OASH

116 FORMAT $(1)$

C

OO $42 I=1, N$
TPRIME $=1-.5$ 
WRITE (6,115) NTI ME (I), TPRIME, (GKEENS (IRAO, I), I YAD =1, Y)

115 FORMAT (I10,F13,1,8 (P1E13,3)!

42 CONTINUE

HRITE $(6,112)$ DASH

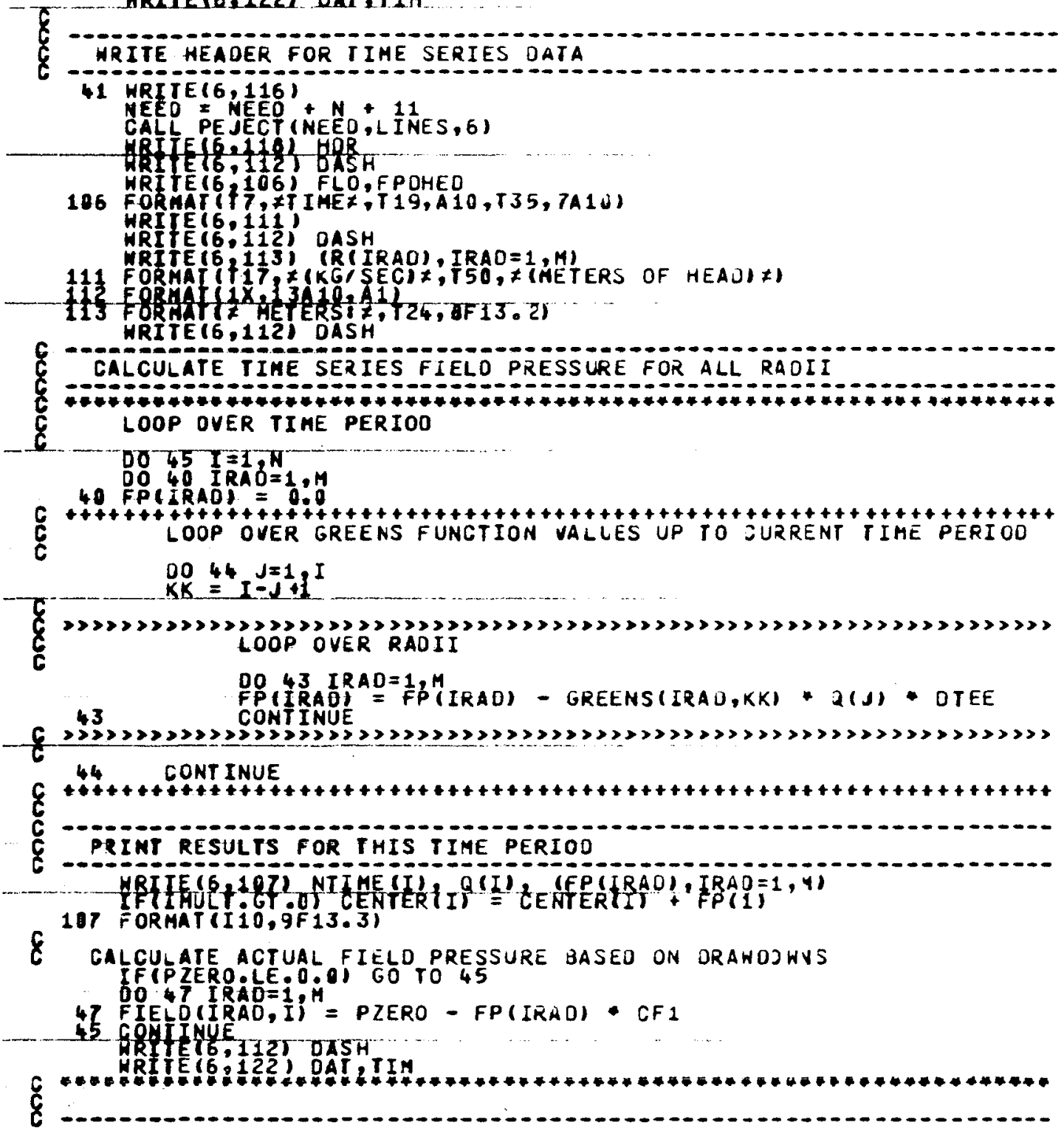

PRINT RESULTS FOR ACTUAL FIELO PRESSURE

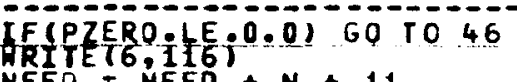

NEED = NEED + +11

CALL PEJECP (NEED,LINES, 6)

WRIIE 6.118 ) HOR

HRITE $(6,112)$ DASH

HRITE $(6,106)$ FLO,FPHEAO

HRITE 16,136

FORHAT(IIT, $7(K G / S E C), I 50,7$ (POUNOS PER JQUARE INOH) \pm )

WRI E $(6,112)$ OASH

WRITE $(6,113)$ (R (IRAD), IRAD $=1, M)$

WRITE $(6,112)$ OASH

$0060 \mathrm{I}=1$ M

60 CONTINUE

WRIIE (6,167) NTIME (I), Q (I), (F+ELO (I KA O,I), I RAD $=1, M)$

WRITE $(6,112)$ DASH 


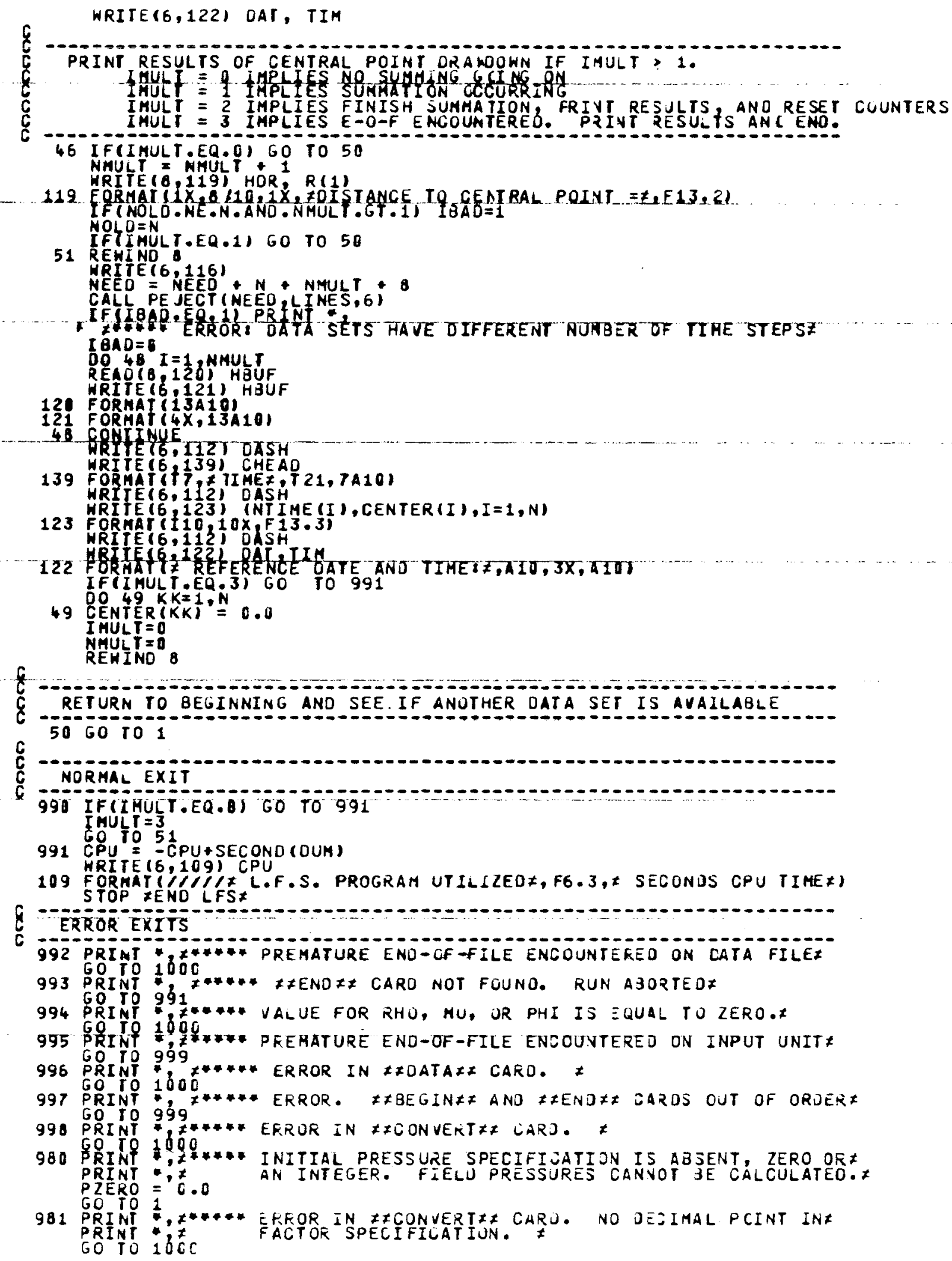




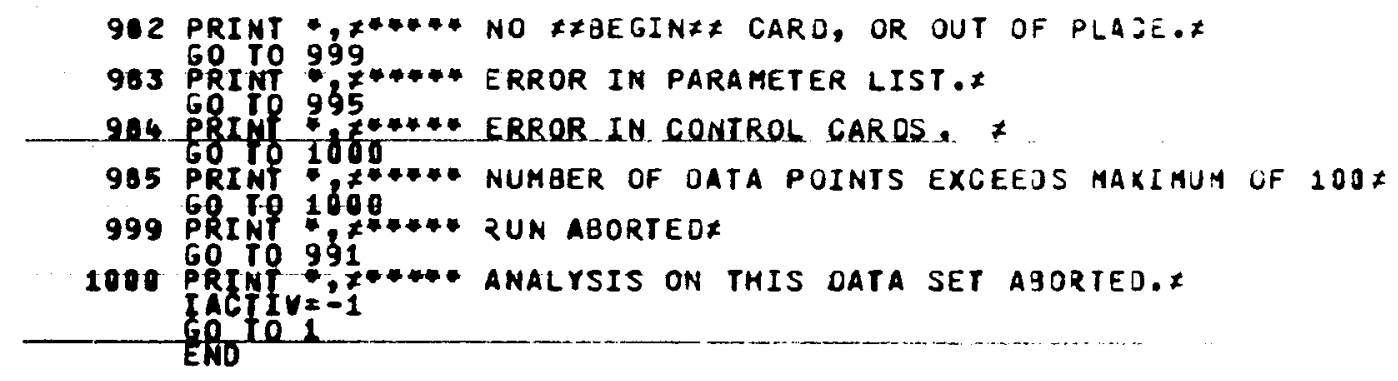


-...-...- FIELO POINT PRESSURES HITH LINEARIZEO FREE SURFACE CONOITION

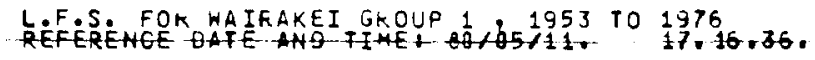

TIME AND FLOW DATA READ FFOM FILE FWLSSI \& WITH FOFYAT $(I 10,15 X, F 15.2)$

FLOH DATA HERE CONVERTED FRCM TYPE 3 I10EG POUNCS/YEAR, TO KG/SEC BY THE MULTIPLICATIVE FACTOR I.437T929OE-02

INPUT PARAMETERS:

NUMBER OF DATA PCINTS INI:

PELTA-TAU:

OERHEAOILIYY IKA:

SINKING VELOCITY (W)
7 RADIUS SPECIFICATIONS:

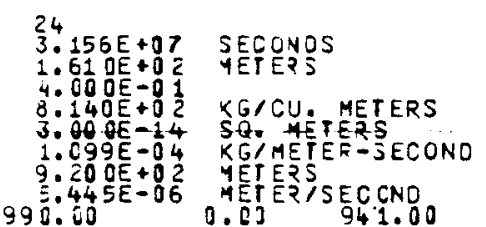

L.F.S. FOK WAIFAKEI GROUP 1,1953 TO 1976

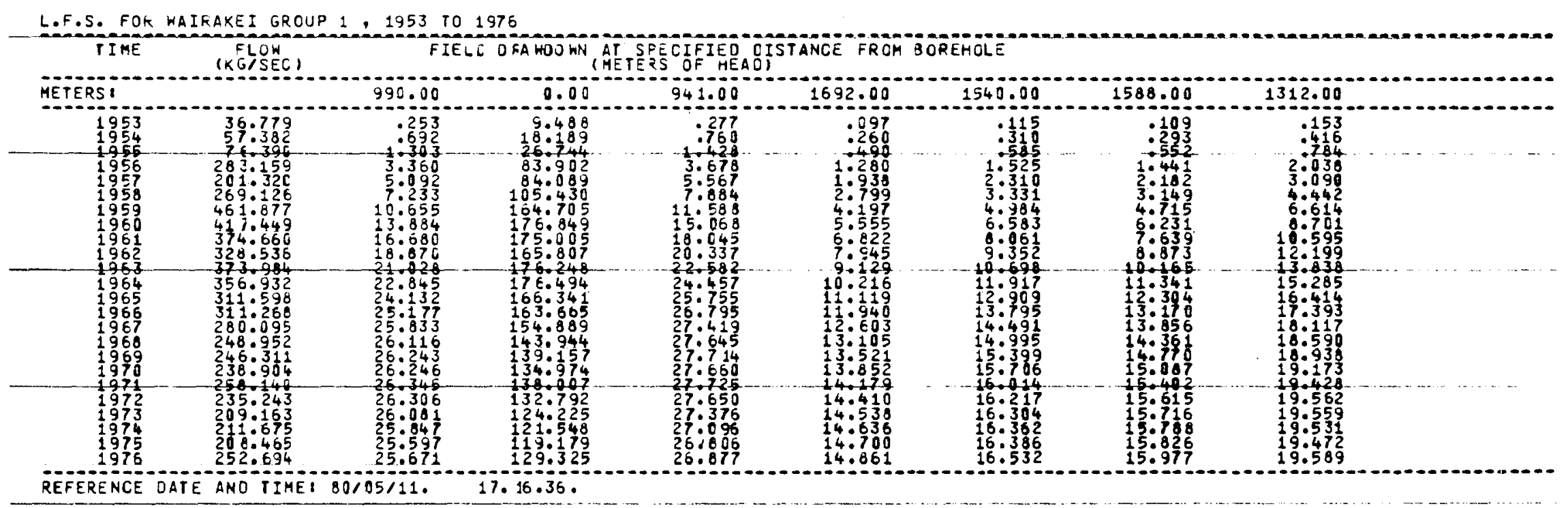




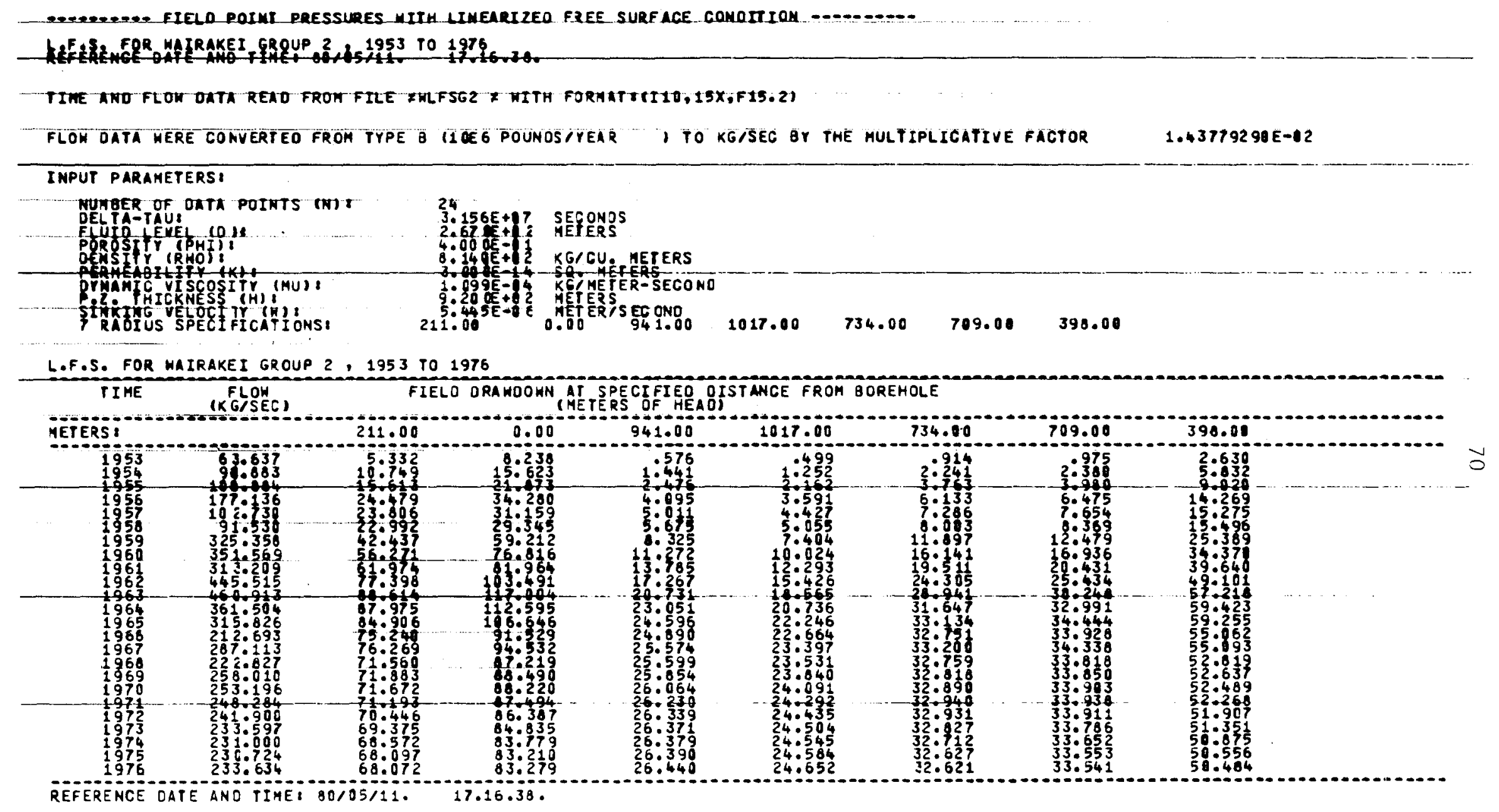


FIELD POINT PRESSUKES HITH LINEARIZEO FREE SURFACE CONDITION ..........

AEFES. FOR WAIRAKEI GROUP 3 6 1953 TO 1975

TIME ANO FLOW DRTA FEAD FROM FILE ZWLFSG $\approx$ WITH FJRMAT: $(I 10,15 \times, F 15.2)$

FLOW DATA WERE CONVERTEO FROM TYPE O 110 G POUNOS/YEAE, I TO KG/SEC BY THE MULTIPLICATIVE FACTOR

$1.43779290 E-02$

INPUT PARAMETERS:

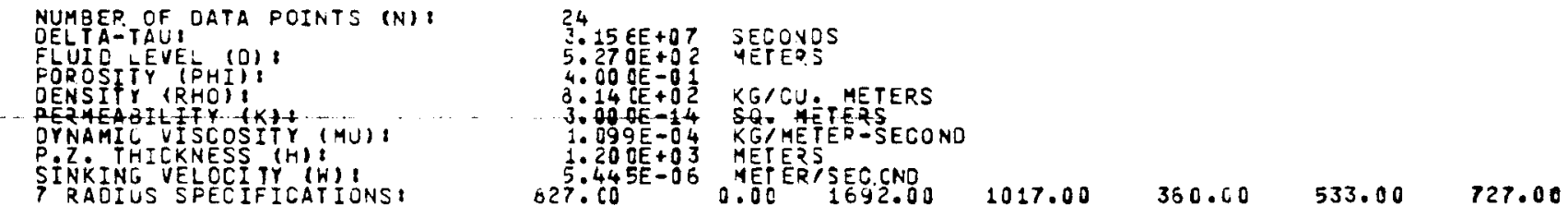

L.F.S. FOK WAIRAKEI GROUP 3,1953 TO 1976

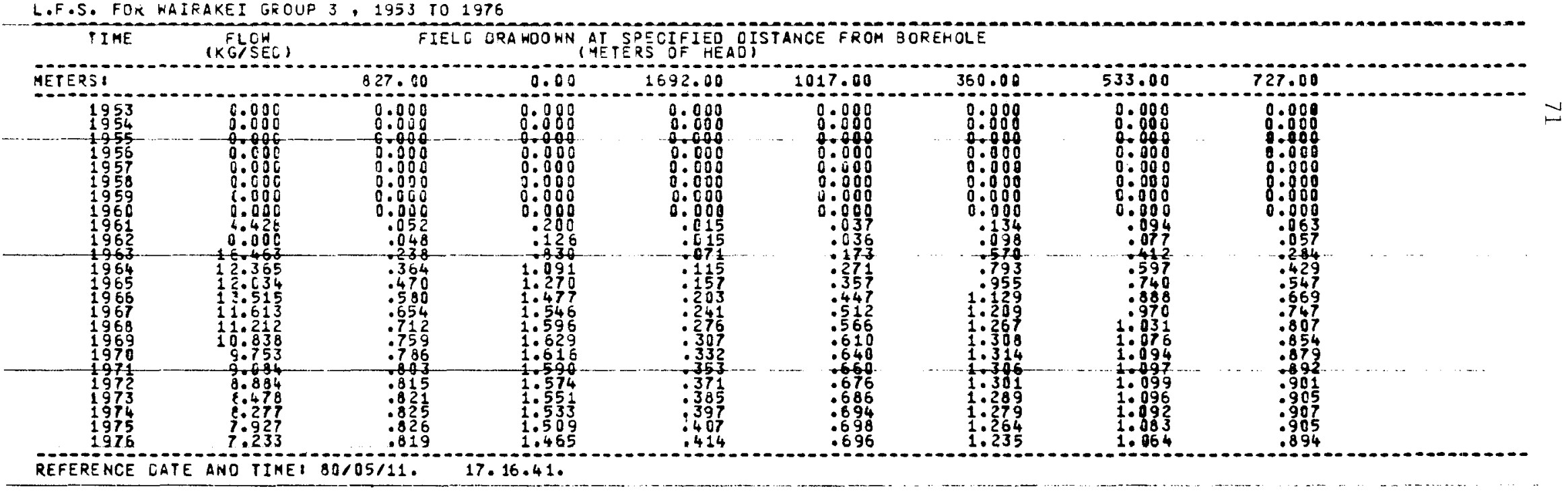


FIELO POIMI PRESSURES WITH LIMEARTZEO FREE SURPACE CONOITION

KLEFE

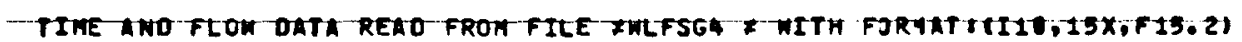

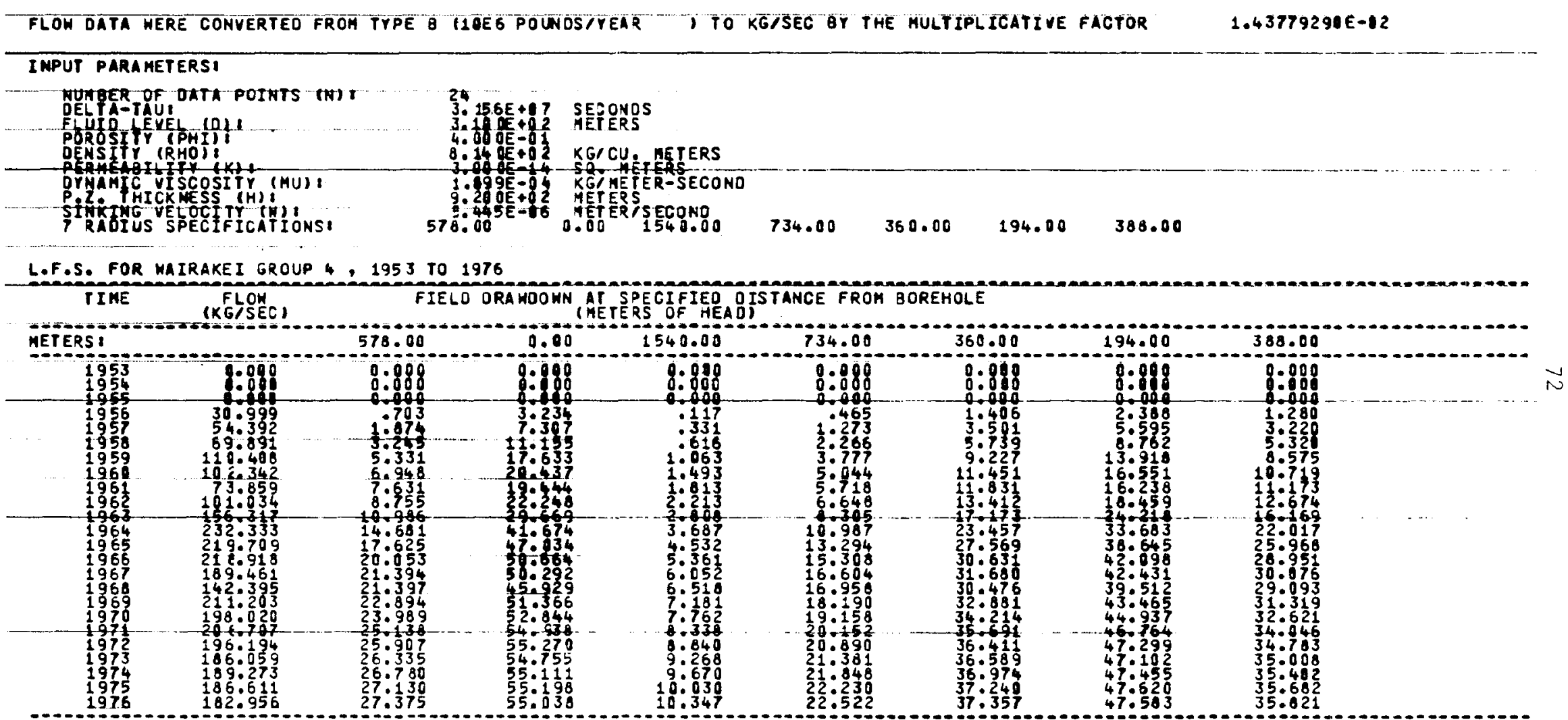

REFERENCE DATE ANO TIMEI BOIO5/11. 17.16 .47 . 
-......- FIELL POINT PRESSUKES WITH LINEARIZED FZEE SURFACE CONCITION ...........

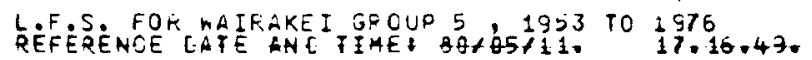

TIME ANO FLOW DATA FEAD FFOM FILE FWLFSGS \& WITH FORMAT:(I10,15X,F15.2)

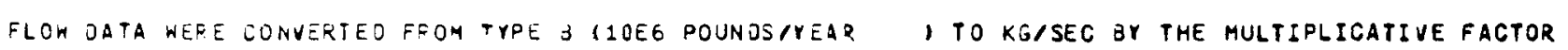

$1.43779290 E-02$ INPUT PARAMETERS:
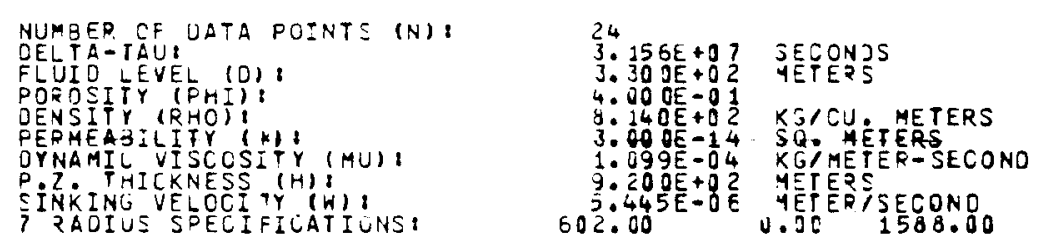

L.F.S. FOR WAIFAKEI GRCUP 5 , 1953 TO 1976

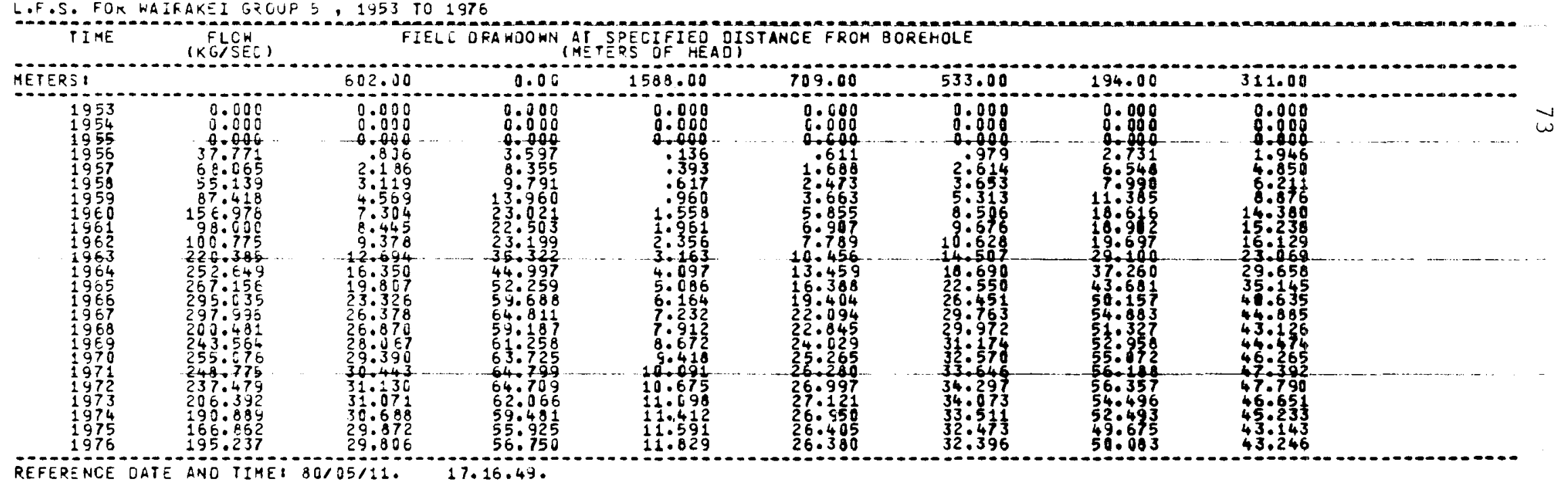


FIELD POINI PRESSURES HITH LIMEARIZEO FREE SURFACE COMOITION

L.F.S.FOK WAIRAKEI GZOUP 6.21953 TO 1976

TIME ANO FLOW OATA REAO FROM FILE FWLFSGG * WITH FORMATI(I10,15X,F15.2)

FLOW DATA WEFE CONVERTEO FROM TYPE B IOEG POUNOSIYEAR, , TO KG /SEC BY THE MULTIPLICATIVE FACTOR

$1.4379290 \mathrm{E}-92$
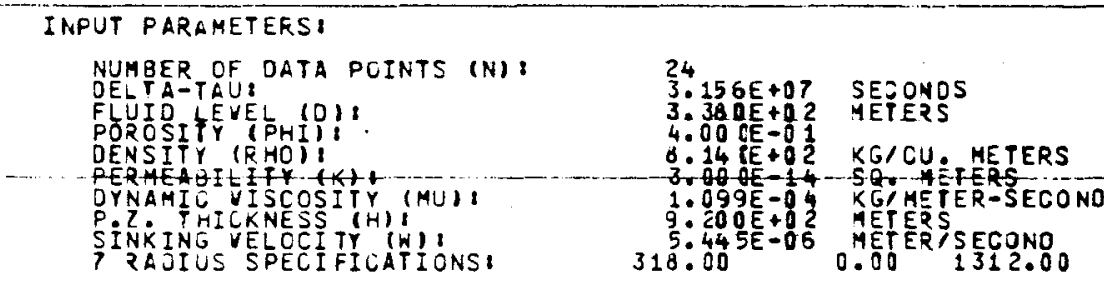

L.F.S. FOR WAIFAKEI GROUP 6,1953 TO 1976

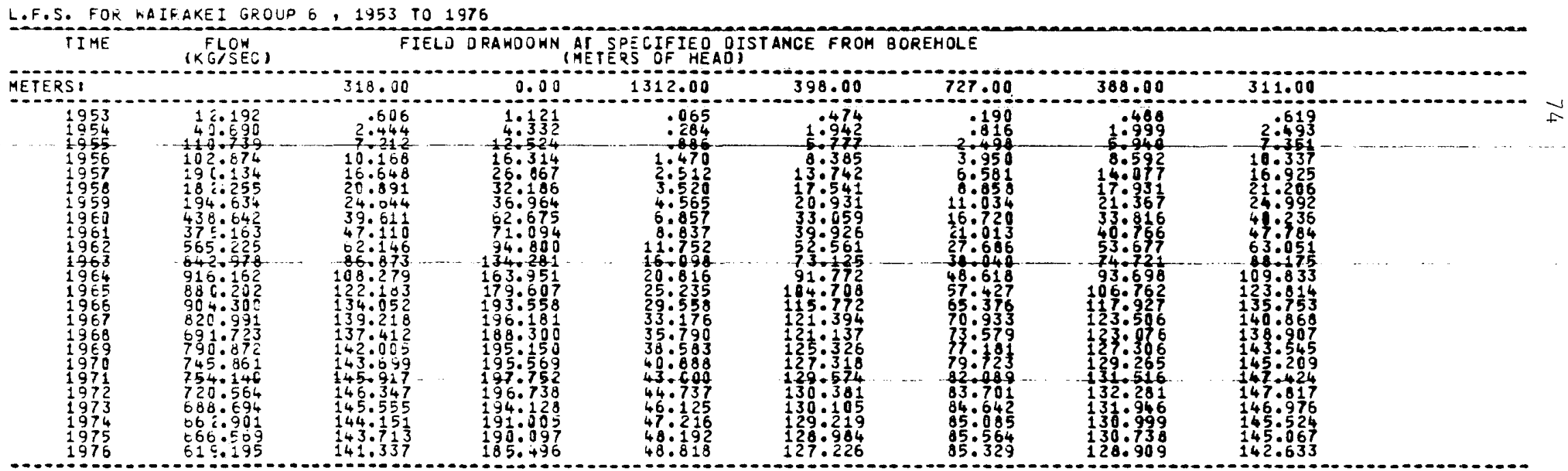

REFERENCE DATE LNC TIME: $80 / 5511$. 


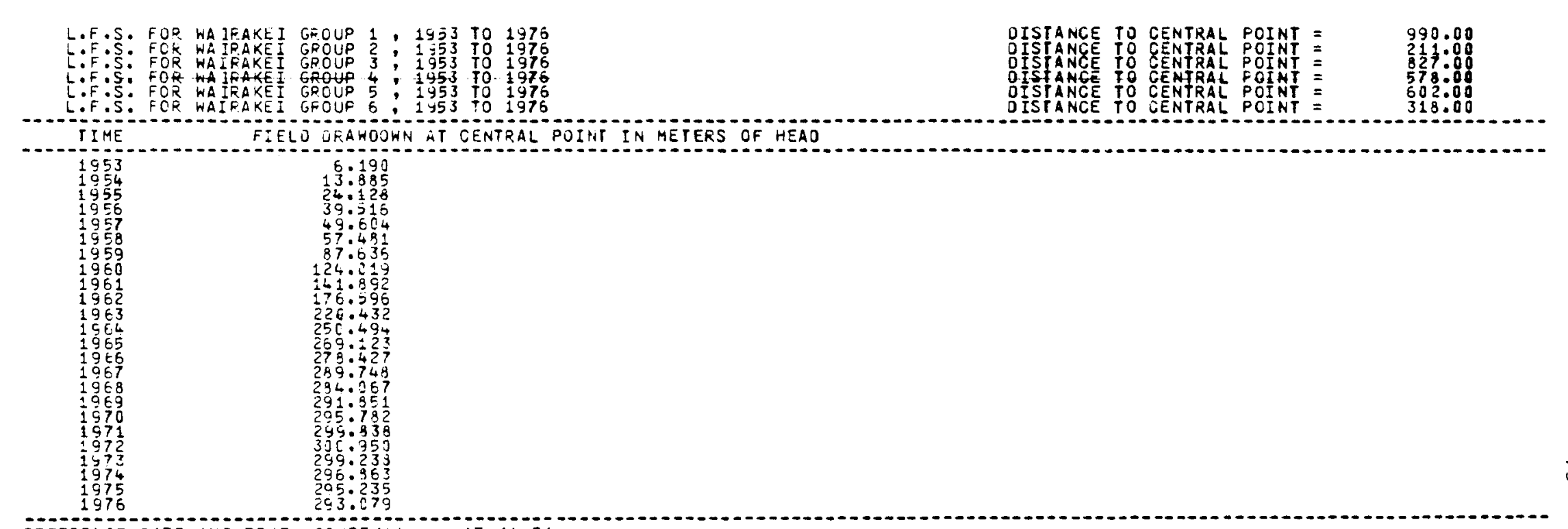

REFERENCE DATE ANO TIME: BOJ05/11. 17.10 .510

L.F.S. PRUGFAM UTILIZED 3.415 SECONOS CFU TIME 
This report was done with support from the Department of Energy. Any conclusions or opinions expressed in this report represent solely those of the author(s) and not necessarily those of The Regents of the University of California, the Lawrence Berkeley Laboratory or the Department of Energy.

Reference to a company or product name does not imply approval or recommendation of the product by the University of California or the U.S. Department of Energy to the exclusion of others that may be suitable. 